\title{
Universidad Nacional de La Plata Facultad de Ciencias Económicas
}

\author{
ESCUELA DE ECONOMÍA DE LA SALUD Y \\ ADMINISTRACIÓN DE ORGANIZACIONES DE \\ SALUD
}
MAESTRÍA EN ECONOMÍA DE LA SALUD Y ADMINISTRACIÓN DE ORGANIZACIONES DE SALUD

\section{TESIS DE MAESTRÍA}

Estudio de las Características de la Demanda y la Satisfacción de Clientes para la Planificación, como Instrumento de Gestión del Laboratorio del Hospital Interzonal Especializado en Agudos y Crónicos (H.I.E.A.y C.) San Juan de Dios de La Plata, para el Año 2012.

Bioquímica CRISTINA SILVIA QUINTANA

Director de tesis: Lic. DANIEL E. SOLARI

La Plata - Buenos Aires - Argentina 


\section{ÍNDICE.}

I. TÍTULO 3

II. RESUMEN 4

III. INTRODUCCIÓN 5

IV. PROBLEMA 6

V. OBJETIVOS 7

VI. ESTADO DE LA CUESTIÓN - JUSTIFICACIÓN 8

VII. MARCO TEÓRICO 10

VII.A. Breve resumen acerca del Hospital y del Servicio de Laboratorio 10

VII.B. Gestión clínica y el Laboratorio de Análisis Clínicos 11

VII.C. Planificación 16

VII.D. Indicadores 20

$\begin{array}{ll}\text { VII.E. Comunicación } & 21\end{array}$

VIII. ASPECTOS METODOLÓGICOS 23

VIII.A. Encuesta "A" 24

VIII.B. Encuesta "B" 26

VIII.C. Encuesta "C" 28

IX. DESARROLLO 30

IX.A. Resultados y comentarios de encuestas $\quad 30$

Encuesta "A" $\quad 30$

Encuesta "B" $\quad 41$

Encuesta "C" $\quad 56$

$\begin{array}{lll}\text { IX.B. Características de la Demanda } & 68\end{array}$

\begin{tabular}{ll} 
IX.C. Indicadores & 73 \\
\hline
\end{tabular}

$\begin{array}{ll}\text { Etapa pre analítica } & 73\end{array}$

$\begin{array}{ll}\text { Etapa analítica } & 74\end{array}$

Etapa pos analítica $\quad 74$

$\begin{array}{ll}\text { IX.D. Planificación } & 76\end{array}$

$\begin{array}{lll}\text { X. CONCLUSIONES } & 79\end{array}$

$\begin{array}{ll}\text { XI. BIBLIOGRAFÍA } & 81\end{array}$

$\begin{array}{lr}\text { Agradecimientos } & 86\end{array}$ 
I. TÍTULO

Estudio de las características de la demanda y la satisfacción de clientes para la Planificación, como instrumento de Gestión del Laboratorio del Hospital Interzonal Especializado en Agudos y Crónicos (H.I.E.A.y C.) San Juan de Dios de La Plata, para el año 2012. 


\section{RESUMEN}

Este Hospital, que depende del Ministerio de Salud de la provincia de Buenos Aires, tiene como característica ser un hospital interzonal especializado (enfermedades pulmonares, cardiovasculares e infecciosas) y el Servicio de Laboratorio atiende además la demanda de Centros de Atención Primaria de la Salud [CAPS] vecinas, dependientes de la municipalidad de la Ciudad de La Plata.

Dado que la planificación permite optimizar el uso de los recursos, lograr una mejora continua de la calidad de la prestación y ampliar la satisfacción de los clientes, este trabajo tiene como objetivos la evaluación del grado de satisfacción tanto de los pacientes como de los profesionales que solicitan las prácticas, el estudio de las características de las órdenes provenientes de médicos del hospital y de las salas sanitarias que se atienden, así como la identificación de indicadores que puedan ayudar en la gestión de laboratorios de análisis clínicos de similar complejidad.

Con la información obtenida se puede pasar a una instancia posterior que es la planificación del Servicio de Laboratorio del H.I.E.A. y C. San Juan de Dios de la ciudad de La Plata. 


\section{INTRODUCCIÓN}

De forma sintética podemos decir que gestionar es dirigir, administrar recursos, conseguir objetivos y metas y analizar los resultados para solucionar los problemas, coordinando y motivando a las personas que trabajan en una organización.

El progreso de la tecnología y de las ciencias médicas determina cambios en los laboratorios de análisis clínicos que requieren una redefinición del papel de quienes se desempeñan en ellos.

El desarrollo de la gestión clínica surge como un elemento para lograrlo, como una necesidad de hacer un uso racional de los recursos disponibles.

Así entonces podemos decir que gestión clínica es la responsabilidad frente al uso de medios y resultados en la asistencia.

El concepto "Gestión Clínica" incorpora los términos de eficiencia (menor uso de recursos posibles) y eficacia (logro de objetivos).

El conocimiento de todos los aspectos que en ella intervienen brinda herramientas fundamentales para la gestión. 


\section{PROBLEMA}

El problema que se intenta resolver puede plantearse a partir de las siguientes preguntas:

- ¿ ¿Cuál es el grado de satisfacción de los pacientes respecto a la atención en el Servicio de Laboratorio?

- ¿Cuál es el grado de satisfacción de los médicos que demandan prestaciones a este Servicio?

- ¿Es necesaria la unificación en un mismo ambiente físico de las tres salas que constituyen el Servicio para una mejor utilización de los recursos?

- ¿Cuál es el grado de satisfacción de los trabajadores del Servicio (profesionales y no profesionales) respecto a la prestación brindada y a la actual disposición de las áreas de trabajo?

- $\quad$ ¿Existen diferencias entre los pedidos realizadas por los médicos del hospital y de los centros de atención primaria?

- ¿Qué indicadores pueden ser de utilidad para la planificación del Servicio? 


\section{OBJETIVOS}

Como objetivo general se pretende realizar un estudio de la demanda y de la satisfacción de los pacientes y profesionales respecto a la prestación que realiza el Servicio.

Como objetivos secundarios se pueden detallar:

- Evaluar el grado de satisfacción de los pacientes que concurren al Servicio.

- Evaluar el grado de conformidad con el servicio prestado desde la visión de los médicos que realizan las indicaciones.

- Evaluar la necesidad de unificar las distintas salas que componen al Servicio en un ambiente físico único para una mejor utilización de los recursos.

- Tratándose de un Hospital Interzonal, detectar cómo se distribuye la demanda que este Servicio atiende.

- Determinar qué indicadores son de mayor utilidad para la planificación del Servicio.

- Con estos propósitos alcanzados y evaluados se puede tender hacia una Planificación correcta, con la finalidad de realizar una optimización en la utilización de recursos en la prestación de servicios que realiza este Laboratorio. 


\section{VI. $\quad$ ESTADO DE LA CUESTIÓN - JUSTIFICACIÓN}

La Planificación es un instrumento de gestión por medio del cual se definen por anticipado las acciones a realizar para alcanzar un objetivo, con el fin de aportar mayor racionalidad a la toma de decisiones y la asignación de los recursos.

Planificar es proyectar una visión de un futuro deseado, como así también considerar los medios necesarios para alcanzarlos.

La planificación es un instrumento que nos sirve para pensar el futuro en base a un conocimiento global de la situación actual con una mirada al futuro.

Es en base a este concepto, el conocimiento global de la situación actual, que este trabajo intenta, mediante su desarrollo obtener dicho conocimiento. No se puede planificar correctamente sin tener un conocimiento real de la situación.

En los años de experiencia en el trabajo dentro del laboratorio, se pueden obtener datos importantes para esta tarea, pero es asimismo importante la medición y cuantificación de los mismos para poder avanzar en forma correcta.

Actualmente, en instituciones tanto públicas como privadas del Sector Salud, existe un creciente interés por evaluar el conocimiento en aspectos relacionados con la calidad de la atención; para mejorarla, en los sistemas de salud se han desarrollado diversas acciones entre las que se encuentran la aplicación de encuestas de opinión a proveedores y usuarios, entre otros.

Dado que el Laboratorio de Análisis clínicos trabaja en forma interdisciplinaria dentro del Sistema de Salud es importante obtener datos de todos aquellos involucrados en el mismo, entendiendo al Laboratorio como un sistema abierto con múltiples intereses internos y externos, para lograr el objetivo final que es brindar la mejor prestación en forma eficiente.

En los últimos años cada vez más la "Gestión Clínica", entendiéndose por tal a la utilización adecuada de los recursos para la mejor atención de los pacientes, está presente en los Servicios de Salud, y la Planificación es un instrumento de la misma que debe ser utilizada en los Laboratorios de Análisis Clínicos como integrantes del Sistema de Salud.

El Servicio de Laboratorio del H.I.E.A.y C. San Juan de Dios presta servicios para pacientes internados y ambulatorios provenientes de este hospital y de centros de atención primaria municipales cercanos.

Es de destacar que en este rubro se observan permanentes cambios, debido a distintas situaciones que se presentan día a día, como actualizaciones permanentes de conocimientos que conllevan a la implementación de nuevos métodos de diagnóstico, presencia de nuevas patologías (epidemias pandemias), cambios en la demanda de atención de la población por razones económicas-sociales, que requieren un correcto análisis para su atención adecuada, entre otras problemáticas. 
La planificación ha de conseguir, sobre todo, conciliar el cambio con la continuidad. Esto supone tanto tener el conocimiento real de la situación en que se encuentra la organización, como detectar los cambios que se producen y elaborar las estrategias necesarias para enfrentar dichos cambios, y así llegar a buen fin.

Dado que los recursos disponibles son escasos, es necesario definir los objetivos a mediano y largo plazo y diseñar las mejores estrategias generales posibles para lograrlo, tratando de diseñar instrumentos que permitan preparar la organización de modo eficiente para el futuro. 
VII. MARCO TEÓRICO

\section{VII.A. Breve resumen acerca del Hospital y del Servicio de Laboratorio}

El Hospital San Juan de Dios [HSJD] de La Plata nace con la Ciudad, inicialmente llamado Hospital de Contagiosos, ocupando el predio de la calle 25 entre 70 y 71. El diseño y funcionamiento correspondía a un criterio urbanístico, edilicio y sanitario propio de la época (corriente higienista del siglo XIX).

Desde el año 1922 toma el nombre de "San Juan de Dios". Se construyen 2 nuevos pabellones: uno para enfermos de lepra y otro para tuberculosos en la manzana comprendida por las calles 70,71, 26 y 27 , a partir de entonces ocupa todo el predio y se van construyendo todas las salas e instalaciones con el correr del tiempo.

En el año 1949, bajo los lineamientos del Plan Quinquenal (1946-1951) conducido por el Dr. Ramón Carrillo que utiliza al Hospital como centro de salud, abrevando en la concepción moderna que se instaló en el siglo XVIII pero procurando centrar la salud en el sujeto y su comunidad, se construyó y puso en funcionamiento el Instituto de Tisiología.

El Hospital San Juan de Dios, toma su forma actual hace 60 años cuando el presidente Juan D. Perón, el 18 de noviembre de 1949, inaugura el nuevo edificio que hoy denominamos área $\mathrm{B}$ y que se ubica en la manzana comprendida entre las calles 70-71-27 y 28.

En la actualidad el HSJD forma parte de la red asistencial pública de la provincia de Buenos Aires y es referencia y centro de derivación de enfermedades cardiológicas, neumonológicas e infecciosas.

El Hospital recibe pacientes de toda la provincia y en menor grado de otros lugares del país. La consulta ambulatoria se reparte entre personas con domicilio en La Plata, los demás municipios de la Región Sanitaria XI y el resto de la provincia.

El Servicio de Laboratorio está integrado por las salas de Laboratorio de Planta, Laboratorio de Medio Interno y Guardia, y Unidad de Internación Virología.

Estas salas se fueron creando a lo largo del tiempo y de acuerdo a las necesidades y al progreso de los conocimientos instalándose no en lugares "programados" sino donde era posible colocarlos de acuerdo a las construcciones existentes, por lo que actualmente se encuentran instaladas en distintos edificios y distantes a más de 100 metros unas de otras, sin que hubiese existido un marco de planificación edilicio, de sus servicios e instalaciones necesarios, diseñadas a partir de diversos requerimientos asistenciales y ajustadas a demandas funcionales e interdependencias de los distintos servicios. 


\section{VII.B. Gestión clínica y el Laboratorio de Análisis Clínicos}

La gestión clínica puede ser definida como "la utilización adecuada de los recursos para la mejor atención de los pacientes" y agrega "esta definición implica que quienes toman día a día decisiones que comprometen los recursos económicos lo hagan en un marco de autoridad delegada y pactada con la gerencia, y que asuman la responsabilidad de sus propias decisiones". (Temes JL.2000)

Desde un enfoque integrador la gestión clínica hace referencia al equipo de salud al hablar de la responsabilidad en la toma de decisiones y surge muy fuertemente la relación de agencia como característica fundamental.

Miguel Ángel Asenjo, se refiere a una doble relación de agencia: la del médico con respecto a la máxima autoridad de la institución ó las autoridades políticas y la del mismo médico con respecto al paciente. (Asenjo,M.A.2000)

Este mismo autor en su libro "Las Claves de la Gestión Hospitalaria" (Asenjo, M.A.2000), describe que gestionar es decidir, y por tanto arriesgar, y consiste en conseguir objetivos, generalmente a través de otros y responsabilizarse de lo que otros han hecho. Dicho riesgo es menor si previamente se ha planificado lo que se debe gestionar, que en el hospital se puede resumir de la siguiente manera:

Primero: La salud de las personas, incluido el nacimiento y la muerte.

Segundo: Interrelaciones personales. Es la institución de máxima interrelación social. Personas que están o se sienten enfermas son ayudadas por otras que se sienten sanas.

Tercero: Los intereses de cuatro amplios y poderosos colectivos:

Ciudadanos enfermos o aparentemente enfermos

Profesionales sanitarios, en su mayoría doctores, licenciados y diplomados universitarios.

Gestores, administrativos y directivos.

Propietarios: políticos en los públicos y accionistas en los privados.

Cuarto: La necesidad de objetivación de dichos intereses.

Quinto: Un gran colectivo personal empleado próximo y superior a dos personas por cama y un enorme colectivo de personal asistido, siendo un lugar de máxima interacción social.

Sexto: Un gran volumen de recursos económicos. 
Es igualmente necesario conocer, la cultura, la idiosincrasia el medio social de los pacientes y de los agentes de la salud, que condicionan las decisiones y actuaciones individuales que, a su vez, inducen a las colectivas; es de este modo fundamental e ineludible en una empresa del conocimiento como es el hospital, que actúa sobre los sentimientos humanos en momentos de máxima ansiedad, considerar a estos factores como determinante para las conductas y relaciones sociales que en él se presentan.

Es obvio que la manera de sentir la enfermedad y la manera de sentir al sistema sanitario, concretamente al hospital, según sea el uso que se haga del mismo condiciona las relaciones: enfermo, profesional, directivo y propietario.

Es importante el conocimiento de los intereses que motivan a estos distintos grupos, destacando para los pacientes la "calidad extrínseca ó aparente", para los profesionales la "calidad científica ó técnica", para los directivos ó gestores la "eficiencia" y para los propietarios la "satisfacción del usuario", para la gestión de los Servicios de manera que puedan ser satisfechos, sin menoscabo de algunos de ellos.

Asimismo se debe recordar que dentro de las características de las Organizaciones de Salud, es que son organizaciones de servicio. El servicio se produce y se consume al mismo tiempo, no se acumula, no se puede controlar previamente. Cualquier falla en la cadena de valor anula la satisfacción del usuario en toda la prestación del servicio. (Mancuso G. 2004)

Al referirnos a gestión clínica debemos pensar también en los modelos de gestión de calidad total. Su objetivo es ofrecer a los pacientes los mejores resultados posibles en la práctica clínica diaria [efectividad, acordes con la información científica que haya demostrado su capacidad para cambiar favorablemente el curso de una enfermedad [eficacia], con los menores costos para el paciente y la sociedad en su conjunto [eficiencia]. (Pérez Lázaro JJ, 2002)

Si se piensa en la calidad de la atención de la salud, a la efectividad, la eficacia y la eficiencia se sumarían otros atributos: la conformidad con lo justo y razonable en la distribución de las acciones de atención médica y sus beneficios [equidad], con los deseos y expectativas individuales de las personas [aceptabilidad] y con los de la sociedad [legitimidad]. (Donabedian A,1999)

También podemos decir, que la calidad es la aptitud para satisfacer necesidades expresadas y explícitas o la aptitud para ofrecer el servicio esperado. (Froman B.2005)

Asimismo al referirnos a calidad asistencial, a la actividad que surge de proporcionar a cada paciente el conjunto de actos diagnósticos y terapéuticos que le asegure el mejor resultado en salud, conforme al estado actual de las ciencias de la salud, al mejor costo, con el menor riesgo y con la mayor satisfacción en términos de procedimientos, resultados y de contactos humanos en el sistema asistencial. (Fernández Espina). 
La satisfacción con los servicios de salud es un concepto complejo que está relacionado con una gran variedad de factores, como son el estilo de vida, las experiencias previas, las expectativas de futuro y los valores del individuo y de la sociedad.

La medida de la satisfacción será entonces, la medida de las diferentes dimensiones que la conforman y ha demostrado ser un instrumento útil para evaluar las intervenciones de los servicios de salud, porque proporciona información sobre la calidad percibida y facilita información a los profesionales, gestores y administradores sobre aquellos aspectos de la organización sanitaria, percibidos como insatisfactorios y que son susceptibles de mejoría. (Castillo, L 2007)

Actualmente, en instituciones tanto públicas como privadas del Sector Salud, existe un creciente interés por evaluar el conocimiento en aspectos relacionados con la calidad de la atención; para mejorarla, en los sistemas de salud se han desarrollado diversas acciones entre las que se encuentran la aplicación de encuestas de opinión a proveedores y usuarios, entre otros.

Prueba de ello es la creación de varias escalas y formas de aplicación para la obtención de resultados y el hecho que tanto proveedores de servicios e investigadores acepten que la satisfacción del paciente es un resultado importante del trabajo realizado en los servicios de atención de salud y un posible factor determinante en la utilización y conducta en lo que respecta a cumplimiento del tratamiento prescripto. (Hulka 1982)

Otros trabajos además incorporan el grado de satisfacción de los usuarios como trazador de adherencia al tratamiento (Ortiz Espinosa R, 2004), otorgándole así dimensiones de eficiencia y efectividad.

La satisfacción del paciente, en el proceso de valoración de la calidad puede verse como el juicio que el mismo posee sobre la bondad de la atención y que se expresa como satisfacción ó insatisfacción y concierne a los escenarios, a las necesidades sentidas de atención, a los tratamientos técnicos, a las características de la relación interpersonal, a las consecuencias físicas, psicológicas y sociales de dichos cuidados y finalmente a aspectos estructurales de confort del ámbito sanitario. La satisfacción del paciente proporciona información sobre el éxito del proveedor en alcanzar los valores y expectativas del paciente, como así también un instrumento valioso para la investigación, administración y planeación de los sistemas de salud. (Subsecretaría de Planificación de la salud- Prov. de Buenos Aires).

La fragmentación en la prestación de servicios en el área salud es cada vez mayor por lo que el usuario se ve obligado a transitar por un laberinto de servicios y obtener una cosa aquí, otra allí, ignorando para qué se realiza cada una de esas investigaciones y realizada sobre su propio cuerpo. La vivencia del consumidor delante de este sistema que es el aparato de asistencia médica, se torna más dramática todavía en la medida que se espera que él le preste informaciones, siga órdenes y se esfuerce en colaborar. Sabemos que 
comúnmente esto implica el desplazamiento físico de un lugar a otro dentro de la misma unidad productiva ó entre diferentes centros de salud. Tal fragmentación de la estructura de servicios no siempre corresponde a una exigencia de naturaleza técnica: son ciertos modelos de organización de servicios que traen consigo ese sentido de aislación, fragmentación y falta de interrelación en las tareas.

De lo anterior, se infiere que la reintegración física y funcional de los servicios es una exigencia de calidad de los servicios vista desde la óptica del usuario aplicando principios organizacionales que resguarden el confort del usuario. (Pasos Nogueira 1997).

Es así, que las encuestas se transforman en herramientas que nos permiten recolectar datos de diversa índole, que pueden ser utilizados para introducir modificaciones en los circuitos, procesos, actividades ó servicios que se brindan cotidianamente. Es un ángulo diferente de observación y conocimiento del funcionamiento del sistema. (Zorraquín S.2001).

Evaluar la calidad de la atención desde la perspectiva del usuario es cada vez más común. A partir de ello, es posible obtener del entrevistado un conjunto de conceptos y actitudes asociados en relación con la atención recibida, con los cuales se adquiere información que beneficia a la organización otorgante de los servicios de salud, a los prestadores directos y a los usuarios mismos en sus necesidades y expectativas. Este método representa una de las formas más rápidas para evaluar aspectos de la calidad de los servicios y ofrece beneficios a un costo relativamente bajo. (Ramírez Sánchez Teresita, 1998)

Las bases conceptuales y metodológicas sobre la calidad de la atención, se han venido justificando en el modelo desarrollado por Donabedian. El análisis de la calidad a partir de las tres dimensiones que propone el autor (estructura, proceso y resultado) ha sido una contribución importante, pues permite medir ordenadamente las variables ligadas a la calidad de los servicios de salud. Este esquema supone que los resultados realmente son consecuencia de la atención proporcionada, lo cual implica que no todos los resultados puedan ser fácil y exclusivamente imputables a los procesos, y no todos los procesos dependerán directa y unívocamente de la estructura. (Donabedian A. 1992)

Con base en lo anterior, se desprende el análisis de la satisfacción de los usuarios, vista como un indicador de la dimensión de resultado, a partir del cual se puede obtener la opinión acerca de los aspectos de la estructura (comodidades, instalaciones físicas, organización), el proceso (procedimientos y acciones realizadas en la consulta) y el resultado (cambios en el estado de salud y la percepción general de la atención recibida). También se puede obtener información sobre aquellas características de los servicios que facilitan u obstaculizan los esfuerzos del usuario para obtener atención (accesibilidad).

En ocasiones, la accesibilidad se traslapa conceptualmente con la definición de calidad, ya que aquélla abarca fenómenos que tienen repercusiones directas en la atención, como son los tiempos de espera, los horarios del servicio o los 
costos de la misma, que en conjunto se consideran como características de la accesibilidad a las organizaciones.

La variable de calidad, grado de "satisfacción de clientes" según lo expresado por Etcheverry, resulta la menos atendida en los laboratorios estudiados y sería por tanto la que más habría que reforzar, teniendo en cuenta que tal información permita mejorar el servicio enfocándolo hacia el cliente.

Las normas de sistemas de gestión de la calidad de la serie de normas ISO 9000 revisadas reconocen ocho principios en los que se sustentan los modelos de gestión de calidad total (Norma ISO 9000-2000, Norma ISO 9004-2000).

Enfoque al cliente: Las organizaciones dependen de ellos y por lo tanto deberían comprender sus necesidades actuales y futuras, satisfacer sus requisitos y esforzarse en exceder sus expectativas.

Liderazgo: Los líderes deberían crear y mantener un ambiente interno en el que el personal pueda involucrarse totalmente en el logro de los objetivos de la organización.

Participación del personal: el total compromiso del personal posibilita que sus habilidades sean usadas para el beneficio de la organización.

Enfoque basado en los procesos: si se gestionan las actividades y recursos como un proceso, el resultado deseado se alcanza con mayor eficiencia.

Enfoque de sistema para la gestión: identificar, entender y gestionar los procesos interrelacionados como un sistema contribuyente a la eficacia y eficiencia de una organización en el logro de sus objetivos.

Mejora continua: la mejora continua del desempeño global de la organización debería ser un objetivo permanente de ésta.

Enfoque basado en hechos para la toma de decisión: el análisis de los datos y la información permite tomar decisiones eficaces.

Relaciones mutuamente provechosas para el proveedor: la capacidad de la organización y de sus proveedores para crear valor aumenta si la relación entre ambos es mutuamente beneficiosa.

Estos principios enmarcados en modelos de gestión clínica son aplicables a organizaciones como son los laboratorios de análisis clínico cuyo objetivo final sea asegurar una prestación de servicio que alcance los niveles de calidad establecidos y consiga mejorar el estado de salud y satisfacer las necesidades del usuario. (Varo J. 1993)

Actualmente, una institución de salud que esté interesada en garantizar la efectividad de la atención sanitaria y eficiencia en la gestión, debe conocer las percepciones de los pacientes respecto a los procesos asistenciales. 
En el caso de los Laboratorios de Análisis Clínicos, se observa que los mismos desarrollan sus tareas en forma interdisciplinaria dentro del Sistema de Salud y al realizar la identificación de los "clientes" para los cuales trabaja se pueden distinguir claramente:

los pacientes a los cuales se les practican los estudios correspondientes, y

los profesionales que ordenan los estudios.

Se reconoce que para la gestión de algunos servicios de salud, entre ellos los laboratorios clínicos, se aplican al mismo tiempo criterios que provienen de las ciencias duras, como los que se observan en la planificación operativa y científica, y otros que son propios de las ciencias sociales, como los utilizados para la gestión de personal o para la económico- administrativa. Ello supone la existencia de mecanismos explícitos, como por ejemplo los planteados por Shewart- Deming (planificar, hacer, controlar, corregir) y de otros implícitos, como aquellos que le confiere a la gestión el carácter sistémico y que pueden explicarse de la Teoría General de Sistemas (T.G.S), entendiéndose como sistema a un conjunto de elementos interrelacionados, un todo integrado aunque compuesto de estructuras diversas interactuantes y especializadas.

Estos dos planteos son complementarios y en ellos se basan varias normas nacionales e internacionales que refieren a sistemas de calidad y a la gestión de sistemas integrados.

El valor del resultado/servicio está dado por las interfaces entre procesos y por mecanismos de retroalimentación que tornan más flexible el sistema laboratorio en algunos casos para corregir desvíos, en otros para mejorar y madurar en la gestión, y otros muy escasos para innovar y crecer. Estos criterios vinculan al laboratorio como un sistema abierto, con la atención de sus múltiples intereses, y permiten la planificación estratégica y re planificación como core de la gestión. (Barral María, 2007)

La administración integral de un servicio de laboratorio es una consideración muy compleja, cuyo proceso involucra la planificación, organización, dirección, administración de personal, coordinación, control y gestión financiera, tal y como lo indican diversos autores (Güllick, 1973; Hampton, 1996, entre otros).

La planificación es el punto de partida de todas las funciones gerenciales; ya que es aquí donde se definen las características de lo que se va a hacer y que a su vez propone cómo se debe organizar el laboratorio para que por medio de sus procesos productivos se alcancen las metas deseadas.

\section{VII.C. Planificación}

Planificación proviene del vocablo francés "prévoir", que significa prever. Sencillamente hablando, planificar significa prepararse para la acción; esto es, 
definir qué es lo que se requiere hacer y elegir los medios y tiempos para hacerlo. (Ruiz Narváez, O, 2004).

La planificación constituye el momento en que se toma la decisión sobre los cursos de acción que se van a seguir, es decir que en forma anticipada, se buscan las mejores respuestas a las siguientes preguntas: ¿Qué se va hacer, para qué, cómo, cuándo, quién, con qué y dónde? (CCSS - Dirección de Planificación Institucional, 1998).

Cuando se habla de planificación, se suele utilizar el término con dos alcances diferentes, pero que en nuestra concepción no disociamos.

-la planificación como elaboración de planes, programas y proyectos

-la planificación como proceso y estrategia.

¿Qué es planificar?

Es un instrumento de gestión y de política que tiene por objetivo aportar mayor racionalidad a la toma de decisiones y asignación de recursos.

Es proyectar una imagen de futuro deseado y los medios para alcanzarlo.

Es un proceso de análisis de los diferentes cursos de acción para alcanzar un objetivo e implica su puesta en práctica.

Es una toma de decisiones anticipada

Implica pasar de una situación inicial (actual) a una situación objetivo futura (deseada).

Es un instrumento para pensar el futuro, predecirlo y anticiparlo, pero no adivinarlo.

Planificar no sólo es la programación en el tiempo de las actividades dirigidas al logro de determinados objetivos y la organización de los recursos necesarios, sino también la prospección de diversos cursos de acción dirigidos a alcanzar los objetivos en medio de acontecimientos imprevisibles. (Spadafora S. 2007)

Planificar es una reflexión sistematizada sobre la naturaleza fundamental del laboratorio y decidir cómo conviene situarlo o posicionarlo en su ambiente, cómo hay que desarrollar y aprovechar sus fuerzas y cómo se afrontarán los riesgos y oportunidades del ambiente. La planificación incluye también refinar las ambiciones básicas y, a corto y largo plazo, traducirlas en objetivos específicos así como en la descripción de los métodos que se utilizaran (Hampton, 1996)

La acción de Planificar implica organizar, integrar y hacer compatibles entre sí un conjunto de decisiones que conducirán la actividad del laboratorio hacia el logro de objetivos y metas preestablecidas (Hernández Orozco Carlos, 1993) 
La planificación es un proceso racional que busca definir el rumbo adecuado y factible para el servicio y la forma cómo se intentará ponerlo en función, mediante el uso correcto de los recursos disponibles. Comprende la previsión, el análisis de la situación y la toma de decisiones (Hernández Carlos, 1994; Arévalo César y Chávez Sileny, 1998)

La planificación comprende el estudio de la situación tanto presente como futura y la toma de decisiones que conducen al mejor aprovechamiento de los recursos existentes con miras a emplear las condiciones externas a favor del laboratorio. Los estilos de planificación suelen clasificarse según diferentes criterios (Arévalo César y Chávez Sileny, 1998)

Si se considera el Grado de obligatoriedad que tienen las decisiones tomadas por el órgano encargado de la planificación, existen dos estilos que son muy diferentes.

La planificación Imperativa que se caracteriza principalmente porque el estado emite normas de carácter obligatorio. Cabe aclarar que todo plan de Gobierno cuenta con la autoridad para determinar la dirección que deben seguir aquellos organismos subordinados a él; es decir, las distintas entidades gubernamentales que lo conforman. Además, es necesario que el estado tenga un alto grado de importancia en relación con el sistema privado y con las áreas en que tiene potestades, con lo cual, las directrices puedan ser obligatorias para la mayoría de sectores de la nación. En estos casos, el Estado, por medio del órgano central de planificación, suele decidir aspectos como, qué producir, cómo utilizar los recursos y a quién distribuir la riqueza.

La planificación indicativa que a diferencia de la anterior, el Estado asume un papel orientador y sugiere acciones que guíen la actividad económica y social del país, pero sin que ello signifique que las personas o empresas estén obligadas a hacerlo. Dentro de las herramientas más utilizadas están la política crediticia, monetaria y fiscal.

De acuerdo con el Nivel en el cual se toman las decisiones producto de la Planificación, el estilo de planificación puede adoptar diferentes grados de centralización o descentralización.

La planificación centralizada: Se caracteriza por la existencia de un solo órgano central dedicado a definir los aspectos más determinantes en materia de planificación.

Cuando este enfoque es el que se lleva a la práctica, suele suceder que dicho órgano cuenta con información amplia, lo que permite disponer de una buena comprensión de la realidad y, en consecuencia, de una mejor visión del conjunto del que dispondrán las unidades de más baja ubicación en la escala organizativa.

La planificación descentralizada: Se distingue porque en ella son las unidades económicas las que deciden si se acogen o no a las orientaciones que indica el órgano de mayor jerarquía, por lo que lejos de existir un único plan, hay 
diversidad de planes de acción según las necesidades y orientaciones que cada unidad decida llevar a la práctica, lo que le agrega un mayor grado de flexibilidad.

Finalmente, si se considera el apego a las normas establecidas durante el proceso y por el grado de participación de los actores involucrados, existen dos estilos de planificación que se oponen: El Normativo y el Estratégico.

La planificación normativa: Se caracteriza por concederle un grado alto de importancia al fiel cumplimiento de las normas que previamente han sido establecidas. Supone que los estándares, usualmente establecidos por especialistas y técnicos, garantizan el cumplimiento de los resultados deseados, o al menos son la mejor manera de acercarse a ellos. Esta actitud, algunas veces, conduce a la desatención de los cambios que ocurren en el entorno y sus efectos en la validez y utilidad del plan. Minimiza además, el efecto que resulta de las relaciones e intereses de los grupos sociales que participan en la elaboración, implementación o de los efectos del plan.

La planificación estratégica: Este enfoque se preocupa por monitorear los cambios que ocurren en el medio ambiente, tanto en la fase de elaboración del plan como durante su implementación, así como en descubrir y vigilar la complejidad de las relaciones entre las variables que lo componen y que afectan la consecución de las metas establecidas.

La Planificación Estratégica reconoce la existencia de diferentes intereses en los grupos sociales afectados por la implementación de los planes, por lo que también deben ser considerados con el propósito de agregarle viabilidad a su ejecución. Interesa a la planificación estratégica comprender las relaciones que existen entre ellos, que pueden convertirse tanto en alianzas como en conflictos. En consecuencia, reconoce que para determinar un plan se requiere de un estudio mucho más complejo y menos determinista que en el enfoque normativo, aunque mucho más difícil de manejar.

La planificación estratégica es un modo de orientar las acciones de una organización, que tiene en cuenta el modelo político vigente y el comportamiento de los diferentes actores sociales que intervienen en él.

La construcción imaginaria del futuro posible, resulta de una prolongación de las tendencias del pasado mediante la proyección de variables "objetivas" y la utilización de modelos deterministas y cuantitativos. Más tarde, con la incorporación de la prospectiva de "primera generación" el eje conceptual de la previsión clásica y del planeamiento sufre modificaciones.

El método de la proferencia, propuesto por Agustín Merello, (proferir significa llevar adelante) para la realización de la prospectiva consiste en pensar el presente desde la óptica del futuro deseado y escalonar programas y metas mediante la proyección de experiencias del pasado y la conjetura sobre los posibles escenarios futuros. 
La reflexión prospectiva propone situarse en el futuro deseado, estableciendo en él el conjunto de valores, deseos e ideas para observar el presente desde esa óptica, "volver la mirada" sobre el presente y estudiar el pasado desde la óptica del futuro deseado. La programación prospectiva consistirá en la previsión y organización de programas, metas, acciones y medidas dispuestas escalonadamente en etapas congruentes con el destino que se pretende alcanzar y la adecuación y puesta en marcha de la organización hacia los fines deseados (Levy, 1981).

En definitiva, la planificación estratégica es un instrumento que pretende realizar un diseño del futuro que se desea alcanzar. Tanto su formulación como su implementación están relacionadas estrechamente. La planificación ha de conseguir, sobre todo, conciliar el cambio con la continuidad. Esto supone tanto como tener el conocimiento real de la situación en que se encuentra la organización, detectar los cambios y conseguir que las estrategias adoptadas lleguen a buen fin. (Corrella J.M., 1996)

\section{VII.D. Indicadores}

En términos generales, un indicador es la medida cuantitativa o la observación cualitativa que permite identificar cambios en el tiempo y cuyo propósito es determinar qué tan bien está funcionando un sistema, dando la voz de alerta sobre la existencia de un problema y permitiendo tomar medidas para solucionarlo, una vez que se tenga claridad sobre las causas que lo generaron.

En este sentido los indicadores se convierten en uno de los elementos centrales de un sistema de referenciación, ya que permiten, dada su naturaleza, la comparación al interior de la organización (referencia interna) ó al exterior de la misma (referencia externa).

Para que un indicador cumpla con ese objetivo de manera efectiva, debe poseer, entre otras, las siguientes características:

-Relevante: debe ser importante ó clave para los propósitos que se buscan.

-Entendible: no debe dar lugar a ambigüedades ó mal interpretaciones que puedan desvirtuar su análisis.

-Basado en información confiable: la precisión del indicador debe ser suficiente para tomar la decisión adecuada.

-Transparente/verificable: su cálculo debe estar adecuadamente soportado y ser documentado para su seguimiento y trazabilidad.

-Basado en información específica con relación al lugar y el tiempo: debe ser asociado a hechos real que faciliten su análisis.

Los indicadores son reflectores de resultados que dan las acciones y a su vez describen el desempeño que detalla cómo fueron realizadas esas acciones 
Los Indicadores en Salud representan medidas-resumen que capturan información relevante sobre distintos atributos y dimensiones del estado de salud y del desempeño del sistema de salud, y que vistos en conjunto intentan reflejar una situación sanitaria de una población y sirven para vigilarla. (OPS, 2001).

En el caso de nuestra organización los indicadores nos dan información acerca del funcionamiento de un sistema ó subsistema y nos permiten realizar comparaciones históricas, con estándares, establecidos por organismos competentes, con el sector.

Los indicadores asimismo nos permiten una permanente evaluación del funcionamiento del objeto en estudio y además realizar una planificación con una base científica. El uso de indicadores en la Gestión en general y en la Gestión de Calidad en particular, es indiscutido en la bibliografía, en los escritorios de la Dirección, mandos medios y algunas jefaturas, no así en los niveles más bajos de la pirámide organizacional por lo que además es necesario demostrar la utilidad de medir, no sólo para una organización sino para las personas en particular.

Tanto desde la educación en los valores de la medición como capacitando en cómo medir, qué medir y cuándo medir, se puede lograr una cultura de la mejora, se puede compartir el conocimiento para mejorar y se pueden lograr personas con una actitud comprometida no sólo con la mejora de la organización, sino también con la mejora personal. (Sabuqui R. 2007)

\section{VII.E. Comunicación}

Las instituciones de salud son organizaciones que se conforman por el cúmulo de personas, infraestructura, tecnología y métodos de trabajo, que deben estar en una búsqueda permanente de nuevas formas de hacer las cosas, para garantizar el desarrollo y la prestación de los servicios de salud, en los ámbitos asistencial y administrativo.

Los seres humanos estamos en una interacción constante con nuestros semejantes, ya sean, nuestras familias, amigos, compañeros de estudios o de trabajo y en algunas ocasiones con extraños. Este es un ciclo vital en el cual estamos inmersos desde que nacemos hasta que morimos.

La comunicación nos permite establecer las relaciones tanto con las personas, como con el mundo que nos rodea, es por ello que la comunicación eficaz es vital para el éxito de una Organización.

Las Organizaciones de Salud tienen como meta ofrecer servicios dirigidos a la recuperación de la salud de sus usuarios a través de la coordinación de los esfuerzos de los individuos y los grupos que la conforman, es por eso, que la comunicación es un proceso de importancia capital en estas Organizaciones y es uno de los aspectos a tener presente al evaluar el grado de satisfacción de los usuarios. 
La comunicación es el intercambio de información entre dos ó más interlocutores. Uno emite, otros recepcionan y responden. Significa enviar y retornar. Si el retorno no está organizado, si no se da, sólo existe información, no hay comunicación.

En el proceso de comunicarse, a menudo se observa que los receptoresemisores asocian a las frases con imágenes que están en función de su propia percepción, de su referente subjetivo, es decir de su propia experiencia. (Malagón 2001)

Se pueden mencionar tres grandes formas de comunicación: Descendente: es la que se genera desde la alta dirección hacia la base de las organizaciones; Ascendente: desde la base hacia la cima de la organización; Lateral: es la que se genera entre las unidades funcionales, departamentos funcionales, servicios etc.

Existen algunas características que se observan en equivocaciones en la comunicación, entre ellas: -La falta de motivación. -La retención consciente de información. -El temor a hacer el ridículo. -La falta de organización. -El desconocimiento de la importancia de la comunicación. - La falta de formación. -Las diferencias culturales. - La falta de dominio en las técnicas de comunicación.

En el caso general de los hospitales, los servicios han creado una dinámica cerrada en sí misma, impermeable a los elementos sustanciales de los objetivos generales. En el caso particular del HSJD la falta de comunicación entre los distintos servicios y niveles en el hospital se ha hecho muy evidente.

Dentro de los beneficios que reportan tener canales de comunicación amplios para la gestión clínica se encuentran: a) favorecer el conocimiento de la satisfacción del usuario, b) reducción de gastos, c) aumento de productividad, d) mejora en la motivación de los empleados, e) mejora la armonía entre todos los Servicios f) mejora la comunicación vertical y lateral que permite la interacción en el proceso asistencial.

Como se ha mencionado anteriormente, el laboratorio desarrolla sus tareas en forma interdisciplinaria, por lo que una buena comunicación tanto dentro del Servicio como con los demás servicios y con los pacientes favorece la obtención de objetivos. 


\section{ASPECTOS METODOLÓGICOS}

En el presente estudio, para tener conocimiento del grado de satisfacción de clientes y de los integrantes del Servicio se realizaron tres tipos de encuestas dirigidas a:

- Pacientes que concurren por consultorio externo al Servicio de Laboratorio.

- $\quad$ Integrantes del Servicio.

- $\quad$ Profesionales que ordenan prestaciones al Servicio de Laboratorio.

Para la evaluación de los pedidos se analizaron las órdenes de consultorio externo, clasificando proveniencia y el pedido ó no de distintas prácticas clasificadas en 10 grupos.

Los resultados se volcaron en tablas que fueron procesadas mediante el uso del Sistema STATA Versión 10.1. 


\section{VIII.A. Encuesta "A"}

Encuesta realizada a los pacientes que concurren por consultorio externo al Servicio de Laboratorio.

1-¿Es la primera vez que concurre a este Servicio?

\begin{tabular}{|c|c|}
\hline Si. & {$[\quad] 01$} \\
\hline No. & {$[\quad] 02$} \\
\hline
\end{tabular}

2-¿Cuál es su lugar de residencia?

\begin{tabular}{|c|c|}
\hline La Plata. & [ ] 01 \\
\hline Provincia de Bs. As. & [ ] 02 \\
\hline Otro. & [ ] 03 \\
\hline
\end{tabular}

3-Si no es atendido médicamente en este hospital: ¿por qué decidió concurrir a este Servicio?

\begin{tabular}{|c|c|}
\hline Cercanía. & {$[\quad] 01$} \\
\hline Obtención de turno. & {$[\quad] 02$} \\
\hline Recomendación. & [ ] 03 \\
\hline Otro. & [ ] 04 \\
\hline
\end{tabular}

4-¿Con qué demora se le otorgó turno?

\begin{tabular}{|l|l|}
\hline Menos de una semana. & {$[$ ] 01} \\
\hline Más de una semana y menos de un mes. & {$[\quad] 02$} \\
\hline Más de un mes. & {$[\quad] 03$} \\
\hline
\end{tabular}

5-¿Cuánto tiempo esperó para ser atendido en el servicio?

\begin{tabular}{|c|c|}
\hline Menos de 15 minutos. & [ ] 01 \\
\hline De 15 minutos a media hora. & [ ] 02 \\
\hline De media hora a una hora. & [ ] 03 \\
\hline Más de una hora. & [ ] 04 \\
\hline
\end{tabular}

6 - ¿Los resultados fueron entregados para el día prometido?

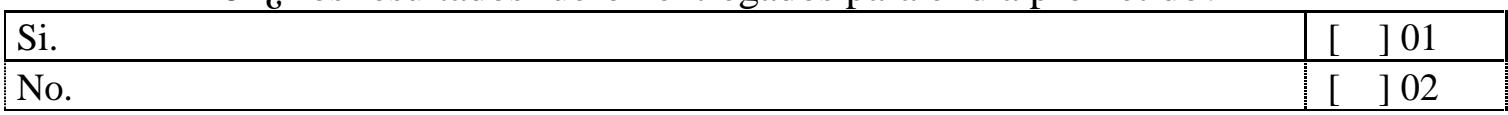


7-¿Cómo considera Usted la atención de Secretaría del Servicio?

\begin{tabular}{|c|c|}
\hline Muy Buena. & [ ] 01 \\
\hline Buena. & [ ] 02 \\
\hline Regular. & [ ] 03 \\
\hline Mala. & [ ] 04 \\
\hline
\end{tabular}

8- ¿Cómo considera Usted la atención en el sector Extracciones?

\begin{tabular}{|c|c|}
\hline Muy Buena. & [ ] 01 \\
\hline Buena. & [ ] 02 \\
\hline Regular. & [ ] 03 \\
\hline Mala. & [ ] 04 \\
\hline
\end{tabular}

9- Como sugerencias para mejorar la prestación que se brinda ¿Cuáles cree que son las más importantes?

(Puede marcar más de una)

\begin{tabular}{|c|c|}
\hline Mejorar el sistema para la obtención de turnos & {$[\quad] 01$} \\
\hline Mejorar el sector Secretaría para la recepción de pacientes & {$[\quad] 02$} \\
\hline Mejorar los tiempos de espera para la atención de pacientes el día del turno & {$[\quad] 03$} \\
\hline Mejorar el edificio de la sala de extracciones - espera & {$[\quad] 04$} \\
\hline $\begin{array}{l}\text { Unificar los tres Laboratorios que integran el Servicio( Laboratorio Central- } \\
\text { Virología-Medio Interno) en un único lugar físico }\end{array}$ & {$[\quad] 05$} \\
\hline Reubicar el Laboratorio en otro lugar del Hospital & {$[\quad] 06$} \\
\hline Disminuir el tiempo para la obtención de resultados & {$[\quad] 07$} \\
\hline Otra. Cuál ? & {$[\quad] 08$} \\
\hline
\end{tabular}




\section{VIII.B. Encuesta "B"}

Encuesta realizada a los integrantes del Servicio

1- Posee un cargo:

\begin{tabular}{|c|c|}
\hline Administrativo. & {$[\quad] 01$} \\
\hline Profesional. & {$[\quad] 02$} \\
\hline No profesional. & [ ] 03 \\
\hline 0tro & [ ] ] 04 \\
\hline
\end{tabular}

2-Cuantos años hace que trabaja en el Hospital:

\begin{tabular}{|c|c|}
\hline Menos de 5 años. & [ ] 01 \\
\hline Entre 5 y 10 años. & {$[\quad] 02$} \\
\hline Más de 10 años. & [ ] 03 \\
\hline
\end{tabular}

3-Considera Ud. que la prestación de Servicio del Laboratorio es:

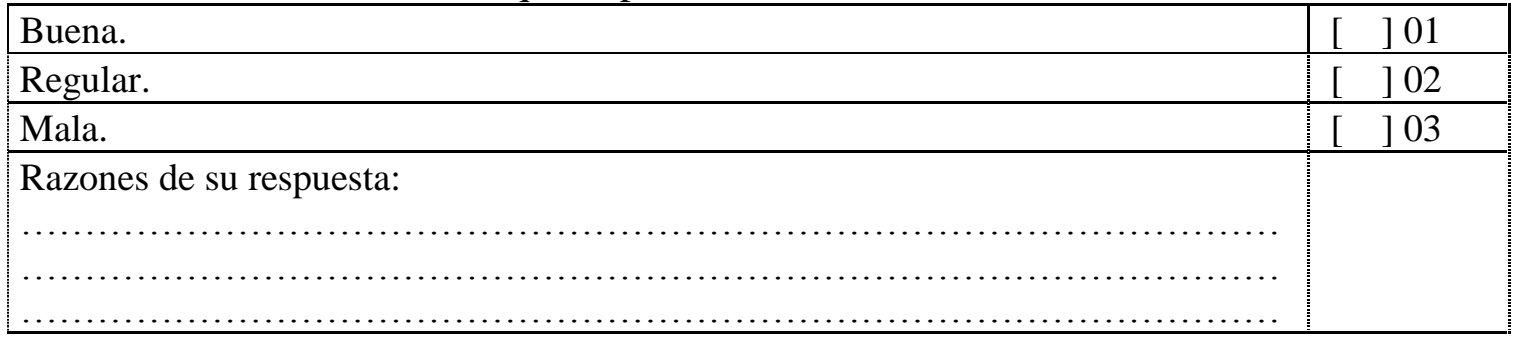

4- Considera que la unificación de las tres salas que componen el Servicio traería beneficios para su funcionamiento

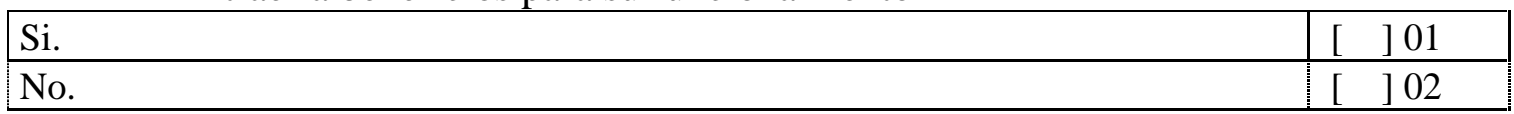

5- Considera que existe superposición de tareas por la forma actual de funcionamiento.

\begin{tabular}{|c|c|}
\hline Si. & [ ] 01 \\
\hline No. & [ ] 02 \\
\hline
\end{tabular}

6- Considera que la unificación de las tres salas significaría una mejora en la calidad de atención

\begin{tabular}{|l|l|}
\hline Si. & {$\left[\begin{array}{l}] \\
01\end{array}\right.$} \\
\hline No. & {$\left[\begin{array}{l}] \\
02\end{array}\right.$} \\
\hline Razones $\ldots \ldots \ldots \ldots \ldots \ldots \ldots \ldots \ldots \ldots \ldots \ldots \ldots \ldots \ldots \ldots \ldots \ldots \ldots \ldots \ldots \ldots \ldots$ \\
\hline
\end{tabular}


7- Con respecto a las relaciones entre miembros del mismo Servicio: ¿cómo cree Ud. que impactaría la unificación del mismo?

\begin{tabular}{|c|c|}
\hline Mejoraría. & [ ] 01 \\
\hline No habría cambios. & [ ] 02 \\
\hline Desmejoraría. & [ ] 03 \\
\hline
\end{tabular}

8-Dentro de las principales quejas que recibe de los pacientes que atiende ¿cuáles son las más frecuentes?

\begin{tabular}{|c|c|}
\hline Demora en la obtención de turnos & {$[\quad] 01$} \\
\hline Demora en la obtención de resultados & {$[\quad] 02$} \\
\hline Falta de claridad en las indicaciones a cumplir para la realización de los estudios & {$[\quad] 03$} \\
\hline Demora en la atención del paciente el día citado & {$[\quad] 04$} \\
\hline Demora en la atención al retirar resultados & {$[\quad] 05$} \\
\hline Quejas por la situación edilicia del Servicio & {$[\quad] 06$} \\
\hline Quejas por la atención en la extracción de muestras & {$[\quad] 07$} \\
\hline Otra. Cuál? & {$[\quad] 08$} \\
\hline
\end{tabular}

9- Dentro de las principales quejas que recibe de los médicos que realizan las prescripciones al Laboratorio. ¿Cuáles considera más importantes?

\begin{tabular}{|c|c|}
\hline Omisión de estudios indicados & {$[\quad] 01$} \\
\hline Demora en la obtención de resultados & {$[\quad] 02$} \\
\hline $\begin{array}{l}\text { Falta de claridad en las indicaciones a cumplir para la realización de los } \\
\text { estudios }\end{array}$ & {$[\quad] 03$} \\
\hline Desconocimiento de las determinaciones que realiza el Servicio & {$[\quad] 04$} \\
\hline $\begin{array}{l}\text { Falta de receptividad por parte del Servicio a las inquietudes planteadas por los } \\
\text { mismos }\end{array}$ & {$\left[\begin{array}{ll}{[} & 05 \\
\end{array}\right.$} \\
\hline Necesidad de incorporación de nuevas determinaciones & {$[\quad] 06$} \\
\hline Confiabilidad de los resultados & {$[\quad] 07$} \\
\hline Otra.¿ Cuál? & {$[\quad] 0$} \\
\hline
\end{tabular}

10-Dentro de las sugerencias que haría para mejorar la prestación del Servicio. Cuáles considera más importantes? (Puede marcar más de uno)

\begin{tabular}{|c|c|}
\hline Unificación de las tres salas que componen el Servicio & {$[\quad] 01$} \\
\hline Mejoras edilicias del Laboratorio & {$[\quad] 02$} \\
\hline Incorporación de un Sistema de Gestión & [ ] 03 \\
\hline Mejora de equipamiento con que cuenta el servicio & {$[\quad] 04$} \\
\hline Mejora en la capacitación del personal & {$[\quad] 05$} \\
\hline Mejora en la comunicación entre todo el personal del Servicio & {$[\quad] 06$} \\
\hline Mejora en la comunicación con el inmediato superior & {$[\quad] 07$} \\
\hline Otra.¿ Cuál? & {$[\quad] 08$} \\
\hline
\end{tabular}




\section{VIII.C. Encuesta "C"}

Encuesta realizada a los profesionales que ordenan prestaciones al Servicio de Laboratorio

1-Posee un cargo profesional:

\begin{tabular}{|c|c|}
\hline Planta permanente & {$[\quad] 01$} \\
\hline Residente & [ ] 02 \\
\hline Beca & [ ] 03 \\
\hline Otro & [ ] 04 \\
\hline
\end{tabular}

2-Conoce Ud. todas las prestaciones que realiza el Servicio de Laboratorio (incluye Laboratorio de Planta, Virología y Medio Interno-Guardia).

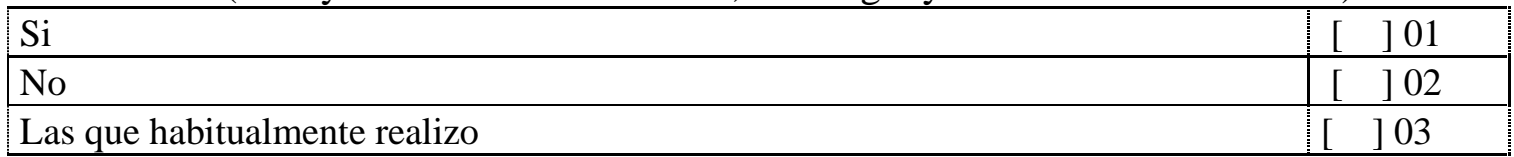

3. Considera que el tiempo de retorno de los resultados (TAT) es el adecuado.

\begin{tabular}{|c|c|}
\hline Siempre & [ ] 01 \\
\hline Casi siempre & [ ] 02 \\
\hline Pocas Veces & [ ] 03 \\
\hline Nunca & {$[\quad] 04$} \\
\hline
\end{tabular}

4. Considera que la unificación de las distintas salas componentes del Servicio, en una única planta física facilitaría su trabajo.

\begin{tabular}{|c|c|}
\hline Si en Mucho & [ ] 01 \\
\hline Algo & [ ] 02 \\
\hline Si en Poco & [ ] 03 \\
\hline No & [ ] 04 \\
\hline
\end{tabular}

5. Considera que los valores encontrados por el Servicio, se encuentran dentro de los esperados (credibilidad de resultados)

\begin{tabular}{|c|c|}
\hline Si en Mucho & {$\left[\begin{array}{ll}{[} & 01 \\
\end{array}\right.$} \\
\hline Algo & {$[\quad] 02$} \\
\hline Si en Poco & {$[\quad] 03$} \\
\hline $\mathrm{No}$ & {$[\quad] 04$} \\
\hline
\end{tabular}


6. Encuentra buena predisposición frente a inquietudes planteadas en la Sala Laboratorio de Planta.

\begin{tabular}{|c|c|}
\hline Siempre & {$[\quad] 01$} \\
\hline Casi siempre & {$\left[\begin{array}{ll}{[} & 02 \\
\end{array}\right.$} \\
\hline Pocas Veces & {$[\quad] 03$} \\
\hline Nunca & {$[\quad] 04$} \\
\hline
\end{tabular}

7. Encuentra buena predisposición frente a inquietudes planteadas en la Sala Laboratorio de Virología.

\begin{tabular}{|c|c|}
\hline Siempre & [ ] 01 \\
\hline Casi siempre & {$[\quad] 02$} \\
\hline Pocas Veces & [ ] 03 \\
\hline Nunca & [ ] 04 \\
\hline
\end{tabular}

8. Encuentra buena predisposición frente a inquietudes planteadas en la Sala Laboratorio de Medio Interno y Guardia.

\begin{tabular}{|c|c|}
\hline Siempre & [ ] 01 \\
\hline Casi siempre & [ ] 02 \\
\hline Pocas Veces & [ ] 03 \\
\hline Nunca & [ ] 04 \\
\hline
\end{tabular}

9-¿Considera que el Servicio cumple con las necesidades diagnósticas de su Servicio?

Desearía la incorporación de otras técnicas diagnósticas

\begin{tabular}{|l|l|}
\hline $\mathrm{Si}$ & {$\left[\begin{array}{l}\mathrm{j} \\
\mathrm{S}\end{array}\right.$} \\
\hline No & {$[\mathrm{j}] 02$} \\
\hline Cuáles & \\
\hline & \\
\hline
\end{tabular}

Por favor indique cuál es el Servicio en el que desempeña sus tareas 


\section{DESARROLLO}

\section{IX.A. Resultados y comentarios de encuestas}

\section{Encuesta "A"}

Encuesta realizada a los pacientes de consultorio externo que concurren al Servicio de Laboratorio

Esta encuesta se realizó en los meses de junio, julio y agosto de 2010, a los pacientes de consultorio externo que voluntariamente aceptaron contestar en el momento que concurrieron a retirar los informes de los estudios realizados.

Cada uno de ellos fue informado debidamente de las razones de tal requerimiento.

La encuesta se realizó en forma auto administrada y anónima, para que los pacientes no sintieran "presión" o "miedo" y pudieran brindar la información requerida con total libertad.

Cabe señalar que muchos pacientes se negaron a responder, posiblemente por temor a no ser atendidos nuevamente o a tener algún tipo de problemas a pesar que se insistió en informar las razones y el anonimato de la misma.

Es de destacar asimismo que un número importante de pacientes no pudieron colaborar manifestando no saber leer ni escribir.

En los siguientes gráficos y tablas se observan las distribuciones de las respuestas obtenidas en las distintas preguntas. 
IX.A.1.a Pregunta $N^{\circ} 1$ "A"

¿Es la primera vez que concurre a este Servicio?

$\mathrm{Si}$

No

Los resultados correspondientes se encuentran representados en el Gráfico 1 "A"

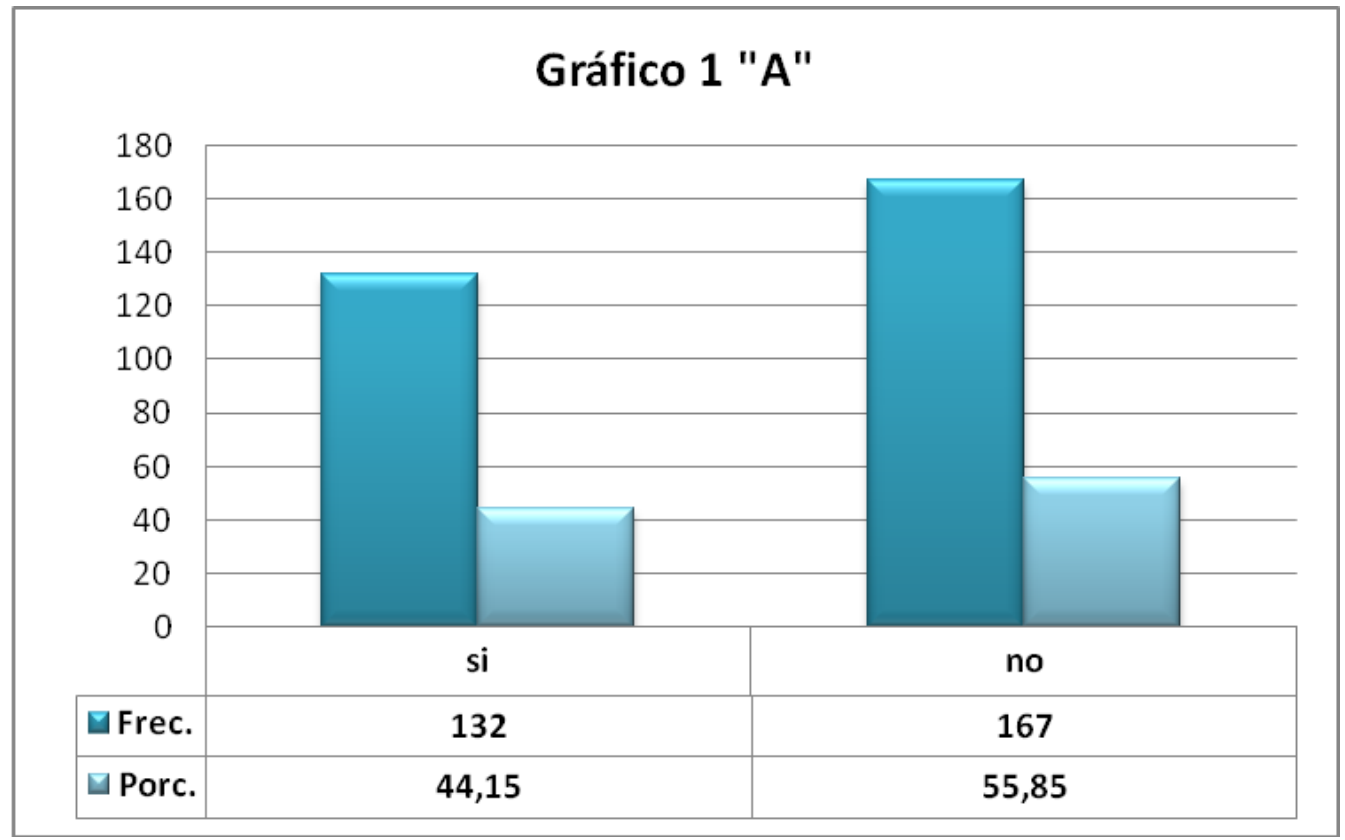

Gráfico IX-1: Pregunta No 1 “A”

$\mathrm{n}=299$

En este caso se obtuvo que el $44.15 \%$ de los pacientes es la primera vez que concurre al Servicio, motivado en gran medida por el incremento de pacientes que ha tenido el Servicio proveniente de las Unidades Sanitarias que se atienden en el período estudiado, mientras que el 55,85\% manifestó haber concurrido ya en otras oportunidades al Servicio. 
IX.A.1.b Pregunta $\mathrm{N}^{\circ} 2$ “A”

¿Cuál es su lugar de residencia?

La Plata Provincia de Buenos Aires Otro

Los resultados correspondientes se encuentran representados en el Gráfico 2 "A"

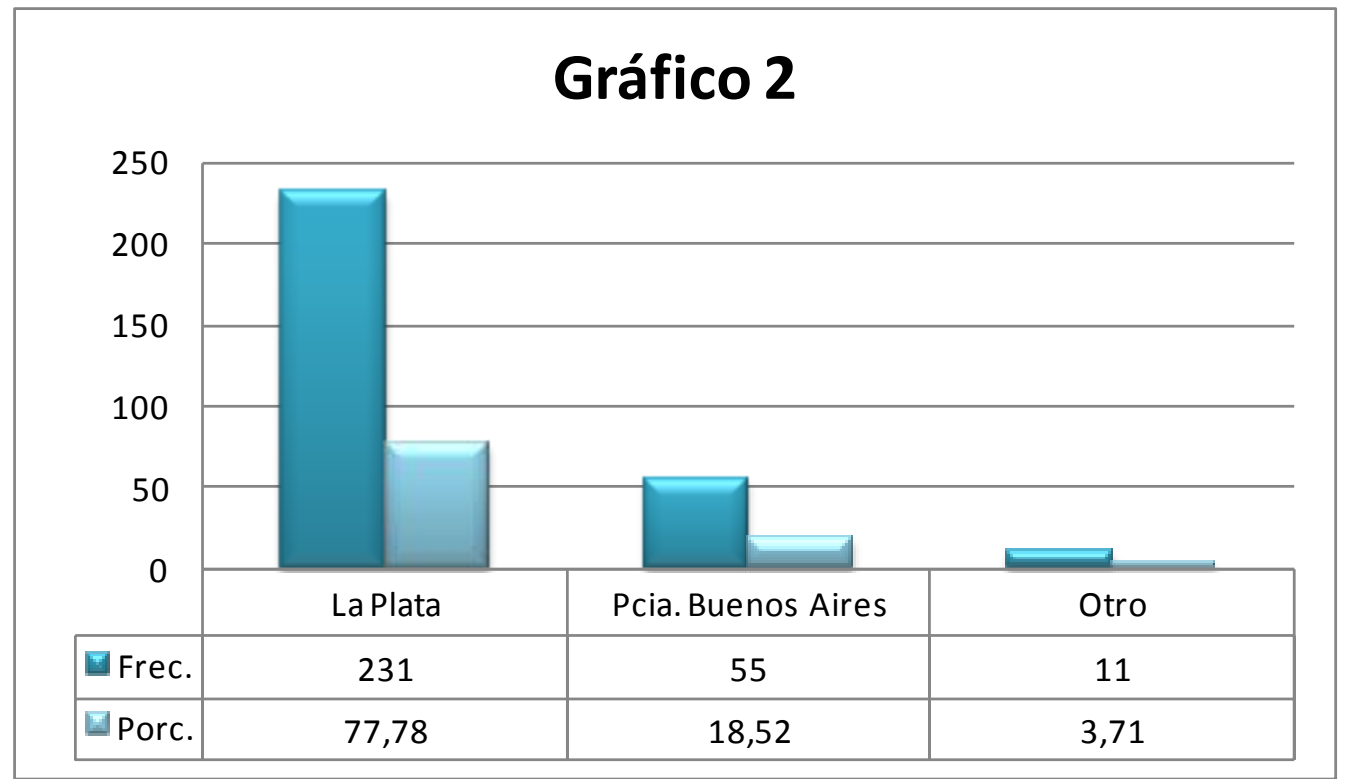

Gráfico IX-2: Pregunta N² “A”

$\mathrm{n}=297$

De este gráfico se desprende que la gran mayoría de pacientes $(77,78 \%)$ que concurren al Servicio provienen de la ciudad de La Plata. Cabe recordar que es un Hospital Interzonal, donde concurren pacientes de otras localidades. El 18,52\% respondió ser paciente del resto de la provincia de Buenos Aires.

En la opción otro, se incluyen un porcentaje muy bajo $(3,71 \%)$ de pacientes que provienen de otras provincias. 
IX.A.1.c Pregunta $N^{\circ} 3$ "A"

Si no es atendido médicamente en este Hospital: ¿Por qué decidió concurrir a este Servicio?

Cercanía Obtención de Turno Recomendación Otro

Los resultados correspondientes se encuentran representados en el Gráfico 3 "A"

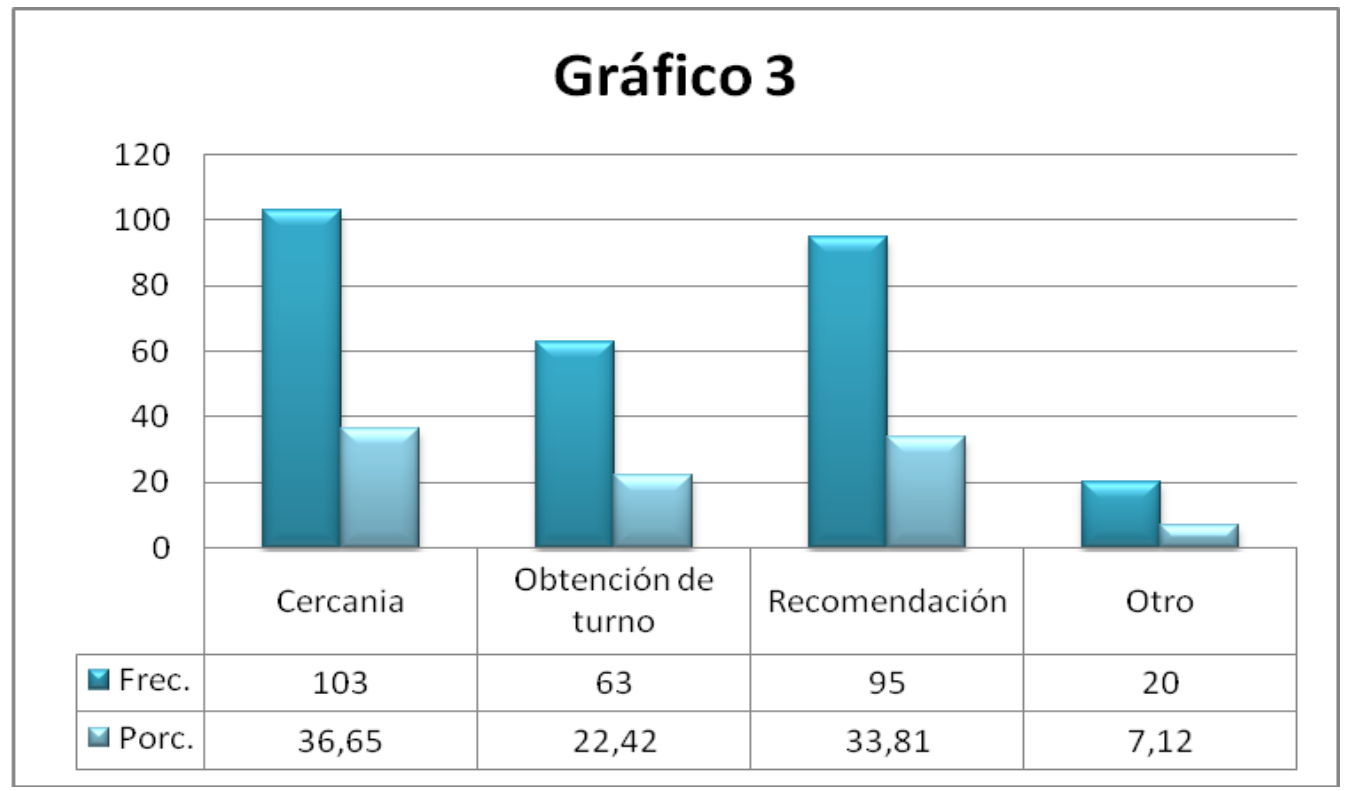

Gráfico IX-3: Pregunta N 3 “A”

$\mathrm{n}=281$

Nuevamente se observan en estos datos que el factor "cercanía" es muy importante, $36.65 \%$ de las respuestas. De acuerdo a lo analizado en la pregunta 1 hay que recordar que las Unidades Sanitarias atendidas pertenecen a un radio cercano al Hospital, de allí entonces los resultados aquí obtenidos.

También es llamativo el porcentaje $(33,81)$ que contestaron haber concurrido por recomendación, lo que es de destacar ya que al tratarse de entidades públicas, fortalece el empeño de los trabajadores de la salud comprometidos con su tarea para lograr una mejor prestación.

El 22,42 \% manifestó haber concurrido por obtención de turno, seguramente dado por la gran concurrencia de pacientes a los hospitales públicos que lleva a un aumento de la demanda de estos Servicios de diagnóstico, por lo que los pacientes tratan de conseguir turnos en otras entidades distintas de aquellas en las que son atendidos médicamente. 


\section{IX.A.1.d Pregunta No 4 "A"}

¿Con qué demora se le otorgó turno?

Menos de una semana Más de una semana y menos de un mes Más de un mes

Los resultados correspondientes se encuentran representados en el Gráfico 4 "A"

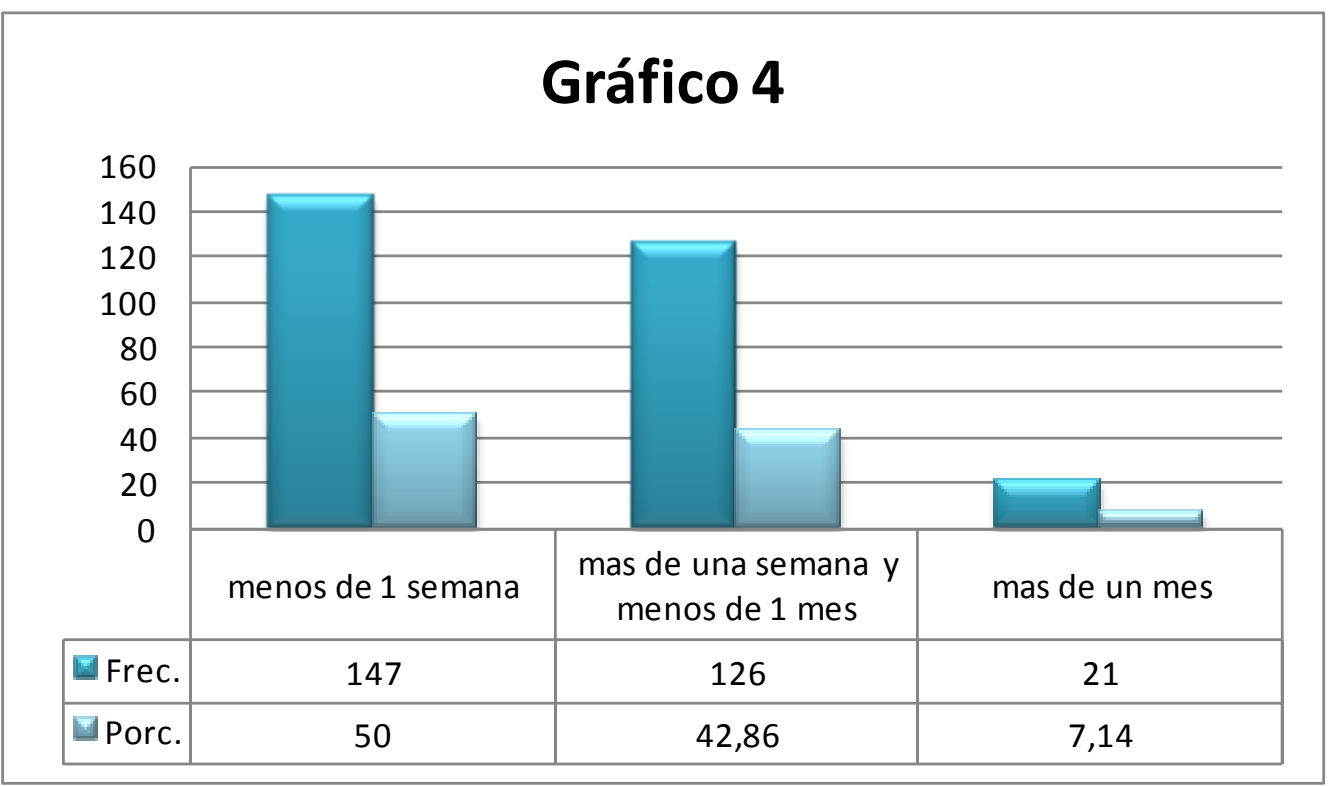

Gráfico IX-4: Pregunta N 4 “A”

$\mathrm{n}=294$

En esta pregunta se observa que la mitad de los pacientes consultados obtuvieron turno dentro de la semana, el $42,86 \%$ entre una semana y un mes y un $7,14 \%$ más de un mes.

De estas respuestas se desprende que es necesario trabajar sobre las necesidades del Servicio para aumentar la oferta de turnos e incrementar el porcentaje de pacientes que puedan obtener su turno dentro de la semana, para así cumplir con las necesidades diagnósticas de los pacientes que concurren.

Cabe señalar que el Servicio se vio muy afectado por bajas jubilatorias en su plantel profesional y técnico, durante los años 2009-2010, comenzando paulatinamente luego a incorporar algunos cargos profesionales y técnicos, pero con las dificultades que una disminución brusca de personal produce y el tiempo que conlleva luego la capacitación y adaptación de nuevos agentes incorporados. 
IX.A.1.e Pregunta $\mathrm{N}^{\circ} 5$ "A"

¿Cuánto tiempo esperó para ser atendido en el Servicio?

Menos de 15 minutos. De 15 minutos a media hora. De media hora a una hora. Más de una hora.

Los resultados correspondientes se encuentran representados en el Gráfico 5 "A"

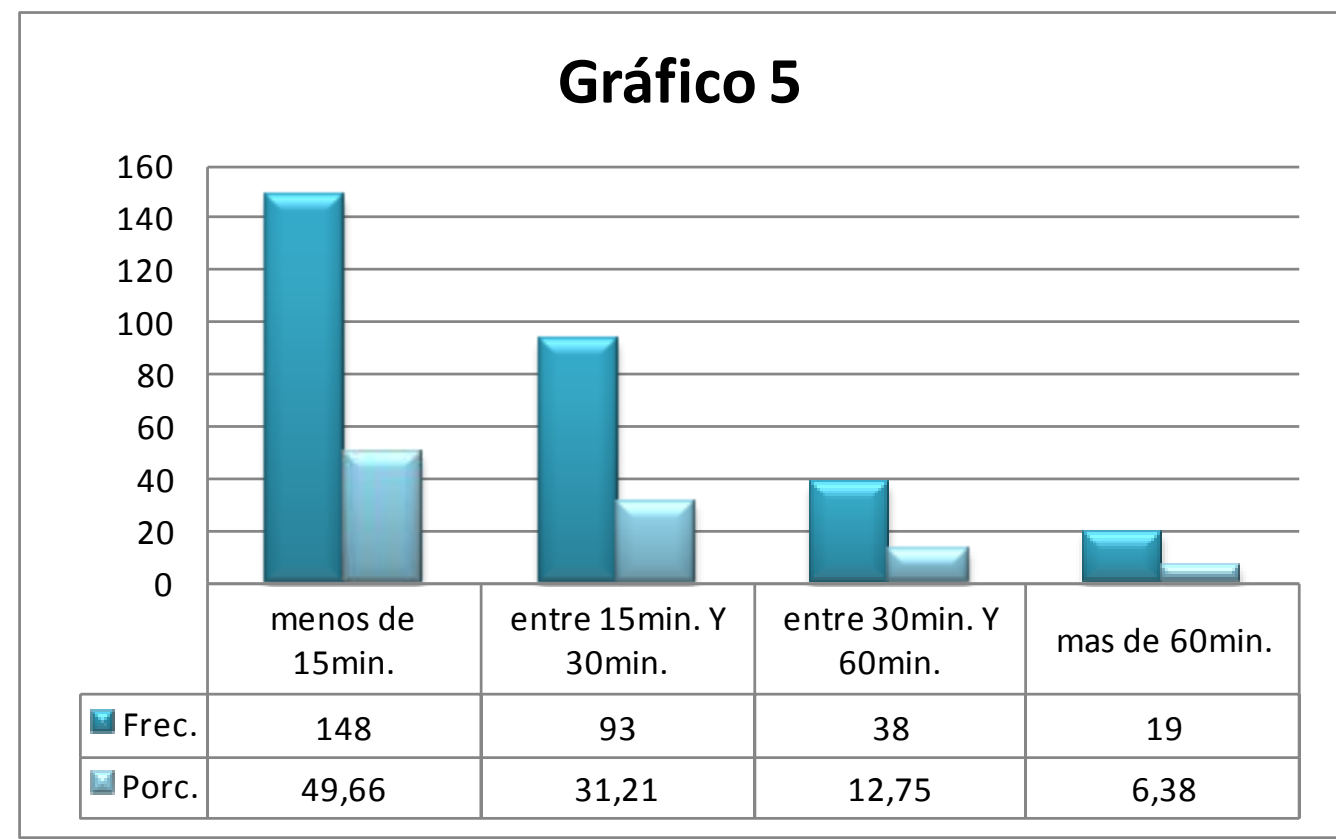

Gráfico IX-5: Pregunta No 5 "A"

$\mathrm{n}=298$

En esta distribución se obtiene que el 49,66\% de los pacientes fueron atendidos dentro de los 15 minutos, el 31,21\% fue atendido entre los 15 minutos y media hora, el $12,75 \%$ entre media hora y una hora y el 6,38\% más de una hora.

Es de recordar que la mayor concentración de concurrencia de pacientes al Servicio se da entre las 7 y 8,30 horas que es el horario en que se realizan las extracciones.

$\mathrm{Al}$ analizar las posibles causas de estas demoras es probable que haya influido la falta de personal administrativo en la admisión de pacientes. El Laboratorio cuenta únicamente con una secretaria estable con asignación, y dos administrativos que fueron planes sociales, suspendidos hace más de un año, por lo que su concurrencia es voluntaria y por lo tanto errática.

Otro de los posibles motivos son las deficiencias edilicias, ya que el Laboratorio cuenta sólo con dos boxes de extracción, que a pesar de la rapidez y habilidad de los extraccionistas resultan insuficientes. 


\section{IX.A.1.f Pregunta $N^{\circ} 6$ “A”}

¿Los resultados fueron entregados el día prometido?

$\mathrm{Si}$ No

Los resultados correspondientes se encuentran representados en el Gráfico 6 "A"

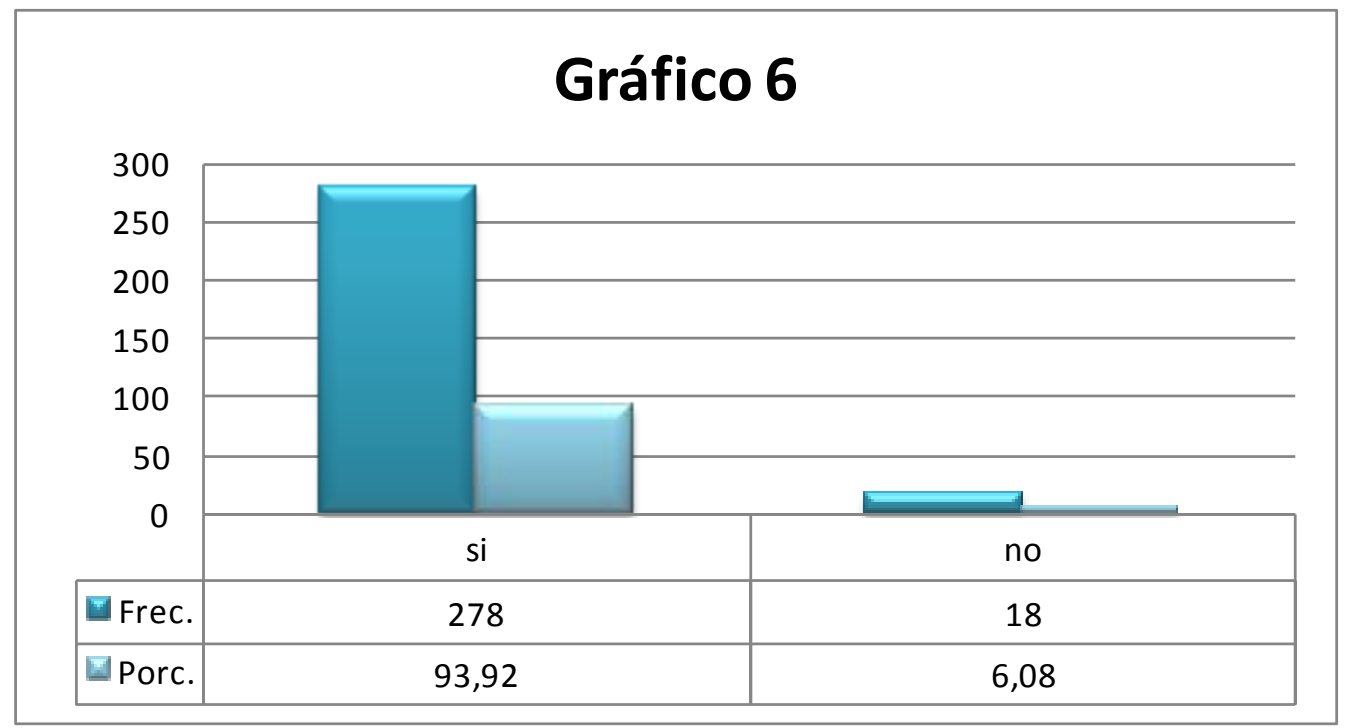

Gráfico IX-6: Pregunta No 6 "A"

$\mathrm{n}=296$

De este gráfico se desprende que el $93,92 \%$ de los consultados obtuvo sus resultados el día prometido, y un $6,08 \%$ respondió que no.

Es necesario seguir trabajando para que la totalidad de pacientes puedan obtener los resultados el día especificado y así disminuir los inconvenientes que conllevan la no entrega de los mismos, apuntando fundamentalmente a la necesidad de obtener un diagnóstico oportuno y certero tan necesario en el área salud. Además, algunas determinaciones complejas se derivan desde nuestro laboratorio a otras instituciones que pudieron ser la causa de demora en los resultados. 


\section{IX.A.1.g Pregunta $\mathrm{N}^{\circ} 7$ "A"}

¿Cómo considera Usted la atención de Secretaría del Servicio?

Muy Buena Buena Regular Mala

Los resultados correspondientes se encuentran representados en el Gráfico 7 "A"

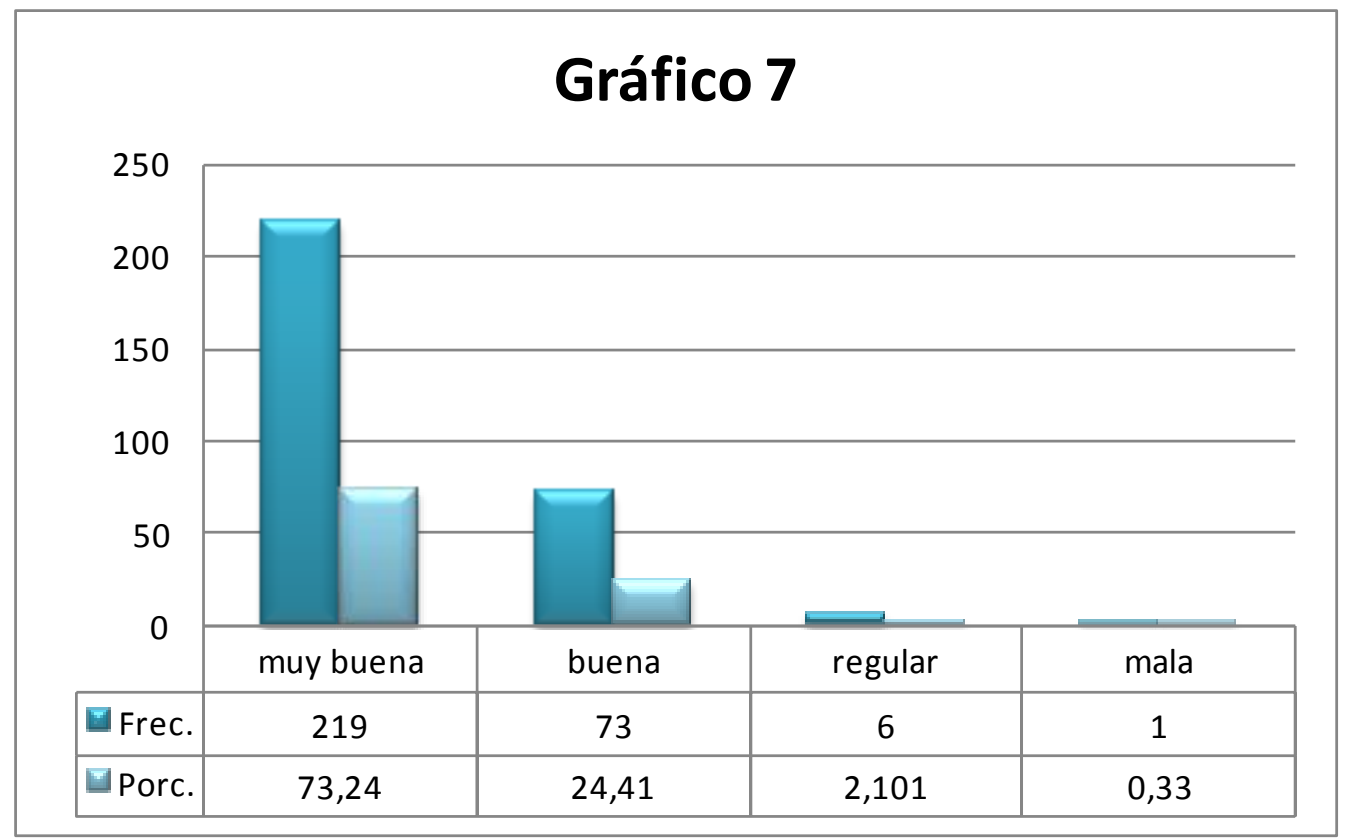

Gráfico IX-7: Pregunta No 7 “A”

$n=299$

En esta pregunta se trató de evaluar la forma en que los pacientes se sienten atendidos en el primer contacto que tienen con el Servicio ya que los turnos son administrados en una oficina central de turnos en forma personal que posee el Hospital para todos los Servicios.

Las respuestas fueron Muy Buena el $73,24 \%$, Buena el $24,41 \%$ con un acumulado del $97,66 \%$, de lo que se desprende que a pesar de lo sobrecargado de trabajo con que se encuentra el Sector el resultado es muy positivo.

Sólo el 0,33\% de la consulta respondió como Mala.

En los Servicios de Salud la función administrativa es fundamental ,resultando el trato con pacientes a menudo engorroso, por lo que es necesario la permanente capacitación de aquellos que cumplen esta tarea tan importante como es recibir a las personas en un momento especial como es el estado de enfermedad. 


\section{IX.A.1.h Pregunta No 8 "A"}

¿Cómo considera Usted la atención en el Sector Extracciones?

Muy Buena Buena Regular Mala

Los resultados correspondientes se encuentran representados en el Gráfico 8"A"

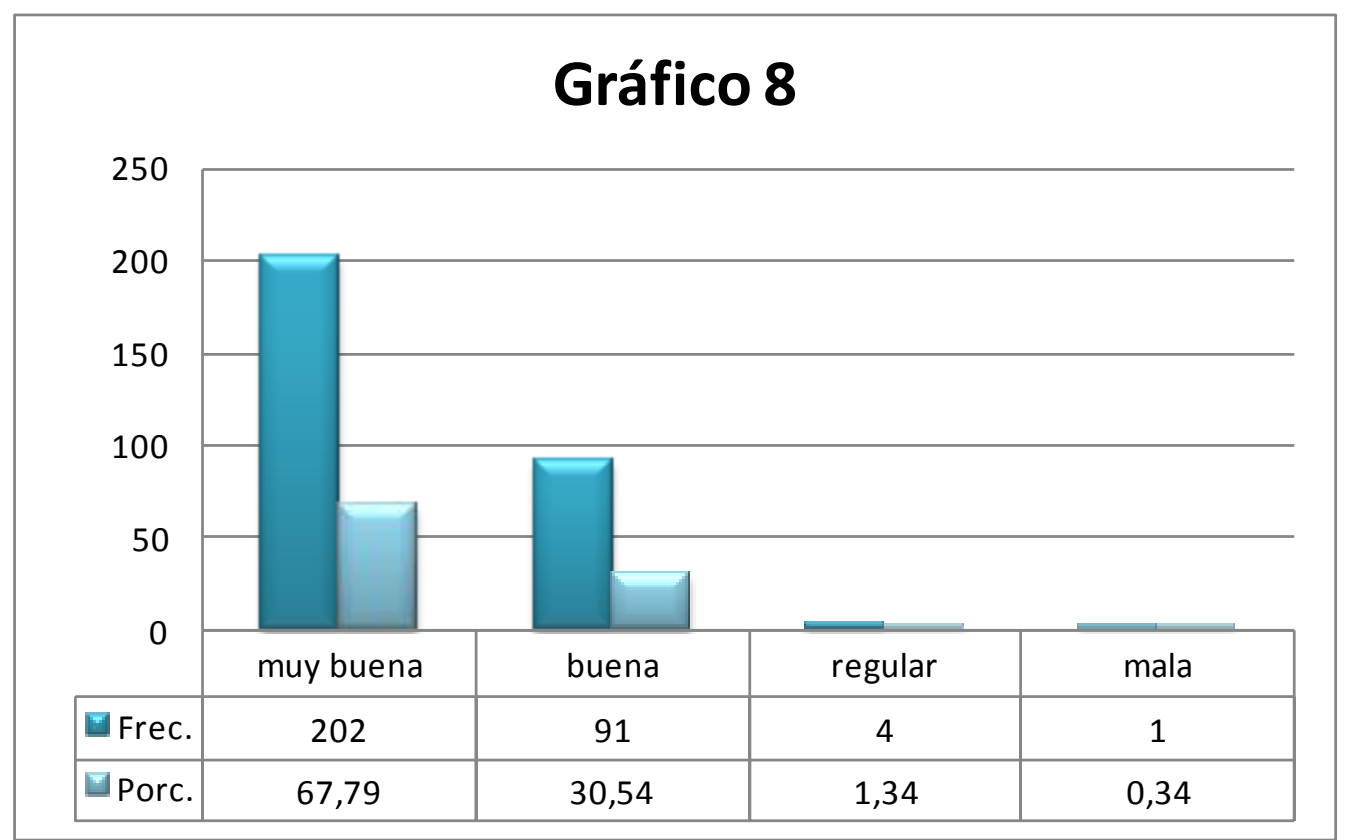

Gráfico IX-8: Pregunta No 8 “A"

$\mathrm{n}=298$

Haciendo el mismo análisis, pero ahora en el Sector extracciones, que es otro de los contactos que tiene el paciente con el Laboratorio, las respuestas fueron:" Muy Buena" 67.79\%," Buena" 30,54\% con un acumulado del $98,32 \%$, arrojando nuevamente un resultado muy positivo en los puntos en que el paciente tuvo contacto con el Servicio.

El 1,34\% respondió "Regular "y el $0,34 \%$ de los encuestados optó por la respuesta "Mala". 
Como sugerencias para mejorar la prestación que se brinda ¿Cuáles cree que son las más importantes?

1) Mejorar el sistema para obtención de turnos.

2) Mejorar el Sector Secretaría para la recepción de pacientes.

3) Mejorar los tiempos de espera para la atención de pacientes el día del turno.

4) Mejorar el edificio de la sala de extracciones-espera.

5) Unificar los tres Laboratorio que integran el Servicio (Laboratorio Central, Planta-Virología-Medio Interno) en un único lugar físico.

6) Reubicar el Laboratorio en otro lugar del Hospital.

7) Disminuir el tiempo para la obtención de resultados.

8) Otra - ¿Cuál?

Los resultados correspondientes se encuentran representados en el Gráfico 9“A”

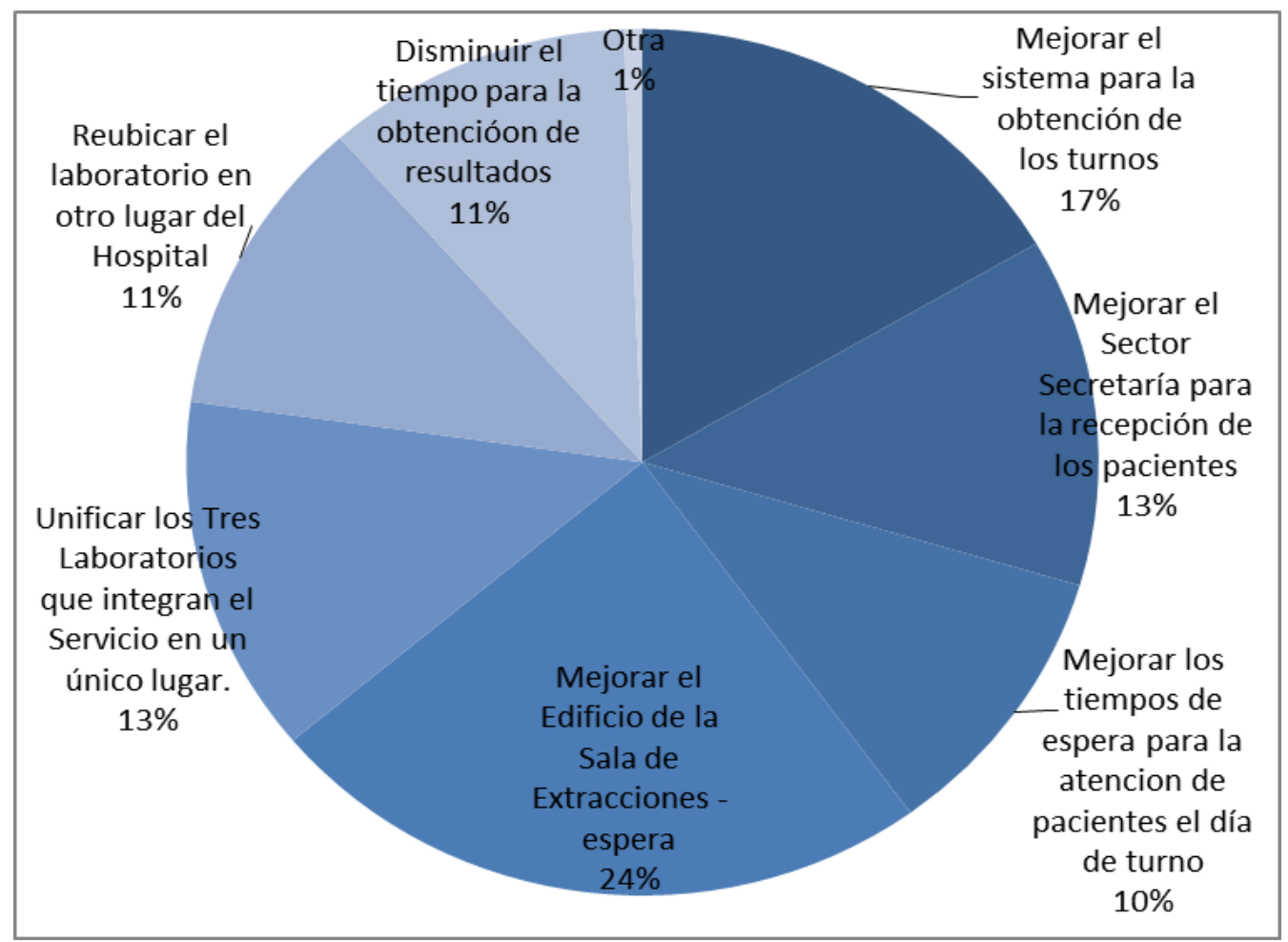

Gráfico IX-9: Pregunta $N^{\circ} 9$ "A"

$\mathrm{n}=299$ 
La opción 1 se refiere al sistema de obtención de turnos, administrados en la central de turnos que posee el hospital, obtuvo el $17 \%$, posiblemente debido a demora en la atención por el caudal de pacientes que atienden, debiéndose estudiar la posibilidad de ser otorgados por el mismo Servicio.

Respecto a las opciones 2 y 4 son los lugares del Servicio a que tienen acceso los pacientes.

Como se detalló oportunamente las tres salas que integran el Servicio se encuentran distribuidas en distintas zonas del Hospital encontrándose los laboratorios de Planta y Virología en una zona de construcción muy antigua con las consiguientes dificultades que ello conlleva.

La opción 5 refiere a la unificación de las tres salas tuvo un porcentaje de 13,33 , seguramente debido a que muchos pacientes requieren estudios que se realizan en las tres salas debiendo concurrir a los mismos con los inconvenientes que conlleva.

La opción 6 (Reubicar el Laboratorio en otro lugar del Hospital) marca un $11,22 \%$, y esto se debe fundamentalmente a que los distintos Laboratorios no tienen una buena accesibilidad para los pacientes de Consultorio Externo.

La opción 7 que hace referencia a los tiempos de espera de resultados un $10,89 \%$ mostró inquietud por disminuir estos tiempos y al relacionarla con la pregunta 3 que se realiza a los profesionales que solicitan estudios se observa en los ambos la necesidad de disminución de estos tiempos.

Con respecto a la opción 8 (Otra), muy pocos pacientes marcaron este ítem $(0,65 \%)$, y al analizarlas en todos los casos se refieren a mejoras edilicias del Hospital en General.

En forma general se puede concluir que las respuestas obtenidas marcan en gran medida dificultades relacionadas a las deficiencias edilicias, (unificación de las tres salas, ubicación del Laboratorio en otro lugar del Hospital, mejora en el sector extracciones y del laboratorio en general) y a la necesidad de poder aumentar la oferta para disminuir el tiempo de obtención de turnos, dado por el mejoramiento del plantel de trabajadores como así también a factores edilicios. 


\section{Encuesta "B"}

Encuesta realizada a los Trabajadores del Servicio.

Se entregaron encuestas a todos los Trabajadores del Servicio que desearon participar, en forma auto administrada y anónima. Respondieron casi la totalidad de los integrantes del servicio.

Los resultados obtenidos se encuentran reflejados en los siguientes gráficos: 
IX.A.1.j Pregunta 1 "B"

Posee un cargo:

Administrativo Profesional No profesional Otro

Los resultados correspondientes se encuentran representados en el Gráfico 1 "B"

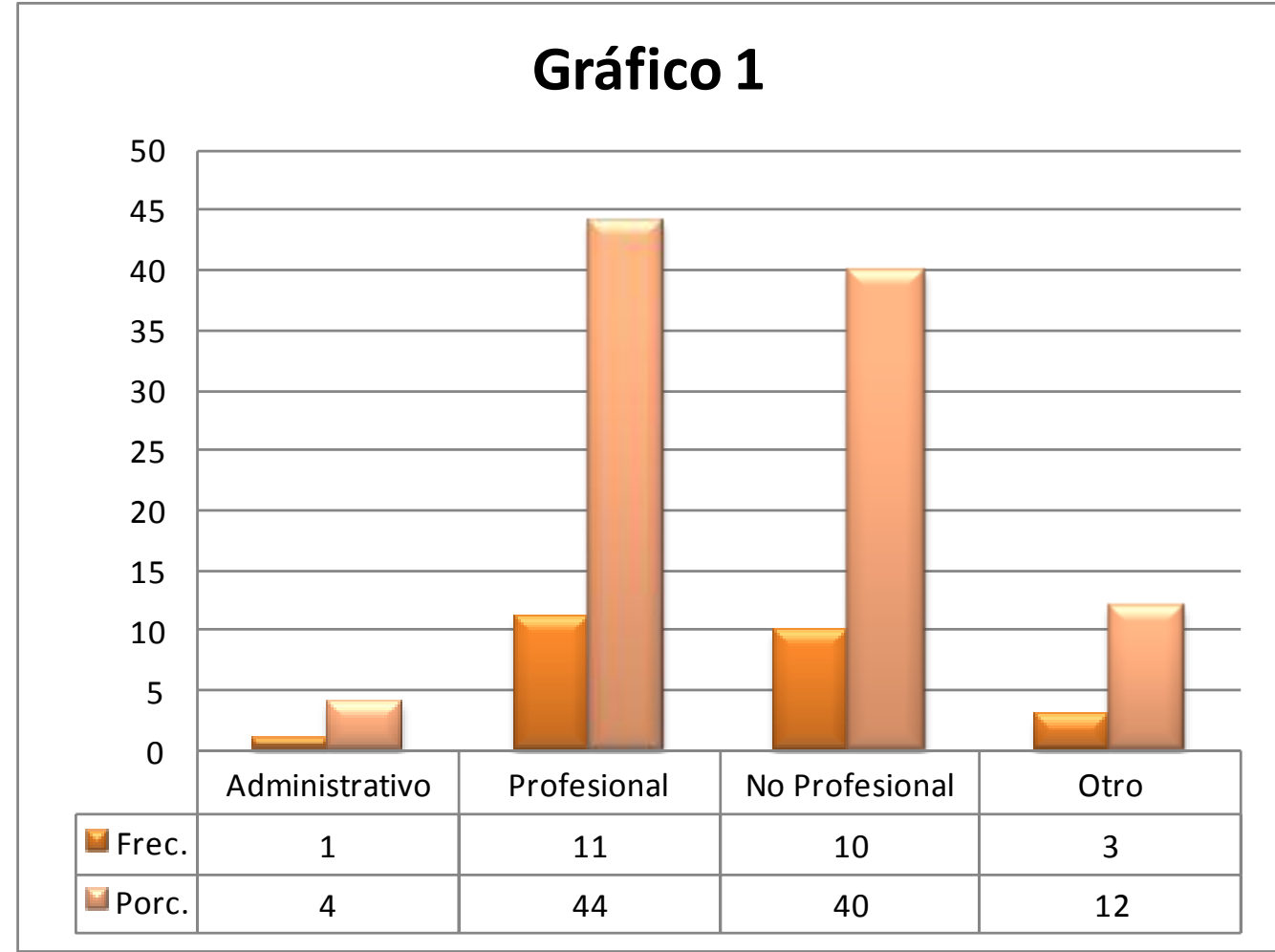

Gráfico IX-10: Pregunta 1 "B”

$\mathrm{n}=25$

La opción otro, incorpora a los agentes que se desempeñan como pasantes, becas, practicantes, estudiantes avanzados, tanto profesionales (universitarios o terciarios) como no profesionales. Dentro de la opción No Profesional se encuentran técnicos, preparadores, mucamas con designación.

De esta distribución se observa que existe un déficit importante tanto de personal no profesional como administrativo debido a bajas jubilatorias que se han ido produciendo a lo largo de los últimos años y que no han sido repuestas.

Respecto al personal profesional, como se ha mencionado en otra oportunidad también se encuentra notablemente disminuido por las mismas razones antes dichas. Si se realiza el cálculo del plantel necesario para el Servicio de acuerdo a la producción medida en unidades de laboratorio, se observa que es necesaria la incorporación de agentes en todas las categorías. 


\section{IX.A.1.k Pregunta 2 "B”}

¿Cuántos años hace que trabaja en el Hospital?

Menos de 5 años $\quad$ Entre 5 y 10 años $\quad$ Más de 10 años

Los resultados correspondientes se encuentran representados en el Gráfico 2 "B"

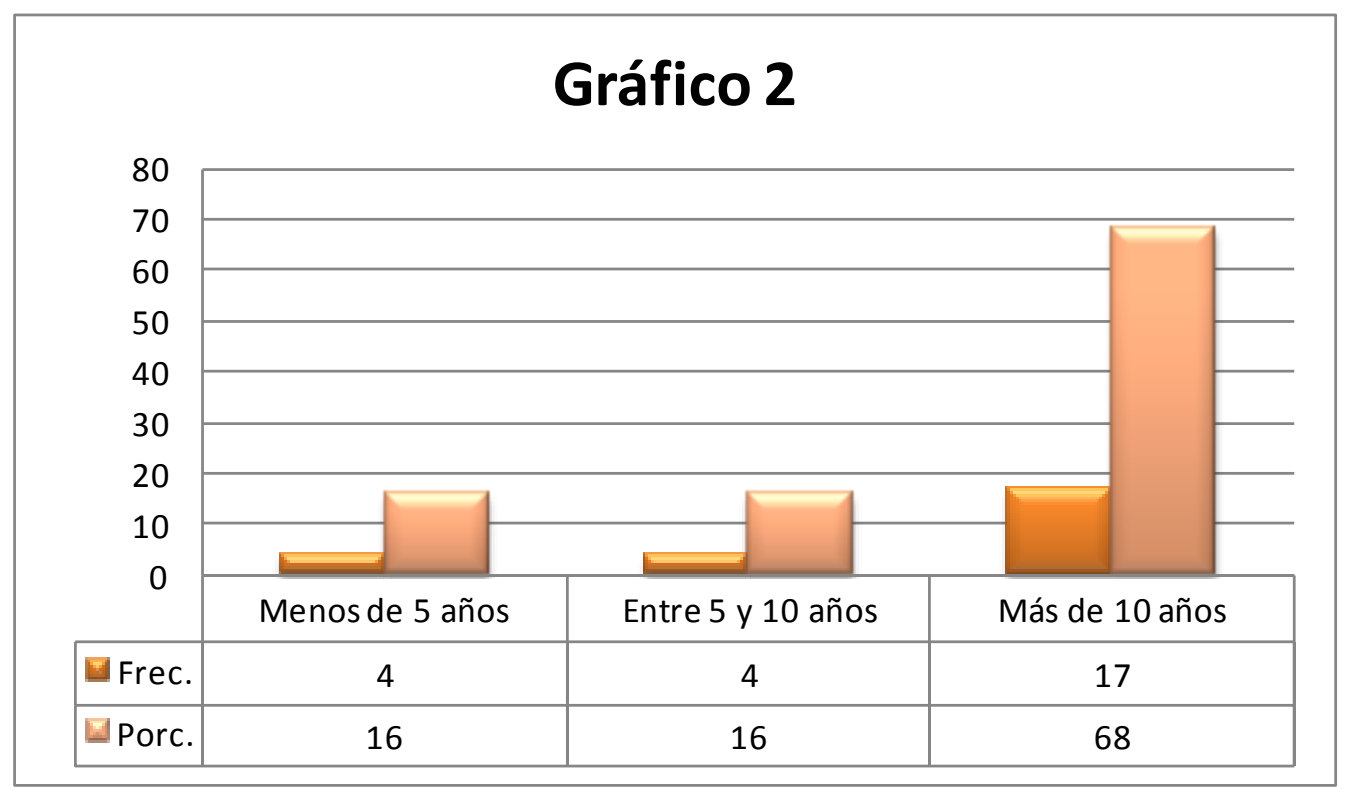

Gráfico IX-11: Pregunta 2 "B"

$\mathrm{n}=25$

En esta distribución se encuentra que el mayor porcentaje (68\%) tiene una antigüedad superior a los 10 años, y el $32 \%$ restante repartido en partes iguales (16\%) para menos de 5 años y entre 5 y 10 años. 
IX.A.1.1 Pregunta 3 "B"

Considera Usted que la prestación de Servicio del Laboratorio es:

Buena $\quad$ Regular Mala

Los resultados correspondientes se encuentran representados en el Gráfico 3 "B"

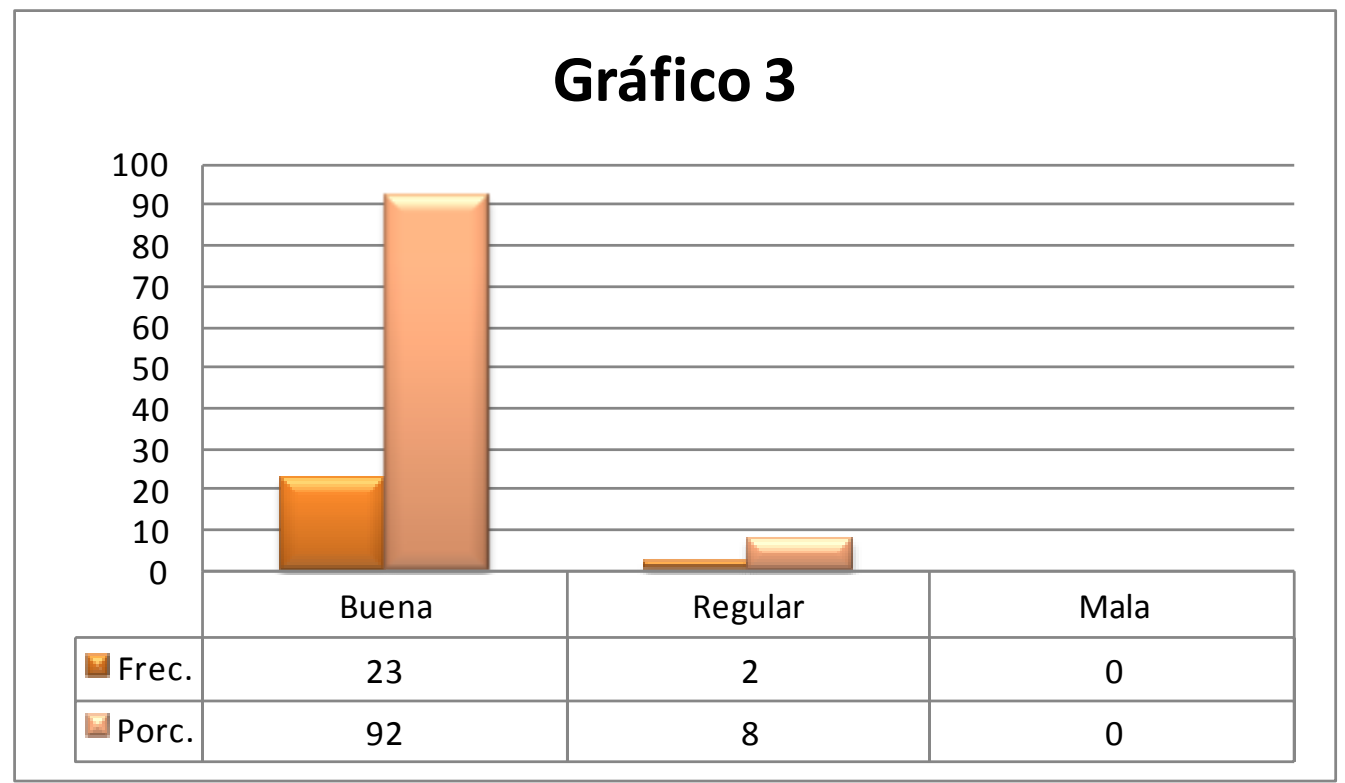

Gráfico IX-12: Pregunta 3 "B"

$\mathrm{n}=25$

En esta pregunta se trató de evaluar cómo ve la prestación de Servicio el trabajador desde dentro del mismo, conociendo la forma en que se trabaja en el Laboratorio.

Se observa que el $92 \%$ respondió Buena y el 8\% Regular.

No se obtuvieron respuestas en la opción Mala, y esto es muy importante, debido a que los análisis de laboratorio en la actualidad, de la mano de la incorporación de tecnología, se han multiplicado en forma exponencial. La confianza en el resultado entregado marca un acierto en los sistemas de control y validación en el procesamiento de la muestra. El personal que trabaja a diario, percibe que las tareas se realizan bien. 
IX.A.1.m Pregunta 4 "B"

¿Considera que la unificación de las tres salas que componen el Servicio traería beneficios para su funcionamiento?

Sí

No

Los resultados correspondientes se encuentran representados en el Gráfico 4 "B"

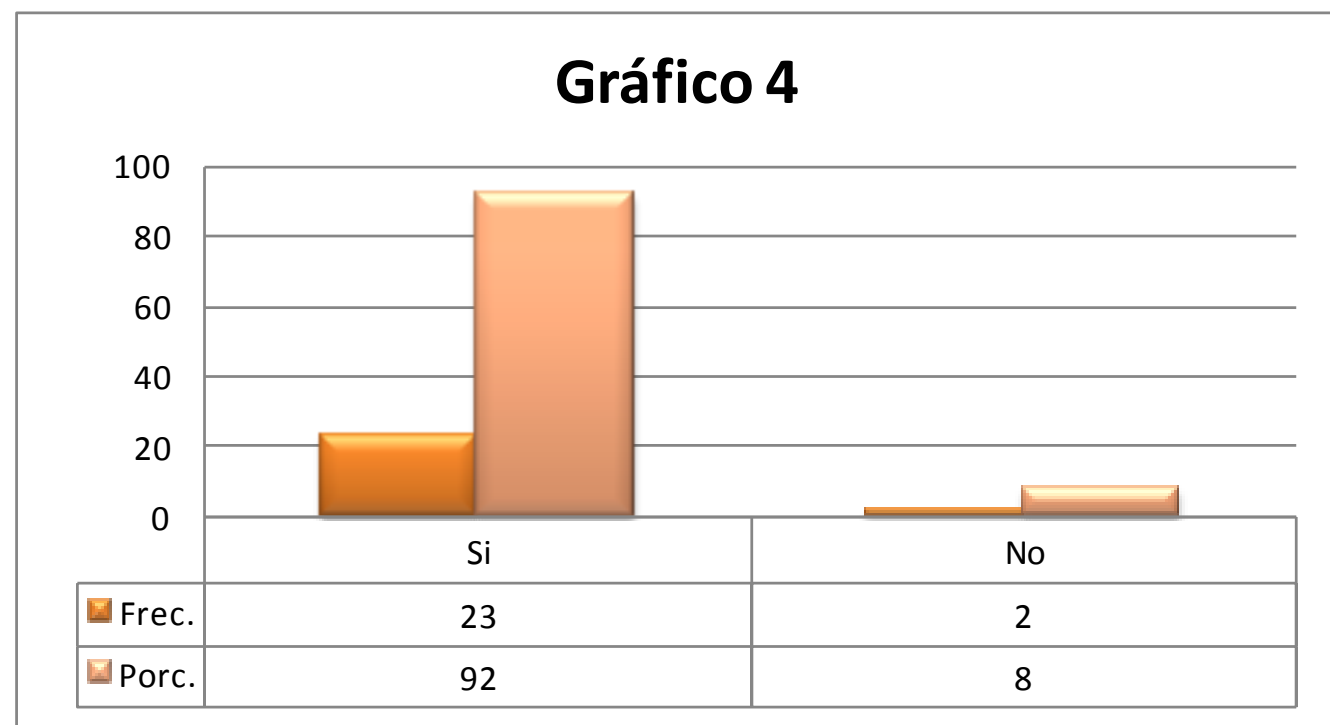

Gráfico IX-13: Pregunta 4 "B"

$\mathrm{n}=25$

En esta interrogación se obtiene que el $92 \%$ de los encuestados responden que la unificación de las tres salas sería beneficiosa para el funcionamiento del Servicio.

Como se mencionó anteriormente el hecho que las tres salas se encuentren alrededor de 100 metros de distancia entre sí, dificulta la interacción de los distintos sectores del Laboratorio y el análisis del conjunto de resultados obtenidos de cada paciente que hacen al normal desempeño de las actividades del Bioquímico.

El 8\% responde negativamente. 
IX.A.1.n Pregunta 5 "B"

¿Considera que existe superposición de tareas por la forma actual de funcionamiento?

$\mathrm{Si}$

No

Los resultados correspondientes se encuentran representados en el Gráfico 5 "B"

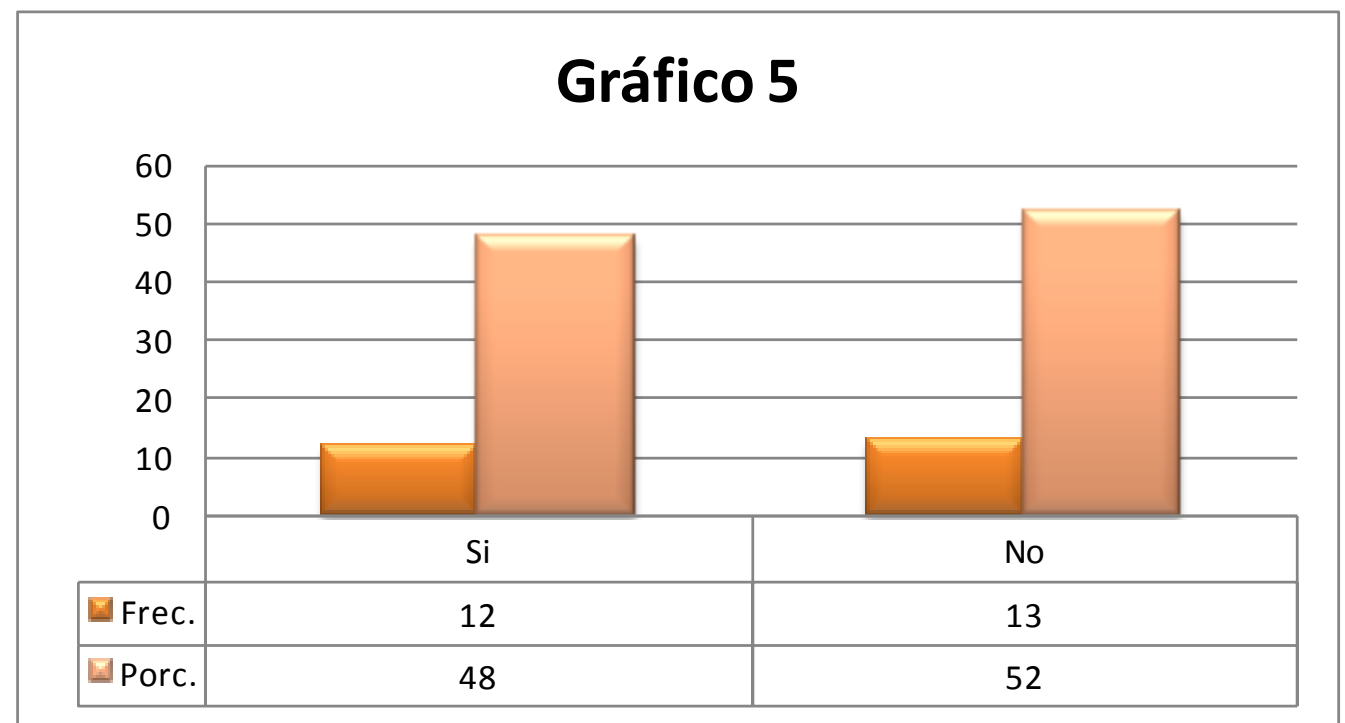

Gráfico IX-14: Pregunta 5 "B”

$\mathrm{n}=25$

En este caso el $52 \%$ responde que no considera que exista superposición de tareas por la forma actual de funcionamiento, mientras que el $48 \%$ considera que sí existe dicha superposición.

Si se analizan los procesos que se llevan a cabo en los distintos sectores, desde la extracción de muestras, procesamiento de las mismas, informe y entrega de resultados, se evidencian procedimientos repetidos en las distintas salas pero que de acuerdo a las respuestas obtenidas de los trabajadores, en la mayoría no se evidencian como superposiciones. 
IX.A.1.o Pregunta 6 "B"

¿Considera que la unificación de las tres salas significaría una mejora en la calidad de atención?

Sí

No

Los resultados correspondientes se encuentran representados en el Gráfico 6 "B"

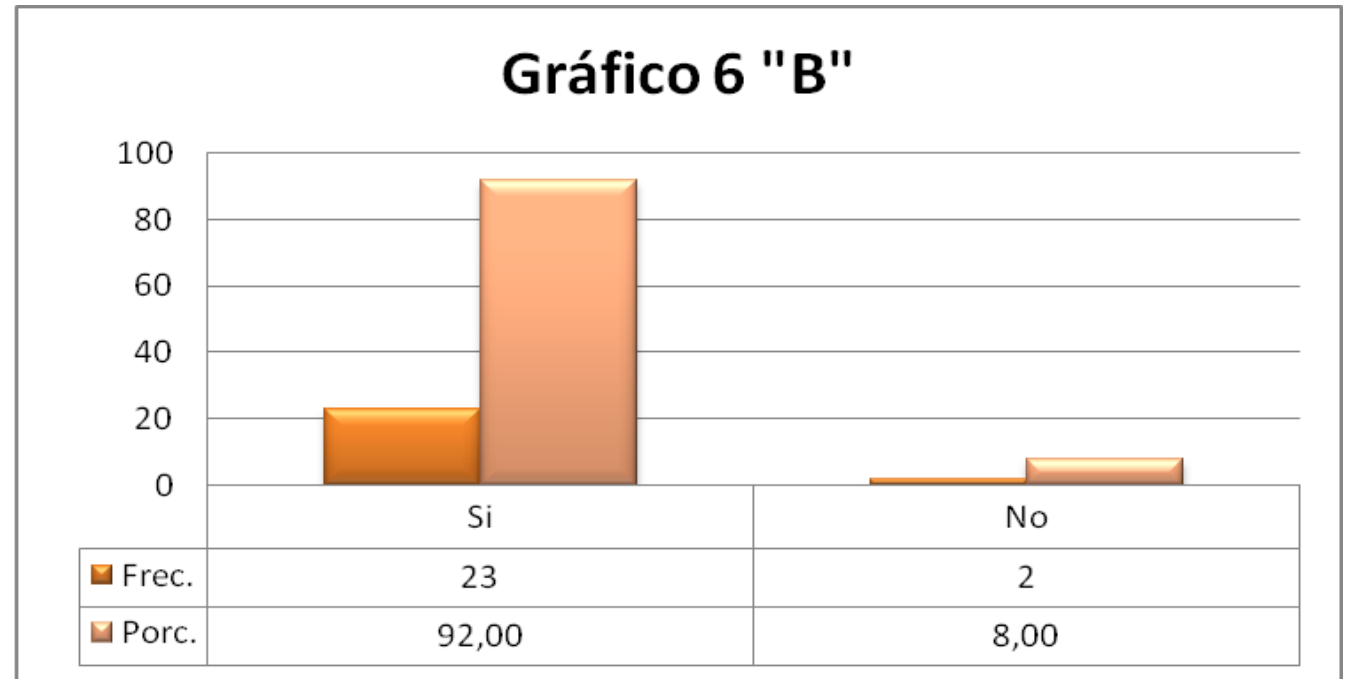

Gráfico IX-15: Pregunta 6 "B"

$\mathrm{n}=25$

Cuando se interroga acerca si mejoraría la calidad de atención al unificar las tres salas, el $92 \%$ responde que si, mientras el $8 \%$ responde negativamente.

El trabajador del Laboratorio vive a diario las dificultades que se producen al estar las tres salas distanciadas físicamente y cómo ello lleva a complicaciones (múltiples extracciones de sangre, entrega de resultados en diferentes secretarías, etc.) para los pacientes, de allí los resultados obtenidos. 
IX.A.1.p Pregunta 7 "B”

Con respeto a las relaciones entre miembros del mismo Servicio: ¿cómo cree Usted que impactaría la unificación del mismo?

Mejoraría No habría cambios Desmejoraría

Los resultados correspondientes se encuentran representados en el Gráfico 7 "B"

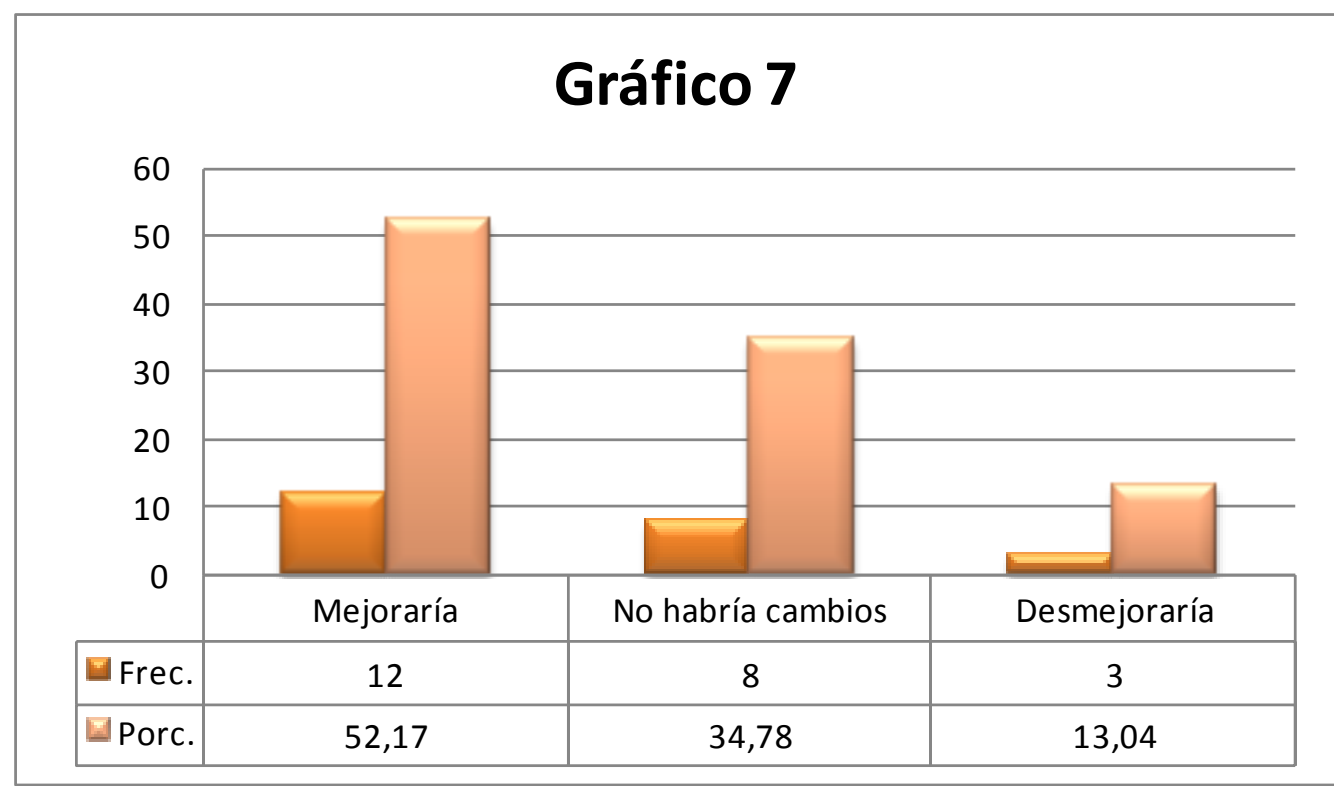

Gráfico IX-16: Pregunta 7 "B”

$\mathrm{n}=23$

El hecho de que las tres salas se encuentran a una distancia de aproximadamente 100 metros entre sí y la dinámica del trabajo diario, hace a que los integrantes de las mismas no tengan un contacto fluido y muchas veces exista hasta desconocimiento de las tareas realizadas por los distintos integrantes, lo que lleva a menudo a generar situaciones de disconformidad entre sus integrantes.

Desde hace varios años se ha pensado en la unificación de las tres salas pero nunca se evaluó concretamente que opinaban de ello sus integrantes.

Aquí los resultados, el 52,17 \% opinó que las relaciones mejorarían, el 34,78\% que no habría cambios y un 13,04\% que desmejoraría. 
IX.A.1.q Pregunta 8 "B"

Dentro de las principales quejas que recibe de los pacientes que atiende ¿cuáles son las más frecuentes?

Demora en la obtención de turnos

Demora en la obtención de resultados

Falta de claridad en las indicaciones a cumplir para la realización de los estudios

Demora en la atención del paciente el día citado

Quejas por la situación edilicia del Servicio

Quejas por la atención en la extracción de muestras

Otra ¿Cuál?

Los resultados correspondientes se encuentran representados en el Gráfico 8 "B"

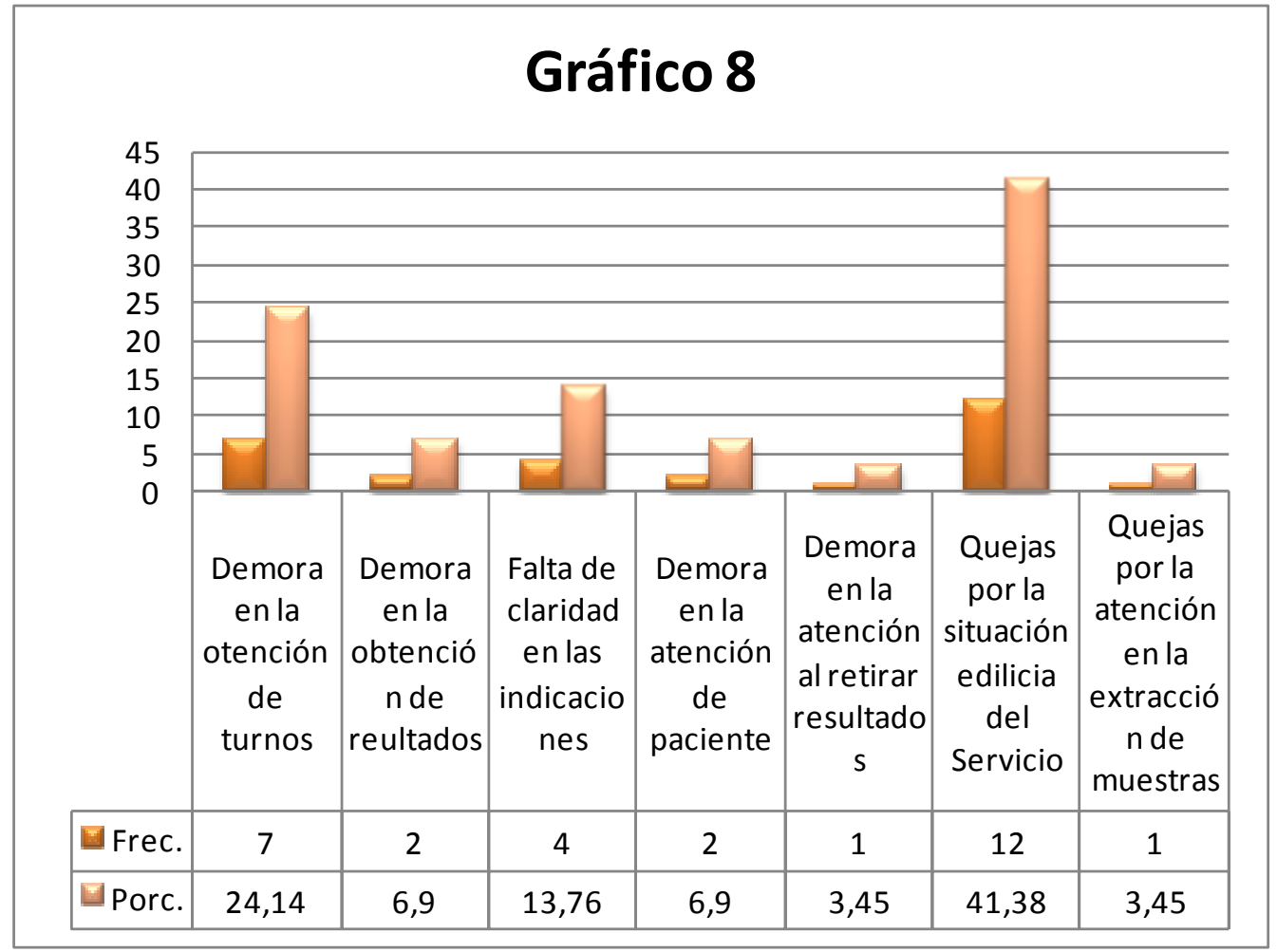

Gráfico IX-: Gráfico 8 "B"

$\mathrm{n}=19$

De estas respuestas se observa que el mayor porcentaje $41,38 \%$, se refiere a quejas por la situación edilicia, seguido a las dificultades de obtención de turno 
$24,14 \%$, lo que al compararlo con las respuestas realizadas por los pacientes existe una total concordancia. Cabe destacar que las dimensiones y estado de mantenimiento edilicio es un indicador de calidad de atención.

La opción de falta de claridad en las indicaciones representa el 13,76 \%, lo que refleja la necesidad de trabajar conjuntamente con los actores involucrados para mejorar dicho aspecto.

Los ítems Demora en la obtención de resultados y la Demora en la atención del paciente el día citado, representan el 6,9\% cada una de ellas. Nuevamente estas respuestas al ser comparadas con las respuestas de los pacientes encuentran correlación. Asimismo al observar las respuestas de los profesionales respecto al tiempo de retorno de resultados, un porcentaje (el 13,51\%) responde que pocas veces es el adecuado, lo que como se mencionó anteriormente lleva a la tarea de trabajar sobre las necesidades del Servicio y de la comunicación del mismo con los profesionales que realizan pedidos para obtener mejores resultados.

La demora en la atención al retirar resultados y quejas por la atención en la extracción de muestras representó el 3,45\% en ambos casos. 
IX.A.1.r Pregunta 9 "B"

Dentro de las principales quejas que recibe de los médicos que realizan las prescripciones al Laboratorio ¿Cuáles considera las más importantes?

Omisión de estudios indicados

Demora en la obtención de resultados

Falta de claridad en las indicaciones a cumplir para la realización de los estudios

Desconocimiento de las determinaciones que realiza el Servicio

Falta de receptividad por parte del Servicio a las inquietudes planteadas por los mismos

Necesidad de incorporación de nuevas determinaciones

Confiabilidad de los resultados

Otra. ¿Cuál?

Los resultados correspondientes se encuentran representados en el Gráfico 9 "B"

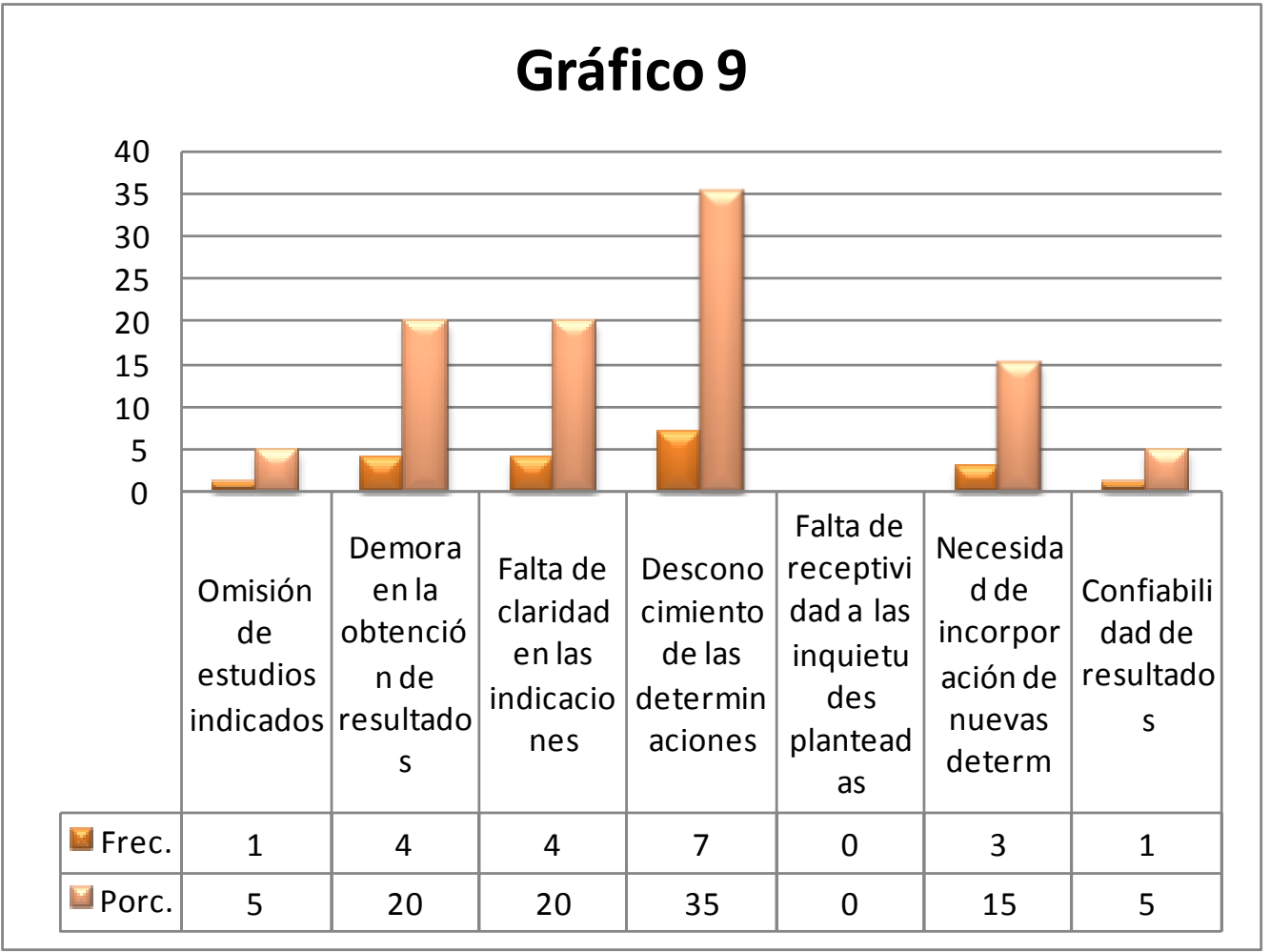

Gráfico IX-17: Gráfico 9 "B"

$\mathrm{n}=20$ 
En esta pregunta se observa que el mayor porcentaje de respuestas se da en el desconocimiento de las prestaciones que realiza el Laboratorio (35\%).Al relacionar esta opción con la pregunta realizada a los profesionales que realizan pedidos al Laboratorio se observa en ellos también un desconocimiento de todas las prestaciones que realiza el Servicio (el 13,51 \% respondió negativamente y $51,35 \%$ las que habitualmente realiza), por lo que nuevamente es de destacar la necesidad de establecer una mejor comunicación, con los distintos Servicios, siendo necesaria la capacitación de los integrantes del Laboratorio para que puedan trasmitir adecuadamente lo que se realiza y lleguen a despertar el interés de quienes las utilizan.

Las opciones Demora en la obtención de resultados representa el $20 \%$.Nuevamente se observa aquí que es necesario trabajar para mejorar la respuesta del Laboratorio como así también la relación con los profesionales para comunicar los tiempos necesarios para cada estudio y así no generar expectativas que no son cumplibles.

La falta de claridad en las indicaciones representa el 20\%. Al comparar este resultado con la pregunta anterior que obtuvo el $13,76 \%$, se destaca la necesidad, como se mencionó anteriormente de trabajar para mejorar en este punto.

La necesidad de incorporación de nuevas técnicas representa el 15\%.Como se mencionó anteriormente el Laboratorio va incorporando paulatinamente nuevos métodos diagnósticos, pero, en cada caso, se debe realizar un estudio consensuado para su implementación, ya que es necesario evaluar costos, demanda estimada, capacitación del personal, equipamiento y necesidad de mantenimiento de la oferta en el tiempo.

La omisión de estudios indicados representa el 5\%. Es de destacar que este Laboratorio no cuenta con un sistema de Gestión, de necesidad indiscutible ya en todos los Laboratorios de Análisis Clínicos, lo que lleva a que se realicen en forma manual las planillas de trabajo diario donde es asentado, para cada estación de trabajo, el listado de muestras a procesar. Dichos datos son volcados a diario, directamente de las solicitudes médicas manualmente, lo que lleva a cometer errores de omisión. Esta metodología de trabajo es realizada en esta forma desde hace varios años, pero el aumento progresivo de determinaciones que realiza el Laboratorio, el aumento de número de pacientes y la necesidad de poder evaluar resultados anteriores (valores históricos) de cada paciente para mejorar la calidad de trabajo hacen ya de esta herramienta una necesidad indiscutible. Es necesario concientizar a las autoridades de esta necesidad para que se puedan destinar los recursos necesarios para su implementación.

La confiabilidad de los resultados representa el 5\%. Como se mencionó en la pregunta 5 realizada a los profesionales que realizan los pedidos al Laboratorio, es necesario dar a conocer la forma en que se trabaja dentro del Laboratorio e informar debidamente los alcances de las distintas técnicas para despejar dudas. 
La falta de receptividad a las inquietudes planteadas obtuvo $0 \%$, por lo que desde los trabajadores del Servicio no se observa como una inquietud a mejorar y fue observado en bajos porcentajes por los profesionales que realizan los pedidos (detallado en preguntas 6,7 y 8 de encuesta "C"). Se deberá prestar atención a esta interacción ya que dado que la atención en salud se realiza en forma conjunta y multidisciplinaria, es necesario que los profesionales que realizan solicitudes sientan atendidas sus necesidades en el Servicio. 
IX.A.1.s Pregunta 10 "B"

Dentro de las sugerencias que haría para mejorar la prestación de Servicio, ¿Cuáles considera más importantes?

Unificación de las tres salas que componen el Servicio

Mejoras edilicias de Laboratorio

Incorporación de un Sistema de Gestión

Mejora de equipamiento con que cuenta el Servicio

Mejora en la capacitación del personal

Mejora en la comunicación entre todo el personal del Servicio

Mejora en la comunicación con el inmediato superior

Otra ¿Cuál?

Los resultados correspondientes se encuentran representados en el Gráfico 10 "B"

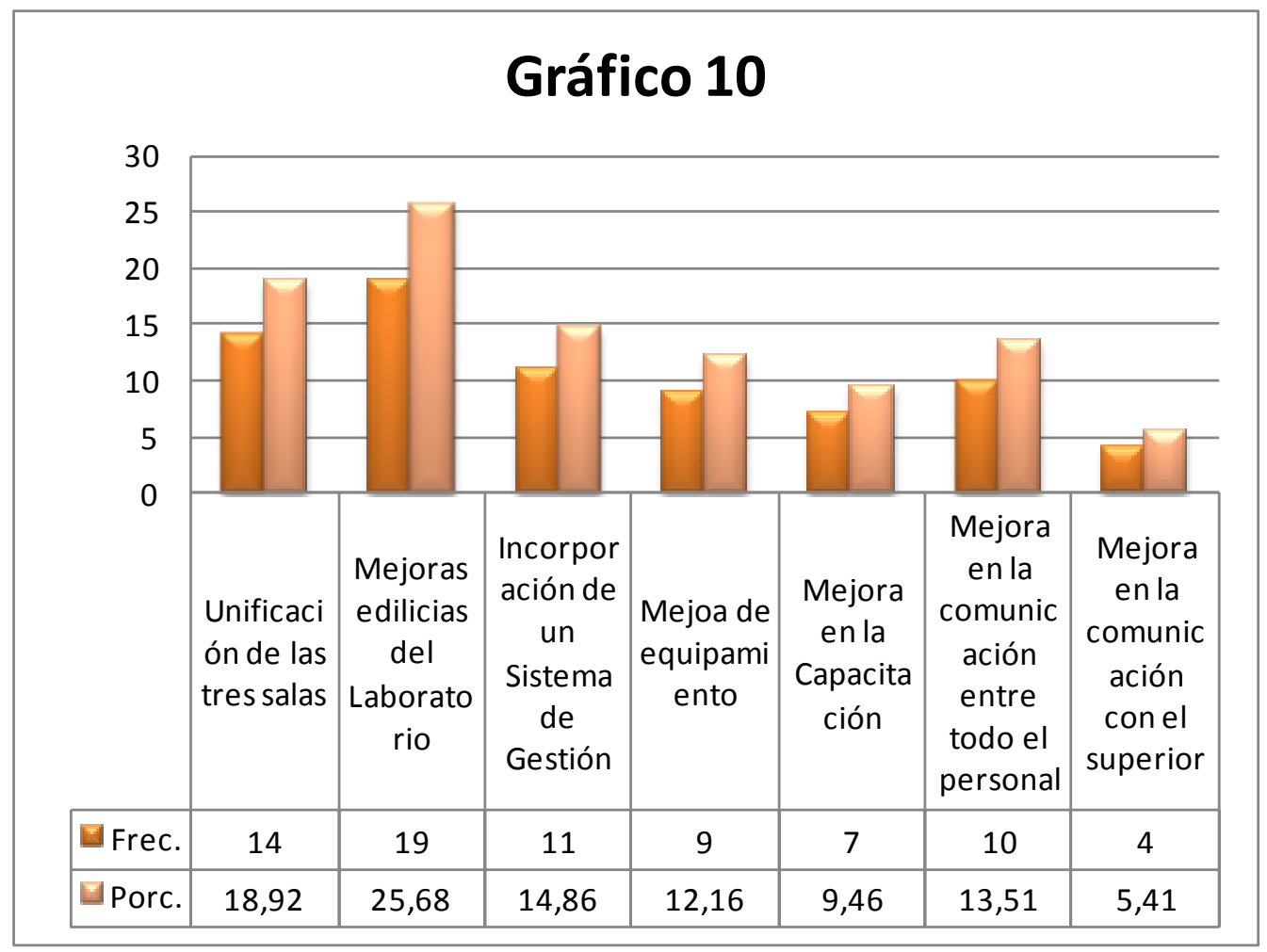

Gráfico IX-18: Gráfico 10 "B"

$\mathrm{n}=25$ 
En esta interrogación se observa que el mayor porcentaje $(25,68 \%)$ responde que son necesarias mejoras edilicias. Como se mencionó anteriormente la Sala de Virología y la Sala de Laboratorio de Planta se encuentran ubicadas en el sector más antiguo del Hospital con poco mantenimiento, y por tanto se encuentra muy deteriorado.

La opción unificación de las tres salas representó el 18,92\%, la incorporación de un Sistema de Gestión el 14,86\%, que fueron comentadas anteriormente.

La opción Mejora de la comunicación entre todo el personal del Servicio obtuvo el 13,51 \%, observando el personal la necesidad de mejora, indispensable para un correcto trabajo en equipo, debiéndose implementar medidas que favorezcan este aspecto.

La mejora en el equipamiento arrojó un 12,16\%. En el Servicio coexisten dos tipos de aparatología: 1-Equipamiento perteneciente al Hospital, que han sido adquiridos en momentos en que el Ministerio de Salud realizaba la compra de equipamiento.

2- Equipamiento en leasing. Actualmente, y dado el permanente avance en materia de analizadores utilizados para las determinaciones, su alto costo y muchas veces su dependencia de reactivos, por decisión del Ministerio de Salud provincial (comisión asesora de laboratorios), desde hace ya varios años, los equipos no son adquiridos, sino que las firmas comerciales proveen insumos y el equipamiento necesario para la realización de las distintas técnicas.

La Mejora en la capacitación arrojó un 9,46 \%. Es necesario trabajar para que el personal de salud tenga la posibilidad de realizar cursos de perfeccionamiento y capacitación, muchas veces muy costosos, por medio de becas u otras formas que posibiliten la realización de los mismos, ya que esta dificultad hace que en varias oportunidades no puedan ser solventados por los propios agentes.

La mejora en la comunicación con el superior arrojo el 5,41\%.Nuevamente aquí, al igual que en la opción 6 , se observa una necesidad de mejora en la comunicación entre los integrantes de Servicio. Es importante trabajar sobre este aspecto para poder lograr que estas dificultades disminuyan y así mejorar el trabajo en Equipo.

En forma general y sintética de lo obtenido en esta encuesta, se puede destacar la necesidad de mejoras edilicias que incluyan la unificación de todo el Servicio, la necesidad de incorporación de un sistema de gestión y una mejora en la comunicación entre todos los integrantes del Servicio. 


\section{Encuesta "C"}

Encuesta realizada a profesionales que solicitan Prestaciones al Servicio de Laboratorio

Esta encuesta se realizó entre los profesionales de los Servicios que posee el hospital y de las Unidades Sanitarias, que accedieron a completarlas, en forma auto administrado y anónimo, entre los meses de julio y diciembre de 2010.

Sólo se pidió al final de cada encuesta que se especifique el Servicio al que pertenecían, para tener una idea de la distribución de profesionales en los distintos Servicios.

Hay que recordar que este Hospital es un Hospital especializado en enfermedades de corazón, pulmón e infecciosas. 
IX.A.1.t Pregunta $\mathrm{N}^{\circ} 1$ “C”

Posee un cargo profesional:

Planta permanente $\quad$ Residente Beca Otro

Los resultados se encuentran representados en el Gráfico 1 "C $\mathrm{C}$ ".

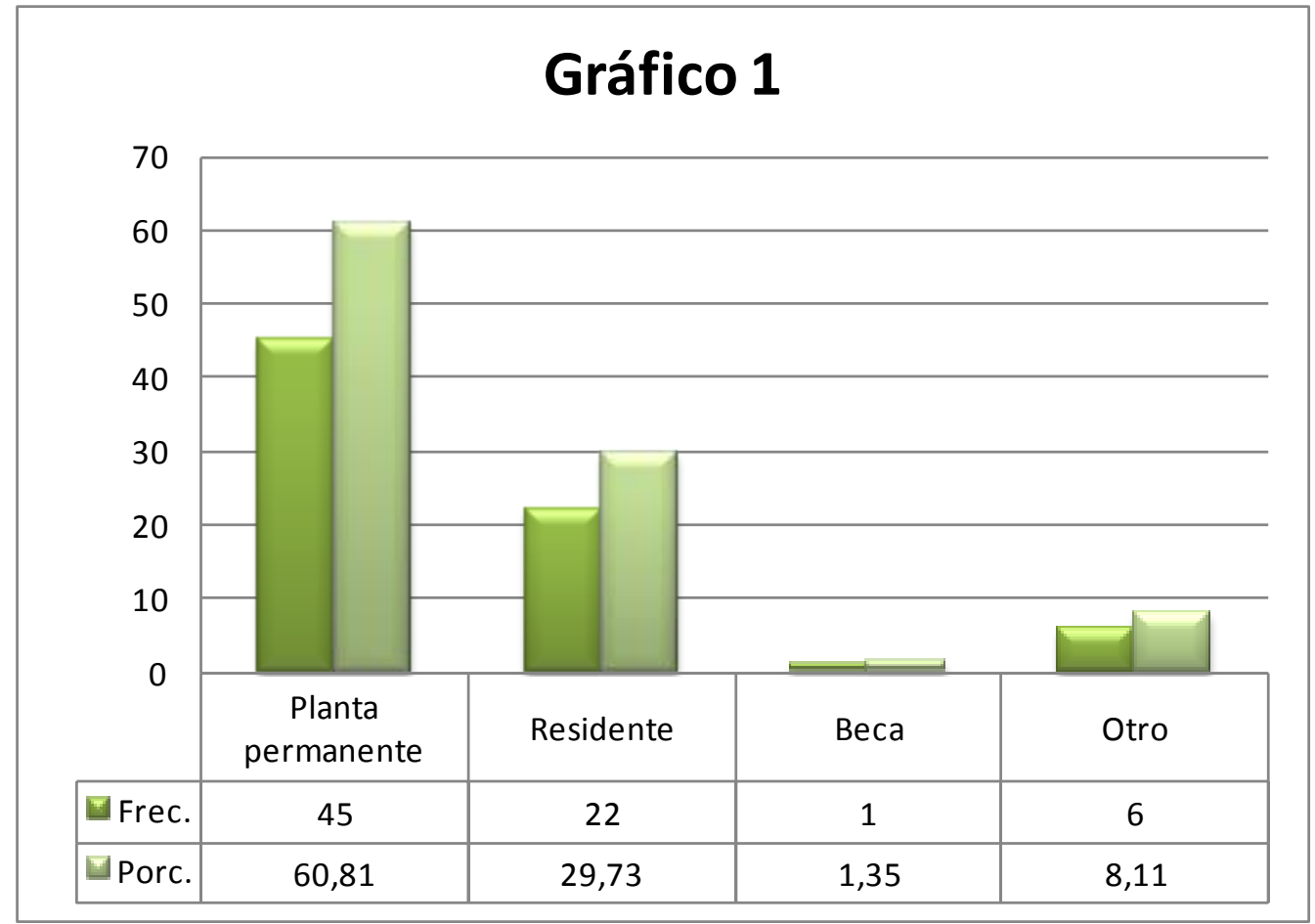

Gráfico IX-19: Gráfico 1 “C”.

$\mathrm{n}=74$

En esta pregunta se trata de evaluar la distribución en que se encuentran los profesionales que realizan solicitudes de exámenes al Laboratorio observando que el mayor porcentaje $(60,81)$ pertenece a profesionales de planta permanente y por tanto con más años de relación con el Servicio.

Cabe señalar que en este Hospital cuenta con residencias de especialización de profesionales en distintas disciplinas, desde hace varios años, las cuales tienen un promedio de duración de tres años. El Laboratorio se encuentra muy relacionado con los mismos ya que poseen un horario más extendido que el resto de profesionales y dado que se encuentran en un proceso de formación y por la modalidad de trabajo tienen un asiduo contacto con el Servicio, de los encuestados representan el 29,73\%.

La última opción "otro", representó el 8,11\% de los encuestados, incorporando en ellos a los profesionales pasantes, los que realizan prácticas supervisadas y concurrentes. El 1,35 \% manifestó tener beca asistencial, otra modalidad que tiene una antigüedad corta, excepto algunos casos puntuales. 


\section{IX.A.1.u Pregunta $\mathrm{N}^{\circ} 2$ "C"}

Conoce Usted todas las prestaciones que Realiza el Servicio de Laboratorio (incluye Laboratorio de Planta, Virología y Medio Interno)

$\mathrm{Si}$

No

Las que habitualmente realizo

Los resultados correspondientes se encuentran representados en el Gráfico 2 "C"

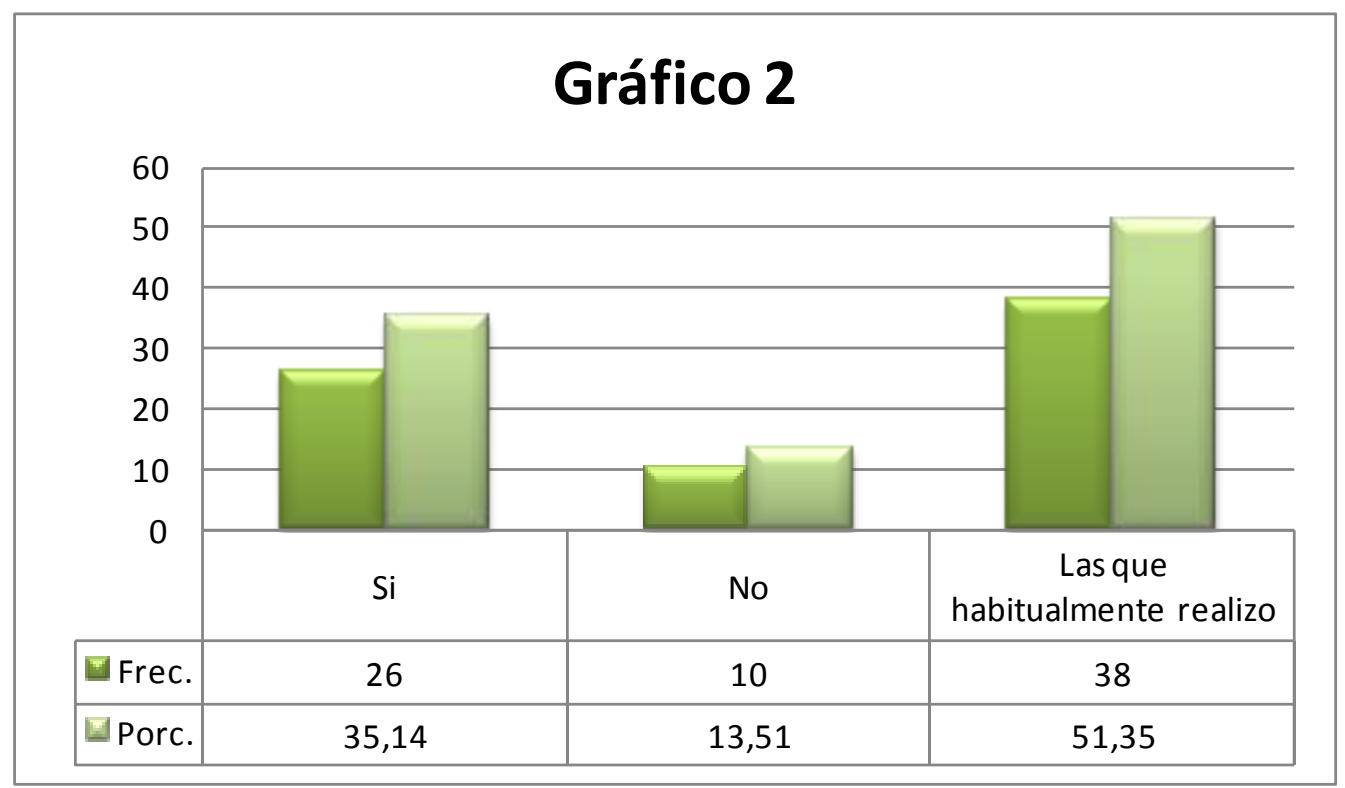

Gráfico IX-20: Gráfico 2 "C"

$\mathrm{n}=74$

Con esta pregunta se trata de evaluar la capacidad de comunicación que tiene el Laboratorio para informar a los distintos Servicios de las nuevas prestaciones que se van incorporando y aquellas que han dejado de realizarse y el interés que despierta en aquellos profesionales que las utilizan el tener conocimiento de las mismas.

Sólo el $35 \%$ de los encuestados respondió que conoce todas las prestaciones, el $13,51 \%$ respondió negativamente y el $51,35 \%$ que conocen las que habitualmente realiza.

De lo expuesto se desprende que existe la necesidad de establecer una mejor comunicación, con los distintos Servicios, siendo necesaria la capacitación de los integrantes del Laboratorio para que puedan trasmitir adecuadamente lo que se realiza y lleguen a despertar el interés de quienes las utilizan para aprovechar mejor la capacidad con que cuenta el Laboratorio. 
IX.A.1.v Pregunta $N^{\circ} 3$ "C"

Considera que el tiempo de retorno de resultados (TAT) es el adecuado

Siempre Casi siempre Pocas veces Nunca

Los resultados correspondientes se encuentran representados en el Gráfico 3 "C"

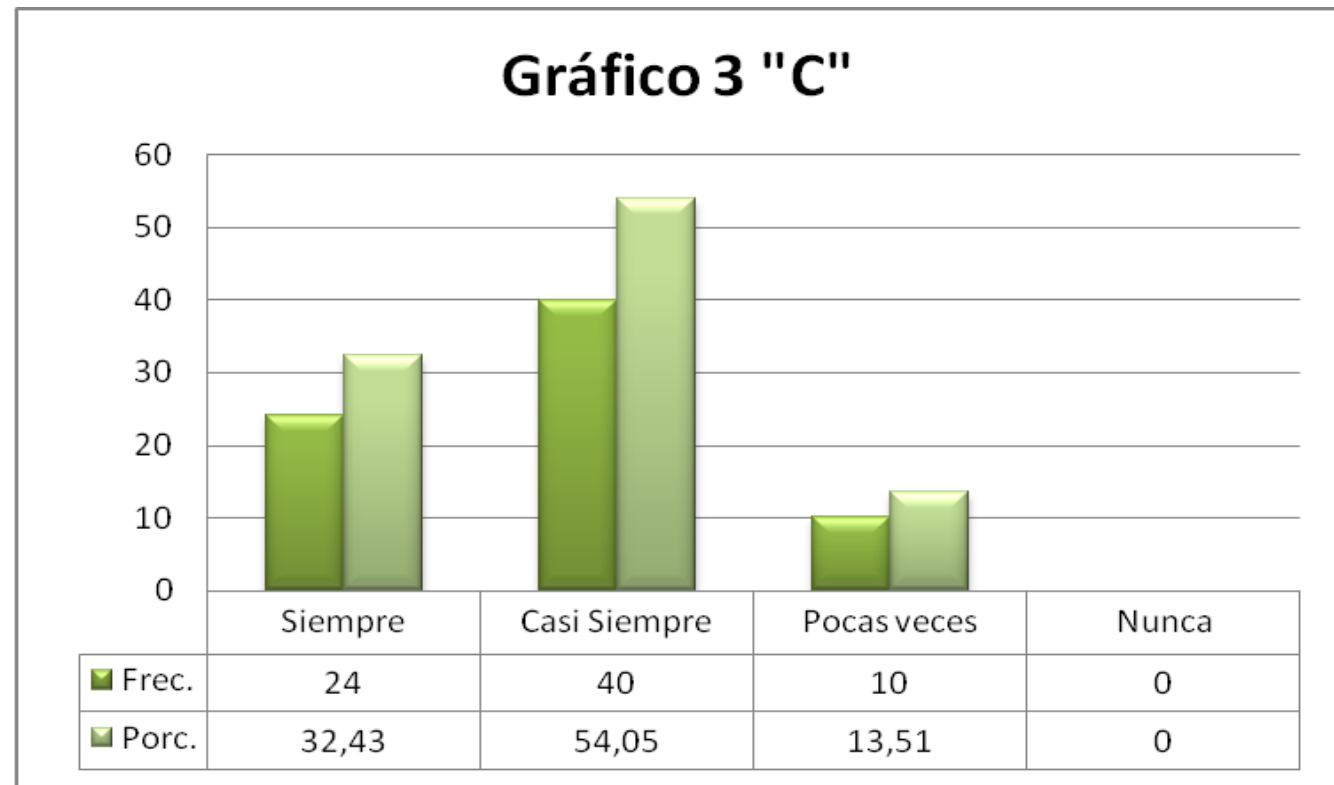

Gráfico IX-21: Gráfico 3 "C"

$\mathrm{n}=74$

El tiempo de retorno de resultados (TAT) es fundamental para la utilización de este recurso diagnóstico en forma adecuada.

Desde el punto de vista de los profesionales que ordenan prestaciones del Servicio, vemos que el mayor porcentaje se da en la opción "casi siempre", con el 54,03\%, la opción siempre el 32,43\%, con un acumulado de 86,49\%, la opción "pocas veces" el 13,51\%, y por último nadie respondió "nunca".

De este detalle se desprende que es necesario informar a los profesionales acerca de los tiempos necesarios para la realización de las distintas técnicas de laboratorio y de la capacidad de trabajo con que cuenta el Servicio, ya que muchas veces al desconocerse llevan a generar expectativas que no se pueden cumplir ,generando disconformidades.

Es necesario asimismo trabajar sobre las necesidades del Servicio que lleven a disminuir los tiempos de entrega de resultados. 


\section{IX.A.1.w Pregunta 4 “C”}

Considera que la unificación de las distintas salas componentes del Servicio, en una única planta física facilitaría su trabajo

Sí en Mucho Algo Sí en Poco No

Los resultados correspondientes se encuentran representados en el Gráfico 4 "C"

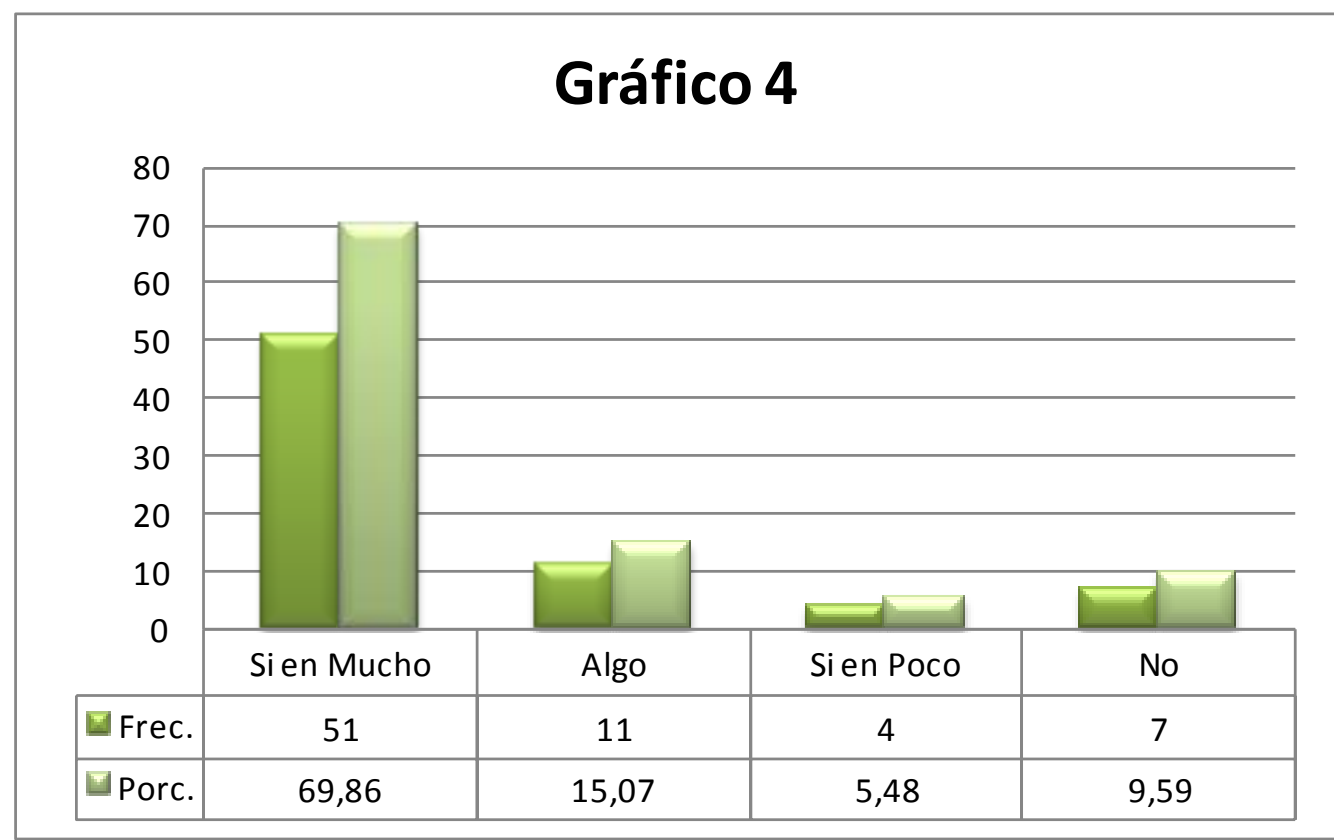

Gráfico IX-22: Gráfico 4 "C"

$\mathrm{n}=73$

Como ya se ha manifestado anteriormente las tres salas que componen el Servicio no se encuentran en el mismo ambiente físico, con lo que muchas veces se ha pensado que ello llevaría a dificultades en el trabajo médico diario, y en esta interrogación se quiso evaluar dicho pensamiento visto desde la óptica de los profesionales que requieren del Laboratorio.

Vemos que el 69,86 \% manifestó que ayudaría en mucho, el 15,07\% algo, con un acumulado del $84,93 \%$, mientras que $5,48 \%$ respondió si en poco y el 9,59 $\%$ que no.

De estas respuestas se infiere que al tener este Hospital edificios muy antiguos, $\mathrm{y}$ al plantear necesidades de construcciones nuevas y remodelaciones de las existentes es necesario tener en cuenta, dentro de las prioridades, la unificación de este Servicio. 


\section{IX.A.1.x Pregunta 5 “C”}

Considera que los valores encontrados por el Servicio, se encuentran dentro de los esperados (credibilidad de resultados).

Si en Mucho Algo Si en Poco No

Los resultados correspondientes se encuentran representados en el Gráfico 5 "C"

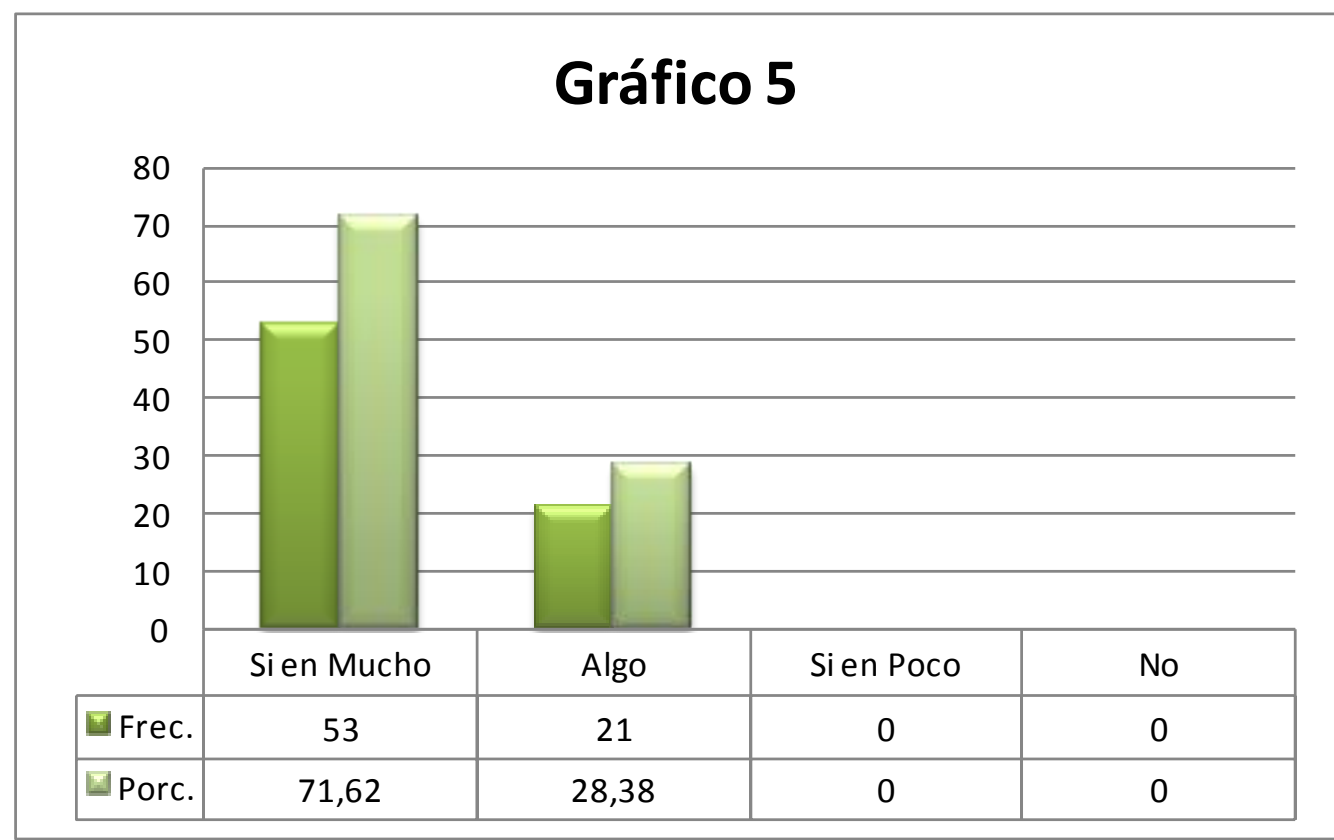

Gráfico IX-23: Gráfico 5 "C"

$\mathrm{n}=74$

Los Laboratorios de análisis clínicos realizan, dentro de sus actividades, una serie de mediciones que garanticen el normal funcionamiento del equipamiento y controlen el funcionamiento de las distintas técnicas utilizadas. Para ello dentro de la Bioquímica se ha desarrollado un amplio campo que es el de "Control de Calidad", aplicado a los distintos momentos que tiene lugar la tarea desarrollada, todos ellos tendientes fundamentalmente a disminuir los errores.

Las tres fases en que se diferencian: pre analítica, analítica propiamente dicha y pos analítica requieren de dedicación, permanente examen y correcciones adecuadas. El estudio de los errores en la fase analítica ha tenido un gran desarrollo y es en la que se ha puesto gran énfasis, existiendo para ello controles de calidad internos y externos (nacionales e internacionales). Actualmente se está trabajando más en las otras dos fases (pre analítica y pos analítica) al observar que ellas también tienen gran importancia en la disminución de errores dentro de la tarea que desarrolla el Laboratorio.

Más allá de lo expuesto anteriormente es importante además saber qué concepto tienen los profesionales que realizan los pedidos al Laboratorio 
respecto a los resultados obtenidos y observamos que el 71,62\% respondió que los valores hallados se encuentran dentro de los esperados, el 28,38\% respondió "algo" con un acumulado del 100\%. No se registraron respuestas "Sí en poco"y "No".

Nuevamente aquí se observa que se deberá poner énfasis en generar un mayor conocimiento puertas afuera, de la forma en que se trabaja dentro del Laboratorio, y de informar los alcances de las distintas técnicas diagnósticas para así despejar posibles dudas. 
IX.A.1.y Pregunta 6 "C"

Encuentra buena predisposición frente a inquietudes planteadas en la Sala de Laboratorio de Planta

Siempre Casi siempre Pocas veces Nunca

Los resultados correspondientes se encuentran representados en el Gráfico 6 "C"

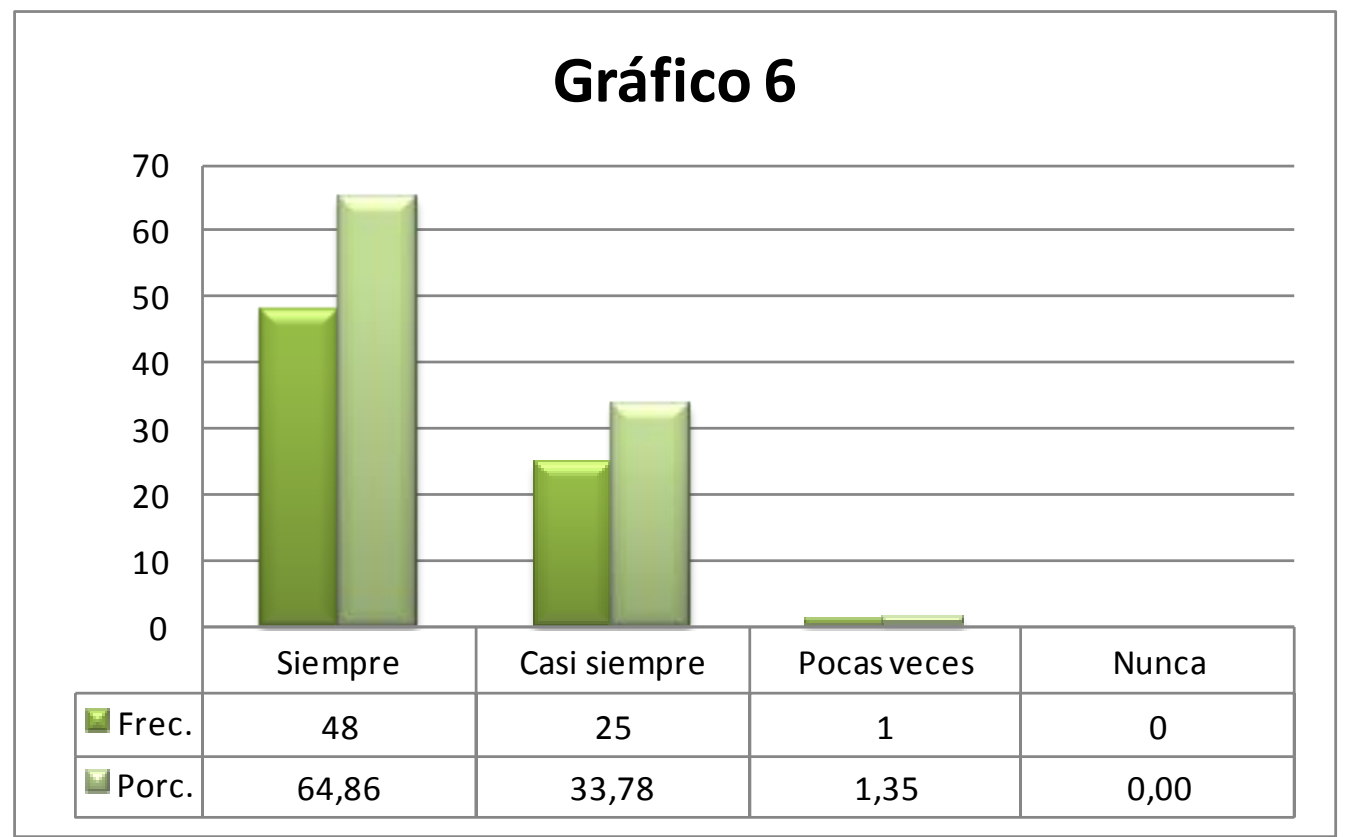

Gráfico IX-24: Gráfico 6 "C"

$\mathrm{n}=74$

Dado que el trabajo dentro del área Salud es un trabajo multidisciplinario, donde es necesario establecer una buena integración de los Servicios para obtener los mejores resultados, se planteó esta pregunta en las distintas salas que componen el Servicio para evaluar la necesidad de trabajar sobre la misma. Los resultados obtenidos para este caso fueron "siempre" el 64,86\%, "Casi Siempre" 33,78\%, Pocas Veces 1,35\%, y Nunca 0\%. 
IX.A.1.z Pregunta 7 "C"

Encuentra buena predisposición frente a inquietudes planteadas en la Sala de Virología

Siempre

Casi Siempre

Pocas veces

Nunca

Los resultados correspondientes se encuentran representados en el Gráfico 7 "C"

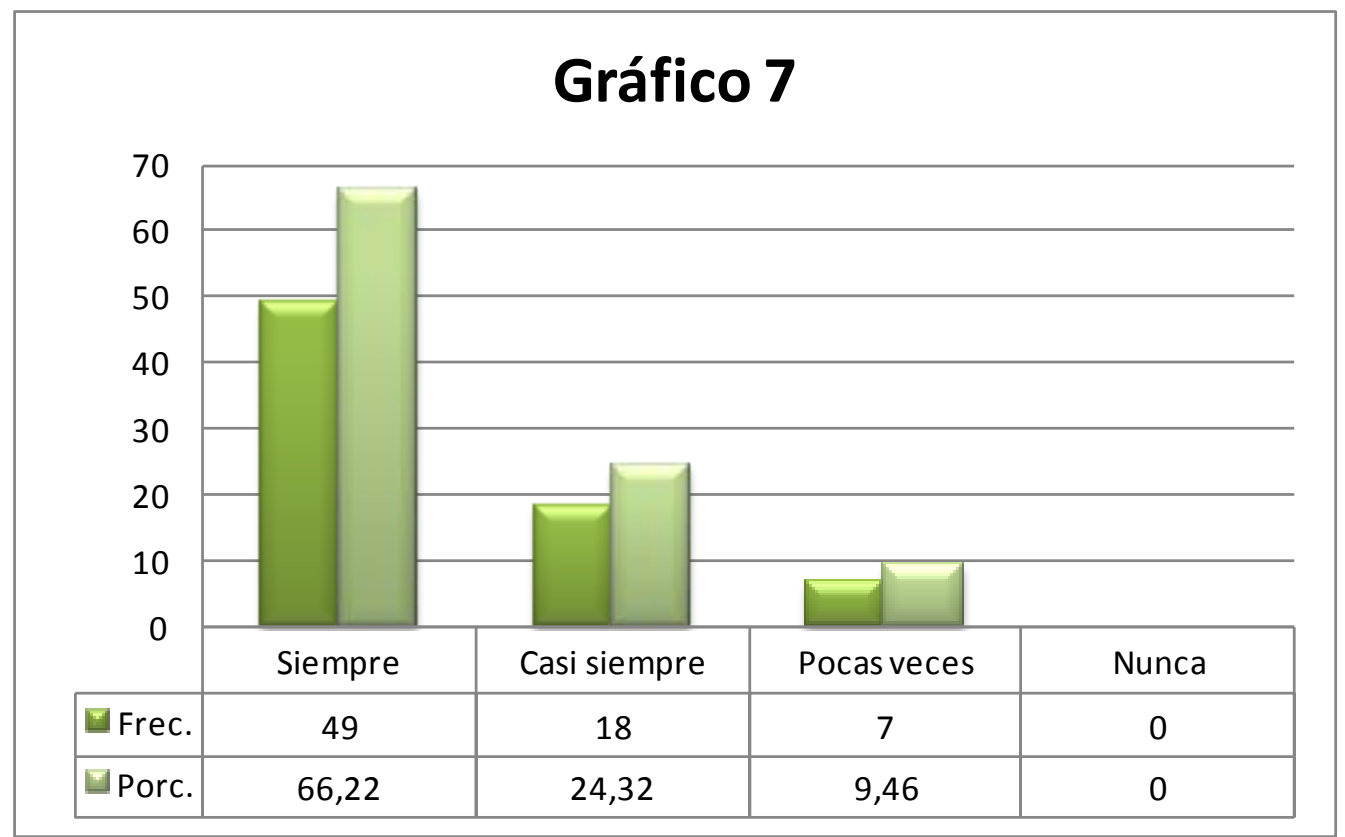

Gráfico IX-25: Gráfico 7 “C”

$\mathrm{n}=74$

La misma pregunta que la anterior se realizó para la Sala de Virología donde los resultados fueron "Siempre el 66,22\%, "Casi Siempre" el 24,32\%, "Pocas Veces" el 9,46\% y" Nunca”0\%. 
IX.A.1.aa Pregunta 8 "C"

Encuentra buena predisposición frente a inquietudes planteadas en la Sala Laboratorio de Medio Interno-Guardia

Siempre Casi siempre Pocas Veces Nunca

Los resultados correspondientes se encuentran representados en el Gráfico 8 "C"

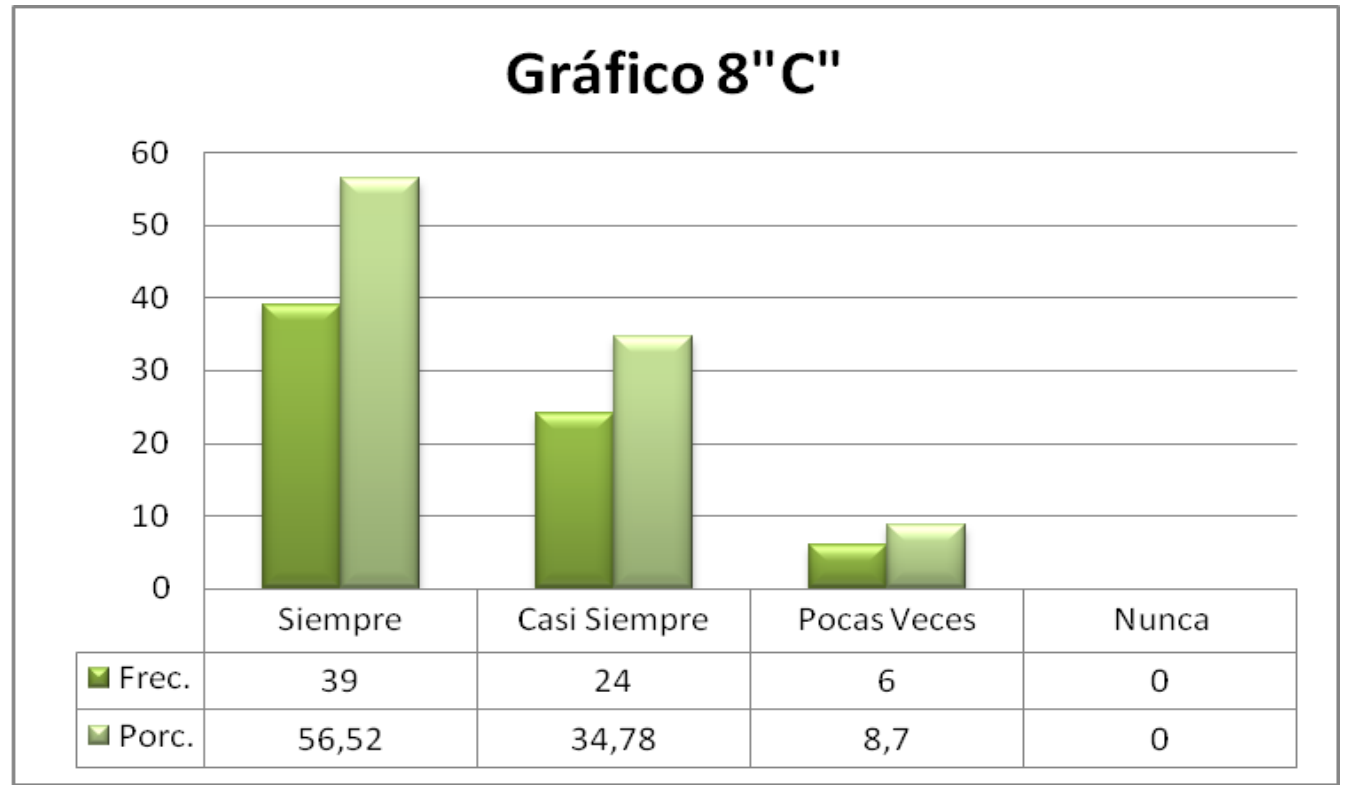

Gráfico IX-26: Gráfico 8 "C"

$\mathrm{n}=69$

Los resultados obtenidos en esta Sala fueron "Siempre" 56,52\%, "Casi Siempre" 34,78\%," Pocas veces" 8,7\% y "Nunca" 0\%.

Del estudio de los datos emanados de las tres Salas se desprende que son similares en las tres, observando un menor porcentaje en la opción "Siempre" en la Sala de Guardia,( 56,52\% frente a 66,22\% y 64,86 de las otras dos salas), posiblemente dado por las características del trabajo allí realizado, donde el factor "urgencia" lleva a que la dinámica requiera de un esfuerzo mayor que posibilite una mejor integración.

Nuevamente es de destacar que el Servicio de Laboratorio es un servicio de Diagnóstico por lo que el trabajo integrado dentro del sistema de Salud mejora la atención de las necesidades de la población, debiendo trabajar para que el porcentaje de las respuestas de la opción "Siempre" se vea incrementado. 


\section{IX.A.1.bb Pregunta 9 "C"}

Considera que el Servicio cumple con las necesidades diagnósticas de su Servicio-

Desearía la incorporación de otras técnicas diagnósticas- Cuáles

Los resultados correspondientes se encuentran representados en el Gráfico 9 "C"

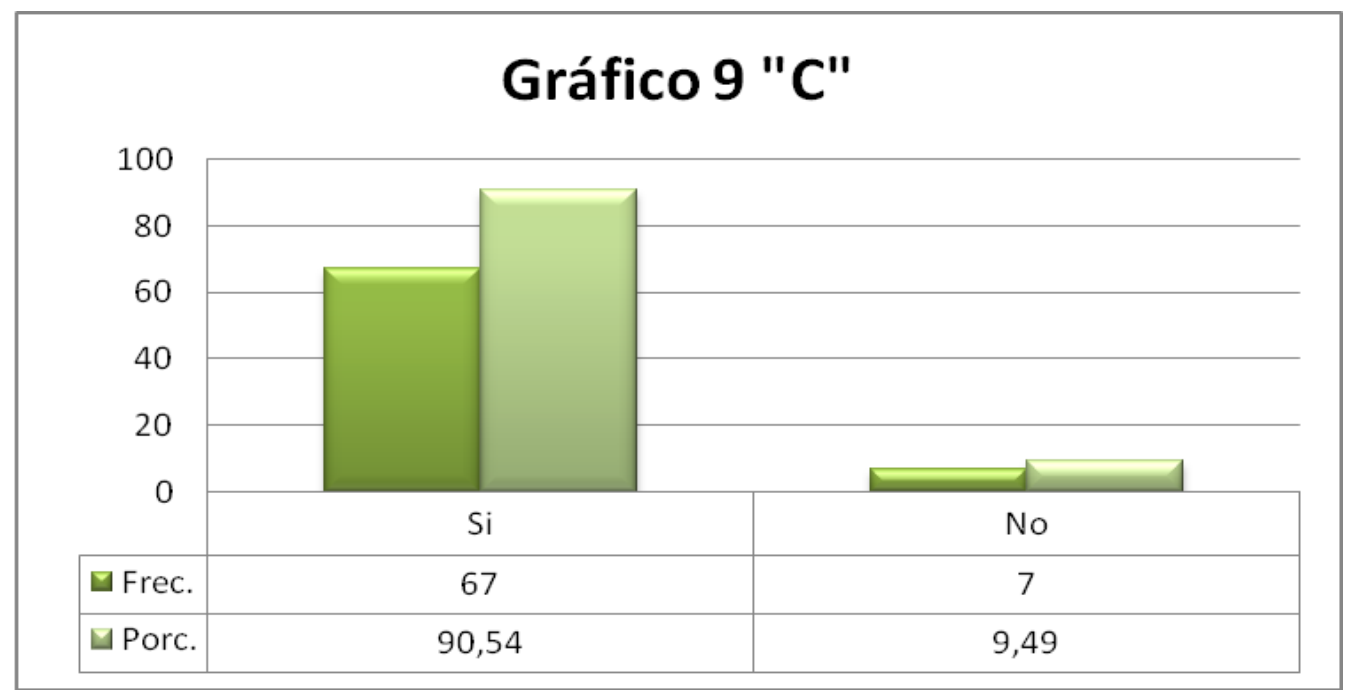

Gráfico IX-27: Gráfico 9 "C"

$\mathrm{n}=74$

En esta pregunta se observa que la gran mayoría de los profesionales $(90,54 \%)$ siente que el Laboratorio cuenta con las determinaciones necesarias para realizar los diagnósticos en los distintos Servicios.

Los constantes avances de las Ciencias llevan a un permanente desarrollo de nuevas técnicas de laboratorio que ayudan al diagnóstico de las distintas patologías.

Es necesario una permanente capacitación y trabajo consensuado en equipo para ir incorporando aquellas que sean necesarias de acuerdo a las necesidades del Hospital.

El estudio de la opción "Cuál", referida a las técnicas que los profesionales desean que se incorporen, muestra una relación con las distintas especialidades de los mismos y serán tenidas en cuenta para determinar las posibilidades de implementación.

Como último ítem se pidió a los profesionales que identificaran el Servicio al que pertenecían y la distribución obtenida fue la siguiente: 


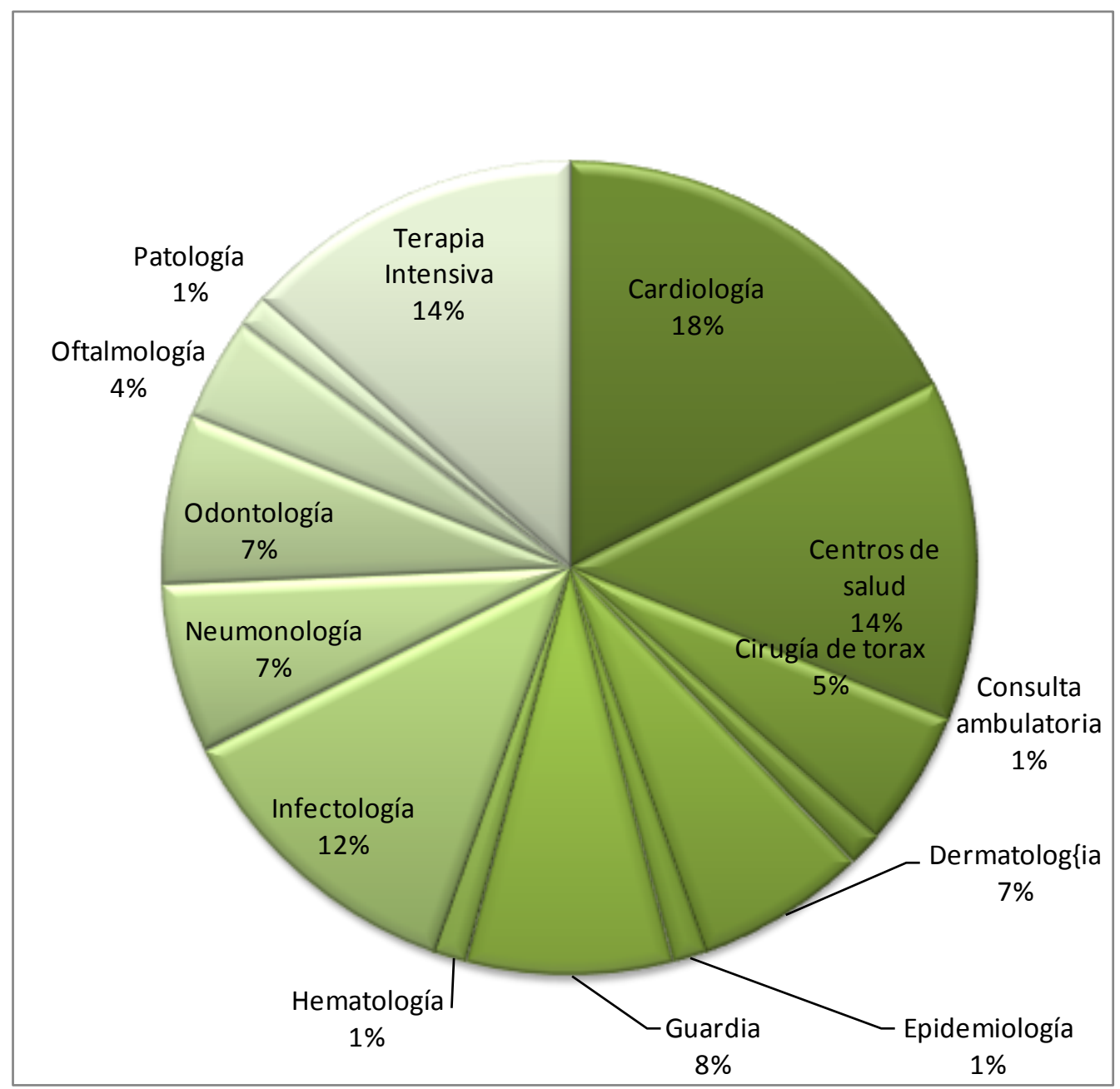

Gráfico IX-28: Distribución de Servicios

Gráfico 10: Distribución de los Servicios en que desempeñan tareas los profesionales que contestaron las encuestas

En forma sintética y general de la encuesta, nuevamente aquí se observa la necesidad de la unificación de las tres salas que integran el Servicio como así también la necesidad de una mejora en la comunicación del Servicio con todos los profesionales que ordenan prestaciones al mismo. 


\section{IX.B. Características de la Demanda}

El Servicio de Laboratorio como se indicó anteriormente presta servicios para pacientes que provienen del hospital, para pacientes que provienen de Unidades Sanitarias del área del Hospital y en muy pocos casos para pacientes que provienen de otros hospitales.

En este estudio se pretende observar si existen diferencias en el grado de complejidad de los estudios solicitados en pacientes que provienen de las Unidades Sanitarias y los provenientes del hospital recordando que éste es un hospital especializado y las Unidades Sanitarias son centros de atención primaria de la salud.

Para ello se realizó el estudio de 996 órdenes de consultorio externo, en días tomados al azar en el periodo comprendido entre agosto y diciembre de 2010, de las cuales 798 fueron órdenes provenientes del hospital y 198 de Unidades Sanitarias.

En las mismas se clasificó la proveniencia, el sexo de los pacientes y si estaban indicados estudios que fueron clasificados en las siguientes agrupaciones:

Rutina: Aquellos pedidos que incorporan una ó más de las siguientes determinaciones: Hemograma, Urea, Glucosa, Creatinina, Ácido Úrico.

Perfil Hepático: Aquellos pedidos que incorporan TGO, TGP, Fosfatasa alcalina, Bilirrubina $\mathrm{T}$ y D.

Perfil Lipídico: Aquellos pedidos que incorporan Colesterol total, Colesterol HDL, Triglicéridos.

Perfil Proteico: Aquellos pedidos que incorporan Proteínas totales, Albúmina, Proteinograma.

\section{$\checkmark \quad$ Serología HIV}

Serología Sífilis, Chagas, Toxoplasmosis: Aquellos pedidos que incorporen una ó más de las mencionadas determinaciones.

Otras determinaciones: Aquellos que incorporen una ó más del resto del panel de determinaciones que realiza el Laboratorio de Planta y Medio Interno.

Otras determinaciones de Virología: Aquellos pedidos que incorporen una o más determinaciones del resto del panel de determinaciones que se realizan en las sala de Virología.

Determinaciones de Endocrinología: Aquellos pedidos que incorporen una o más determinaciones hormonales. 
Determinaciones en Orina de 24 hs: Aquellos pedidos que incorporen una o más determinaciones en orina de 24 horas.

Del estudio de los resultados obtenidos se puede observar:

Que mientras los porcentajes de pacientes masculinos y femeninos provenientes del Hospital son similares $(52,88 \%$ y 47,12 \%) respectivamente, en el caso de las Unidades Sanitarias el porcentaje de femeninos es marcadamente superior $(86,36 \%$ y $13,64 \%)$, dado seguramente por el hecho que la gran mayoría de pacientes provenientes de las Unidades Sanitarias pertenecen a controles de embarazo.

Estos datos se ven reflejados en el siguiente gráfico:

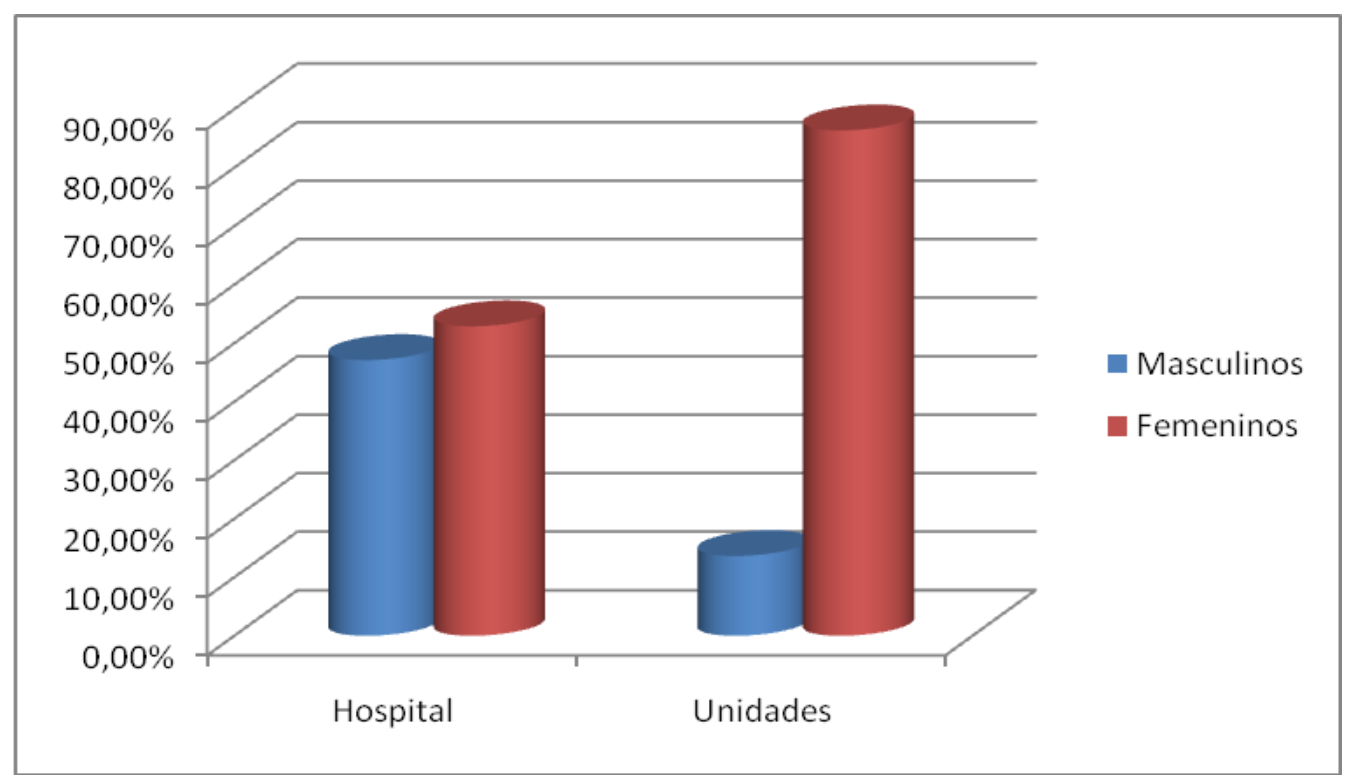

Gráfico IX-29: Distribución de poblaciones en Hospital y Unidades

Si se observan los datos obtenidos de los pedidos a la población femenina vemos que no existen diferencias muy marcadas.

Podemos observar que el pedido de perfil lipídico es mayor en las pacientes provenientes del Hospital así como el perfil proteico, posiblemente dado por la orientación cardiológica del mismo.

Respecto al incremento observado en serología de HIV, Serología para Sífilis, Chagas, Toxoplasmosis y otras determinaciones de Virología, de las pacientes provenientes de las Unidades Sanitarias encuentra explicación en el hecho mencionado anteriormente de que la mayoría de las mismas responden a pedidos relacionados con controles de embarazo.

Respecto a las determinaciones en orina de 24 horas se observa un mayor porcentaje en pacientes provenientes del Hospital, nuevamente aquí poniendo de manifiesto el perfil cardiológico del Hospital. 
Estos porcentajes se encuentran expresados en la siguiente tabla y reflejado en el gráfico siguiente.

\begin{tabular}{|c|r|r|r|r|r|r|r|r|r|r|}
\hline & Rutina & $\begin{array}{c}\text { Perfil } \\
\text { Hepático }\end{array}$ & $\begin{array}{c}\text { Perfil } \\
\text { Lipídico }\end{array}$ & $\begin{array}{c}\text { Perfil } \\
\text { Proteico }\end{array}$ & $\begin{array}{c}\text { Serolgía } \\
\text { HIV }\end{array}$ & $\begin{array}{c}\text { Serología } \\
\text { Sífilis, } \\
\text { Chagas, } \\
\text { Toxo. }\end{array}$ & $\begin{array}{c}\text { Otras } \\
\text { Det. }\end{array}$ & $\begin{array}{c}\text { Otras } \\
\text { Det. de } \\
\text { Virología }\end{array}$ & $\begin{array}{c}\text { Det. de } \\
\text { Endocrino. }\end{array}$ & $\begin{array}{c}\text { Det. en } \\
\text { orina de } \\
24 h s .\end{array}$ \\
\hline Fem. Hospital & $69.9 \%$ & $66.8 \%$ & $61.8 \%$ & $16.1 \%$ & $13.7 \%$ & $33.6 \%$ & $21.3 \%$ & $13.3 \%$ & $20.1 \%$ & $8.1 \%$ \\
\hline Fem. Unidades & $66.7 \%$ & $63.7 \%$ & $44.4 \%$ & $2.9 \%$ & $24.6 \%$ & $45.0 \%$ & $17.0 \%$ & $31.6 \%$ & $24.0 \%$ & $4.7 \%$ \\
\hline
\end{tabular}

Tabla IX-1: Prestaciones solicitadas en población femenina

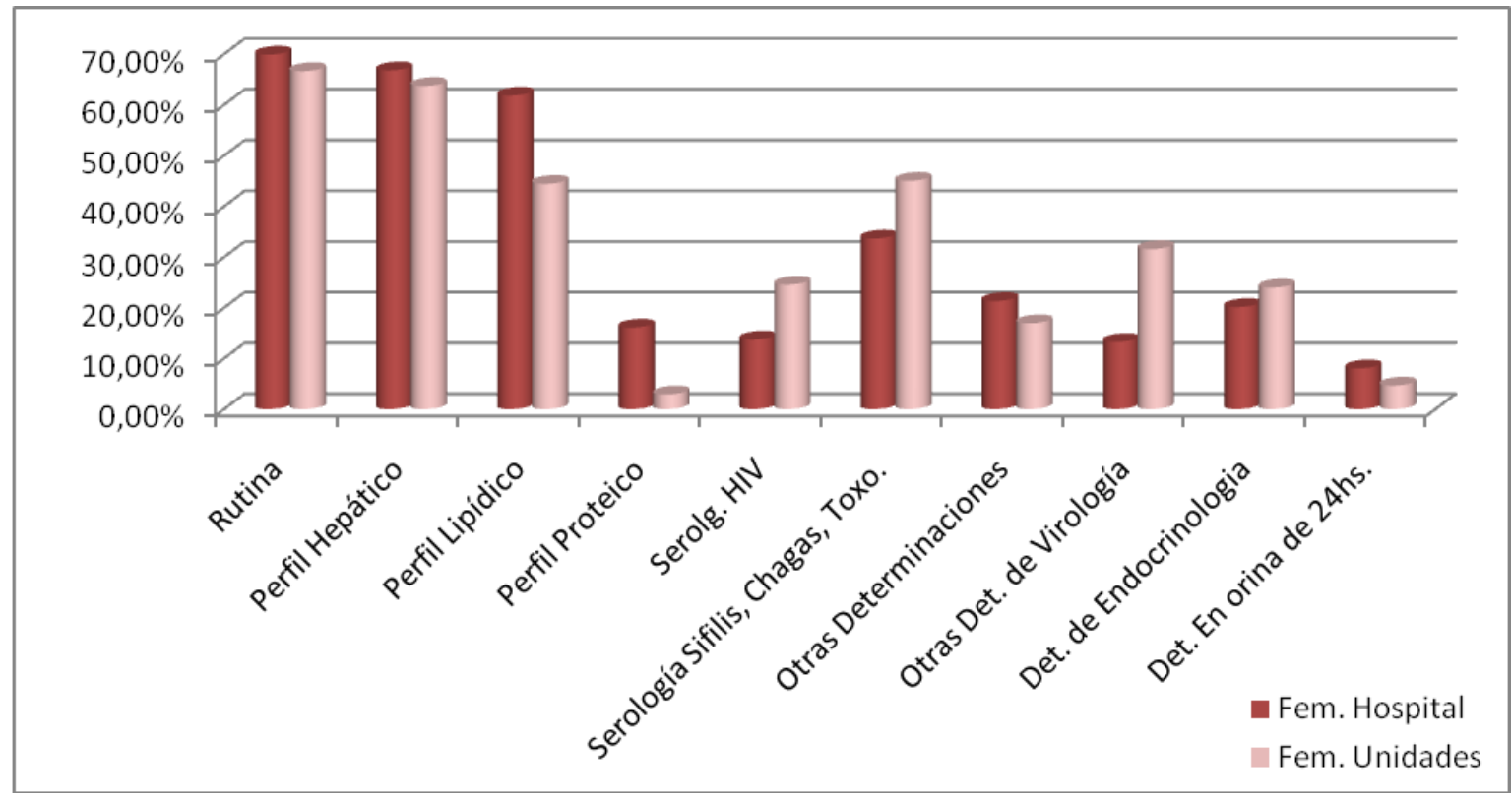

Gráfico IX-30: Prestaciones solicitadas en población femenina

Si realizamos el mismo estudio de los resultados obtenidos en la población masculina tampoco, al igual que en la población femenina, se observan grandes diferencias.

Haciendo un análisis más detallado podemos ver que:

Existe un mayor porcentaje de pedido de rutinas en las provenientes de las Unidades Sanitarias $(66,49 \%$ frente a $77,78 \%)$; el perfil lipídico muestra porcentajes muy similares.

Con respecto al perfil proteico, nuevamente, al igual que en el caso de la población femenina los pedidos del Hospital presentan un mayor porcentaje $(14,89 \%$ frente a $7,41 \%)$.

Los pedidos de serología para HIV así como otras determinaciones de Virología, encuentran en población masculina un incremento en los pedidos hospitalarios, reflejando aquí el perfil infectológico que presenta el Hospital $(19.15 \%$ frente a $11,11 \%)$. 
El incremento observado en el pedido de serología para chagas, sífilis y toxoplasmosis en las Unidades Sanitarias (44,44\% frente a 27,66\%), posiblemente obedezca al hecho de que en las mismas son atendidos pacientes mayoritariamente provenientes del norte argentino ó de países limítrofes donde fundamentalmente el Chagas es una enfermedad endémica.

Con respecto al incremento observado en las determinaciones de Endocrinología de los pacientes provenientes de las Unidades Sanitarias no se ha encontrado una explicación fundamentada $(22,22 \%$ frente a $14,36 \%)$.

Las determinaciones en orina de 24 horas en los pacientes provenientes del hospital presentan un porcentaje similar a la población femenina, no observándose en el período estudiado dichos pedidos en la población masculina proveniente de las Unidades Sanitarias, marcando así el perfil cardiológico del Hospital.

Estos datos se encuentran en expresados en la siguiente tabla y el gráfico siguiente.

\begin{tabular}{|l|r|r|r|r|r|r|r|r|r|r|}
\hline & Rutina & $\begin{array}{c}\text { Perfil } \\
\text { Hepático }\end{array}$ & $\begin{array}{c}\text { Perfil } \\
\text { Lipídico }\end{array}$ & $\begin{array}{c}\text { Perfil } \\
\text { Proteico }\end{array}$ & $\begin{array}{c}\text { Serolgía } \\
\text { HIV }\end{array}$ & $\begin{array}{c}\text { Serología } \\
\text { Sífilis, } \\
\text { Chagas, } \\
\text { Toxo. }\end{array}$ & $\begin{array}{c}\text { Otras } \\
\text { Det. }\end{array}$ & $\begin{array}{c}\text { Otras } \\
\text { Det. de } \\
\text { Virología }\end{array}$ & $\begin{array}{c}\text { Det. de } \\
\text { Endocrino. }\end{array}$ & $\begin{array}{c}\text { Det. en } \\
\text { orina de } \\
24 h s .\end{array}$ \\
\hline Masc. Hospital & $66.5 \%$ & $66.0 \%$ & $55.1 \%$ & $14.9 \%$ & $19.1 \%$ & $27.7 \%$ & $17.3 \%$ & $16.8 \%$ & $14.4 \%$ & $8.5 \%$ \\
\hline Masc. Unidades & $77.8 \%$ & $66.7 \%$ & $55.6 \%$ & $7.4 \%$ & $11.1 \%$ & $44.4 \%$ & $14.8 \%$ & $11.1 \%$ & $22.2 \%$ & $0.0 \%$ \\
\hline
\end{tabular}

Tabla IX-2: Prestaciones solicitadas en población masculina

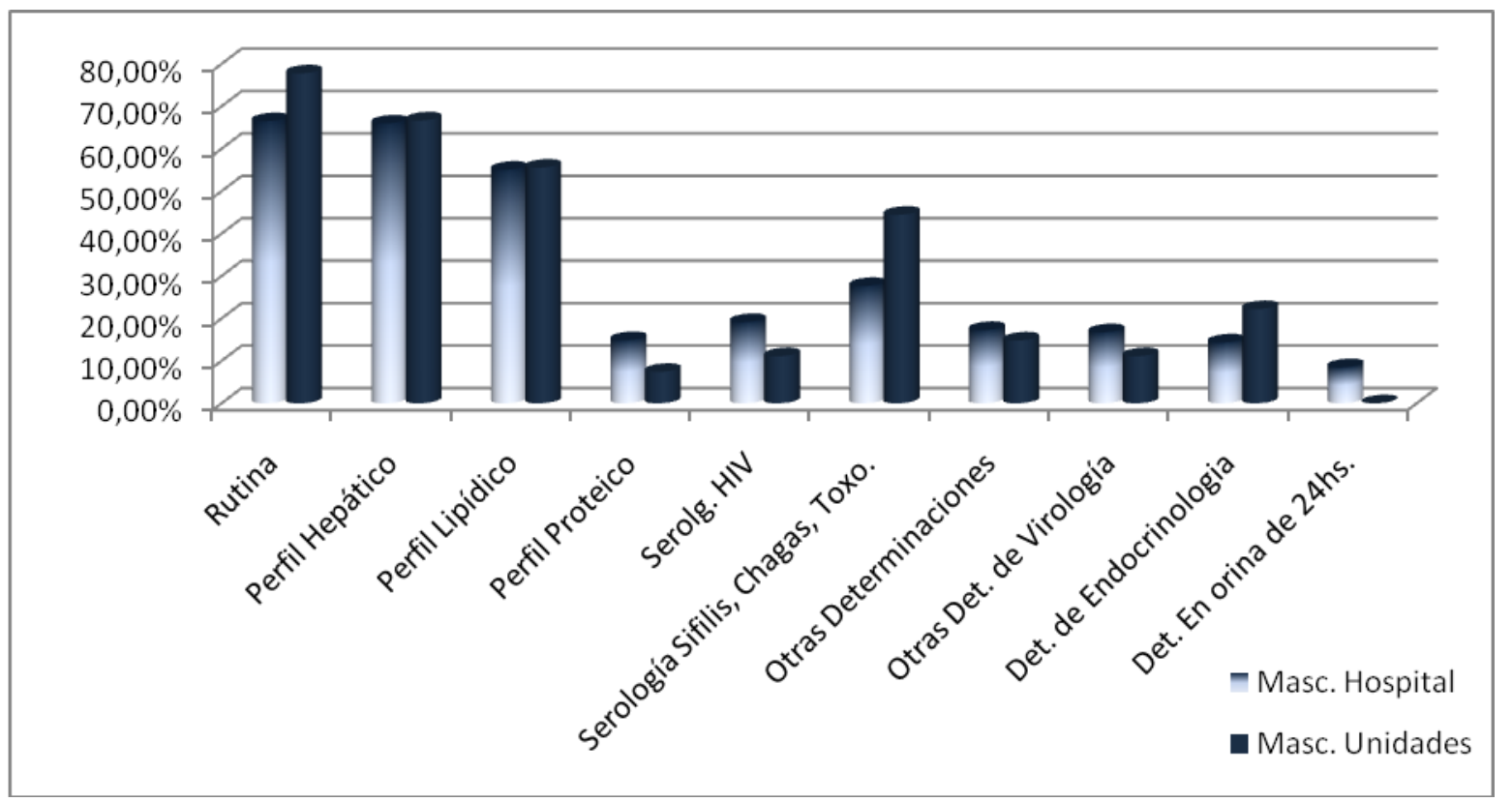

Gráfico IX-31: Prestaciones solicitadas en población masculina 
Por todo lo expuesto anteriormente, teniendo en cuenta las diferencias encontradas en los porcentajes de solicitudes, no se observa una mayor complejidad de los pedidos provenientes del hospital con respecto a las provenientes de las Unidades Sanitarias.

De este hecho se desprende que en la planificación de insumos y de personal necesario para la actividad normal que desarrolla el Laboratorio no es necesario la discriminación de estas dos poblaciones de pacientes atendidos. 


\section{IX.C. Indicadores}

Al diagramar indicadores que nos brinden información sobre el funcionamiento de un Laboratorio de análisis clínicos podemos diferenciar claramente tres etapas en las que se desarrollan las tareas en el mismo:

Etapa pre analítica

- Etapa analítica propiamente dicha

$\vartheta \quad$ Etapa pos analítica

$\vartheta$

Pudiendo establecer indicadores en cada una de ellas

\section{Etapa pre analítica}

\section{$\mathrm{N}^{\circ}$ turnos dados correctamente / $\mathrm{N}^{\circ}$ turnos totales}

Como se indicó anteriormente los turnos para los distintos laboratorios son administrados desde la oficina central de turnos que posee el hospital .Los administrativos que allí se desempeñan tienen las indicaciones necesarias para otorgar el turno al laboratorio correspondiente de acuerdo a las prácticas solicitadas a cada paciente. Se han observado errores en dicho procedimiento, con este indicador se trata de cuantificar dichos errores.

\section{$\mathbf{N}^{\circ}$ de errores en el ingreso de las prácticas solicitadas / $\mathbf{N}^{\circ}$ de prácticas ingresadas totales}

Dado que el Servicio no cuenta con un Sistema de Gestión que permita el ingreso de las prácticas desde la orden médica a las respectivas estaciones de trabajo, la misma se realiza en forma manual observándose la producción de errores involuntarios.

Este indicador pondera dicho error y es una herramienta en la fundamentación de la necesidad de implementación de dicho sistema.

\section{$\mathbf{N}^{\circ}$ de errores en los tubos de extracción / $\mathbf{N}^{\circ}$ de ordenes}

Las distintas prácticas que se realizan en un Laboratorio de Análisis Clínicos requieren de la toma de muestra en distintos recipientes apropiados. Uno de los motivos de impedimento de realización de las mismas es que el recipiente no sea el adecuado.

Con este indicador se evalúa dicho procedimiento en el sector extracciones.

\section{$\mathbf{N}^{\circ}$ de pacientes en condiciones / $\mathbf{N}^{\circ}$ total de pacientes}


Como se detalló anteriormente la central de turnos es quien otorga turnos e indica a los pacientes las condiciones en que debe concurrir el paciente el día indicado y además envía al paciente al Servicio en caso que sea necesario retirar recipientes e indicaciones especiales para determinadas prácticas.

Con este indicador se evalúan las indicaciones y la forma en que son otorgadas.

$\mathrm{N}^{\circ}$ de muestras mal rotuladas provenientes de salas/ $\mathrm{N}^{\circ}$ total de muestras de internados

Las muestras que provienen de pacientes internados son tomadas por las salas y el Servicio las retira diariamente.

Con este indicador se trata de evaluar el control que realiza el personal del laboratorio sobre las muestras y órdenes que provienen de las salas.

\section{Etapa analítica}

$\mathrm{N}^{\circ}$ de prácticas realizadas $\mathbf{y}$ no solicitadas $/ \mathrm{N}^{\circ}$ total de prácticas realizadas

En este caso se pretende evaluar la confección del plan de trabajo.

$\mathrm{N}^{\circ}$ de prácticas no realizadas / total de prácticas solicitadas

Como en el caso anterior este indicador pretende evaluar el plan de trabajo.

$\mathrm{N}^{\circ}$ de prácticas no realizadas por falta de insumos y solicitadas / $\mathrm{N}^{\circ}$ de prácticas solicitadas

Con este indicador se trata de evaluar la provisión de insumos.

\section{Etapa pos analítica}

$\mathrm{N}^{\circ}$ de resultados repetidos luego de informados / total de resultados

Al realizar los distintos estudios los profesionales luego de analizar los resultados, repiten los que sean necesarios, pasan los mismos a una instancia posterior que es el informe, lo que se conoce como validación de resultados. Luego del informe, hay una nueva observación de los mismos para su firma, es en esta instancia que el profesional frente a una duda vuelve para repetir alguna determinación.

Con este indicador se trata de evaluar la validación de resultados

$\mathrm{N}^{\circ}$ de resultados re impresos / total de resultados 
La impresión de resultados es en el Servicio realizada en distintas formas: mediante computadoras asociadas a equipos analizadores, en forma manual por profesionales y administrativos, luego de lo cual son controlados por los profesionales, firmados y sellados.

Con este indicador se trata de evaluar los errores cometidos en esta etapa.

\section{$\mathbf{N}^{\circ}$ de resultados reclamados como no entregados por las salas/total de resultados de internados}

En el caso de pacientes internados, el Servicio es quien distribuye los resultados a las distintas salas, de allí la necesidad de evaluar los errores que se cometen en dicha entrega.

\section{$\mathrm{N}^{\circ}$ de reclamos médicos/ total de prestaciones}

Como se mencionó anteriormente, el Laboratorio brinda sus Servicios a los pacientes y profesionales que realizan los pedidos, existiendo una permanente comunicación con los mismos.

Con este indicador se pretende evaluar la credibilidad de resultados, entendiendo como reclamos aquellos en que el profesional encuentra discordancia entre los datos informados y los esperados.

\section{$\mathbf{N}^{\circ}$ de resultados no entregados el día indicado por demora en su obtención/total de resultados}

El día de extracción de muestras los pacientes son citados para retirar sus informes de acuerdo a los pedidos de estudios que tengan.

Con este indicador se trata de evaluar en forma general la actuación del Servicio y en base a ello se puede estudiar donde se encuentran las mayores dificultades.

Cabe señalar que estos indicadores no han sido aún utilizados en el Servicio, sino que surgen de una observación de los distintos procesos que se realizan en el Laboratorio y serán propuestos para su medición, poniendo énfasis en la necesidad de contar con datos confiables que permitan luego de su análisis la identificación de necesidad de correcciones, no para castigo, sino para una mejora en la calidad de la prestación.

Es de destacar asimismo que en la implementación de estas medidas se deberá involucrar y concientizar a todos los integrantes para permitir una mejora tanto del servicio en general como en las personas en particular. 


\section{IX.D. Planificación}

Para entrar en el desarrollo de la planificación del Servicio, definiré la VISION, MISION y VALORES sobre los que se sustenta el Servicio y que a su vez responden a la Visión y Misión del Hospital.

\section{VISIÓN}

Ser un Servicio de excelencia que cubra todas las especialidades bioquímicas que el perfil del Hospital requiera y combinar un alto nivel académico de los integrantes del Servicio con tecnología de última generación, con estándares de calidad total.

\section{MISIÓN}

Brindar un Servicio de excelencia para la realización y asesoramiento de estudios bioquímicos con el compromiso de avanzar en nuevas metodologías que permitan la satisfacción plena de los pacientes y profesionales de la salud que requieran del Servicio.

\section{VALORES}

- Garantizar la confiabilidad del resultado de la determinación individual, utilizando métodos y valores de referencia apropiados sobre muestras correctas.

- $\quad$ Capacidad de respuesta en tiempos óptimos.

- Información y asesoramiento sobre aspectos bioquímicos de utilidad mediante la interrelación permanente con los distintos Servicios del Hospital.

- $\quad$ Confidencialidad en la identidad del paciente.

- Permanente capacitación de todos los integrantes del mismo en post de una mejora continúa de la calidad.

- Identificación de todos sus integrantes en relación a la pertenencia con el Servicio y el Hospital.

- Permanente dedicación de todo el Servicio para brindar una mejor prestación.

Dentro de la Planificación del Servicio podemos definir distintas áreas de gestión definiendo distintos objetivos o Ejes específicos, Líneas de acción, y Metas para cada una de ellas resumidos en la Tabla siguiente, y que deberán ser, en una instancia posterior, desarrolladas ampliamente para su ejecución. 


\begin{tabular}{|c|c|c|c|c|}
\hline Área & $\begin{array}{l}\text { Objetivos o ejes } \\
\text { específicos }\end{array}$ & $\begin{array}{c}\text { Líneas de acción ó } \\
\text { actividades }\end{array}$ & Metas $1^{\circ}$ semestre & Metas $2^{\circ}$ semestre \\
\hline $\begin{array}{l}\text { Gestión } \\
\text { Gerencial }\end{array}$ & $\begin{array}{l}\text { Coordinar los } \\
\text { recursos para atender } \\
\text { las necesidades de } \\
\text { pacientes y } \\
\text { profesionales } \\
\text { actuantes }\end{array}$ & $\begin{array}{c}\text { Realización y evaluación } \\
\text { de nuevas encuestas a } \\
\text { pacientes, trabajadores y } \\
\text { profesionales. } \\
\text { Coordinación de tareas } \\
\text { para corregir errores. } \\
\text { Evaluación de indicadores }\end{array}$ & $\begin{array}{c}\text { Implementar nuevas } \\
\text { técnicas y metodologías. } \\
\text { Tomar acciones correctivas } \\
\text { a las necesidades } \\
\text { observadas. } \\
\text { Realización de charlas } \\
\text { informativas con los } \\
\text { distintos Servicios del } \\
\text { Hospital para detallar todas } \\
\text { las prestaciones que se } \\
\text { realizan. }\end{array}$ & $\begin{array}{l}\text { Sostener la oferta de } \\
\text { prestaciones y dar respuesta } \\
\text { a posibles necesidades que } \\
\text { afecten a la población } \\
\\
\text { Elaborar un tablero de } \\
\text { gestión con aquellos } \\
\text { indicadores que permitan el } \\
\text { seguimiento y detección de } \\
\text { inconvenientes para su } \\
\text { evaluación y corrección. }\end{array}$ \\
\hline $\begin{array}{c}\text { Gestión de } \\
\text { los equipo de } \\
\text { trabajo }\end{array}$ & $\begin{array}{l}\text { Lograr la formación } \\
\text { e integración de los } \\
\text { nuevos profesionales } \\
\text { y técnicos a los } \\
\text { procedimientos } \\
\text { existentes para } \\
\text { alcanzar una } \\
\text { transferencia del } \\
\text { conocimiento } \\
\text { bioquímico clínico } \\
\text { tendiente a mantener } \\
\text { la calidad } \\
\text { Incorporación de } 2 \\
\text { nuevos residentes }\end{array}$ & $\begin{array}{c}\text { Elaboración de manuales } \\
\text { de procedimientos para } \\
\text { cada estación de trabajo en } \\
\text { las distintas salas. } \\
\text { Educación continua de } \\
\text { todo el personal (ateneos, } \\
\text { cursos, charlas). } \\
\text { Reuniones periódicas para } \\
\text { fomentar la integración. } \\
\text { Actividad docente } \\
\text { pregrado, alumnos de la } \\
\text { carrera de Bioquímica, } \\
\text { Tecnicatura en Salud y } \\
\text { posgrado Residencia } \\
\text { Bioquímica }\end{array}$ & $\begin{array}{c}\text { Elaborar de manuales de } \\
\text { procedimiento del } 50 \% \text { de } \\
\text { los proyectados (toma de } \\
\text { muestras y admisión, } \\
\text { hematología, orinas). Un } \\
\text { ateneo mensual para } \\
\text { profesionales. } \\
\text { Capacitación de técnicos } \\
\text { con al menos un } \\
\text { curso(Extracción de sangre } \\
\text { por técnica de vacío) }\end{array}$ & $\begin{array}{l}\text { Completar los manuales de } \\
\text { procedimientos. } \\
\text { Participación del Servicio en } \\
\text { ateneos interdisciplinarios } \\
\text { que permitan la interacción } \\
\text { del Laboratorio con los } \\
\text { demás Servicios. } \\
\text { Capacitación de } \\
\text { Administrativos Elaboración } \\
\text { y procesamiento de } \\
\text { estadísticas de producción. }\end{array}$ \\
\hline $\begin{array}{l}\text { Gestión de } \\
\text { recursos }\end{array}$ & $\begin{array}{l}\text { Lograr la aprobación } \\
\text { de las licitaciones } \\
\text { para insumos y } \\
\text { equipamiento. Lograr } \\
\text { la designación de } \\
\text { técnicos (3), } \\
\text { profesionales (2), } \\
\text { Administrativos (2). } \\
\text { Recuperación de un } \\
\text { cargo de Jefe de Sala. }\end{array}$ & $\begin{array}{c}\text { Seguimiento de las } \\
\text { Licitaciones de } \\
\text { equipamiento e insumos y } \\
\text { coordinación de su entrega } \\
\text { para la normal prestación } \\
\text { de servicio. Seguimiento } \\
\text { de las designaciones. }\end{array}$ & $\begin{array}{l}\text { Cubrir con normalidad la } \\
\text { demanda asistencial y } \\
\text { atender posibles } \\
\text { distorsiones estacionales } \\
\text { epidemiológicas que } \\
\text { surjan. }\end{array}$ & $\begin{array}{l}\text { Lograr mejoras edilicias para } \\
\text { Lab. de guardia (habitación } \\
\text { de descanso), reparación de } \\
\text { techos en Virología } \\
\text { reparación de sala de espera } \\
\text { y boxes del Laboratorio de } \\
\text { Planta. }\end{array}$ \\
\hline $\begin{array}{l}\text { Gestión de la } \\
\text { calidad }\end{array}$ & $\begin{array}{l}\text { Coordinar la mejor } \\
\text { utilización de los } \\
\text { recursos en las tres } \\
\text { salas para mejorar la } \\
\text { prestación. Disminuir } \\
\text { los errores en las tres } \\
\text { etapas analíticas. } \\
\text { Lograr la adquisición } \\
\text { e implementación de } \\
\text { un sistema de } \\
\text { gestión. }\end{array}$ & $\begin{array}{c}\text { Reuniones periódicas con } \\
\text { los profesionales, técnicos, } \\
\text { y administrativos del } \\
\text { Servicio para evaluar } \\
\text { errores e implementar } \\
\text { correcciones. Capacitación } \\
\text { en el uso del sistema de } \\
\text { gestión. } \\
\text { Utilización de indicadores } \\
\text { para evaluar las tres } \\
\text { etapas analíticas. }\end{array}$ & $\begin{array}{l}\text { Implementar la técnica de } \\
\text { extracción por vacío en } \\
\text { consultorio externo y } \\
\text { utilización de tubo } \\
\text { primario. Procesar los } \\
\text { controles de calidad en la } \\
\text { etapa analítica (Min. De } \\
\text { Salud y Cemic) y } \\
\text { disminución de errores. } \\
\text { Medir y evaluar } \\
\text { indicadores de la etapa } \\
\text { analítica, determinar } \\
\text { errores e implementar } \\
\text { correcciones. }\end{array}$ & $\begin{array}{l}\text { Implementar la técnica de } \\
\text { vacío en algunas salas } \\
\text { (Terapia, Cirugía } \\
\text { Cardiovascular). Disminuir } \\
\text { al menos un } 25 \% \text { los errores } \\
\text { administrativos con la } \\
\text { incorporación del nuevo } \\
\text { cargo y comienzo de la } \\
\text { utilización del sistema de } \\
\text { gestión. } \\
\text { Medir y evaluar indicadores } \\
\text { de las etapas preanalítica y } \\
\text { posanalítica, determinar } \\
\text { errores e implementar } \\
\text { correcciones. }\end{array}$ \\
\hline
\end{tabular}


TESIS DE MAESTRÍA

Estudio de las Características de la Demanda y Satisfacción de Clientes

\begin{tabular}{|c|c|c|c|c|}
\hline $\begin{array}{l}\text { Gestión de } \\
\text { Pacientes }\end{array}$ & $\begin{array}{c}\text { Disminuir el tiempo } \\
\text { de retorno de } \\
\text { resultados. } \\
\text { Incrementar los } \\
\text { turnos diarios para } \\
\text { disminuir el tiempo } \\
\text { de espera. }\end{array}$ & $\begin{array}{l}\text { Capacitación del personal } \\
\text { en oficina de turnos para } \\
\text { evitar recitaciones de } \\
\text { pacientes. Capacitación de } \\
\text { administrativos y técnicos } \\
\text { del Servicio para mejorar } \\
\text { la atención y disminuir } \\
\text { errores. }\end{array}$ & $\begin{array}{l}\text { Disminuir el tiempo de } \\
\text { espera para turno a un } \\
\text { plazo de } 5 \text { días en el } 95 \% \\
\text { de los casos. Disminuir el } \\
\text { tiempo de retorno de } \\
\text { resultados en la totalidad } \\
\text { de prestaciones del } \\
\text { Servicio a una semana } \\
\text { como máximo. }\end{array}$ & $\begin{array}{c}\text { Repetir encuestas de } \\
\text { satisfacción para evaluar si } \\
\text { existieron cambios y } \\
\text { determinar las correcciones } \\
\text { necesarias. Lograr que los } \\
\text { pacientes del hospital tengan } \\
\text { la debida prioridad en la } \\
\text { obtención de turnos. }\end{array}$ \\
\hline
\end{tabular}


Como conclusiones obtenidas de este estudio se destacan:

- Debido a que no se observaron diferencias en la complejidad de determinaciones solicitadas por profesionales que se desempeñan en las Unidades Sanitarias como aquellos que se desempeñan en el Hospital, no es necesaria su discriminación para la planificación de recursos.

- En forma general se puede concluir que las respuestas obtenidas en la encuesta realizada a los pacientes marcan en gran medida dificultades relacionadas a las deficiencias edilicias, (unificación de las tres salas, ubicación del Laboratorio en otro lugar del Hospital, mejora en el sector extracciones y del laboratorio en general) y a la necesidad de disminución del tiempo de obtención de turnos y de resultados que permitan un diagnóstico oportuno. Para ello se deberá evaluar la posibilidad de adecuación del plantel de trabajadores, optimización de procesos, como así también mejoras edilicias.

- Es de destacar que en los sectores del Servicio donde el paciente tiene contacto con el personal la respuesta favorable (buena-muy buena) alcanza un $97-98 \%$.

- En forma sintética y general de la encuesta realizada a los profesionales que requieren de los servicios del Laboratorio, se observa la necesidad de una mejora en la comunicación del Servicio con todos los profesionales que ordenan prestaciones al mismo para: -dar conocimiento de todas las prácticas que se realizan -informar sobre alcances de las técnicas y tiempos de realización- aumentar la receptividad a inquietudes planteadas por los mismos-incrementar la credibilidad de resultados.

- Trabajar en las necesidades del Servicio (edilicias, de personal, insumos) y mejora de los procesos que lleven a la obtención de resultados con mayor celeridad.

- Necesidad de unificación de las tres salas que componen el Servicio, manifestado en su mayoría por los tres grupos consultados.

- De lo expresado por los trabajadores del Servicio, además de la necesidad de unificación de las tres salas, se desprende la carencia de un Sistema de Gestión, acorde con los requerimientos del Servicio y del Hospital que permitan tanto el almacenamiento como la disponibilidad en forma rápida y oportuna de datos obtenidos en el Servicio como así también la disminución del trabajo que se realiza actualmente en forma manual, con la consiguiente disminución de errores.

- Importancia de contar con personal estable adecuado para cubrir la demanda, cuyo recambio se realice en forma paulatina que permita la incorporación de nuevos agentes, con el tiempo necesario para su integración y capacitación, que no lleve a disminuciones en la producción del trabajo ni en su calidad. 
จ Como en todas las organizaciones es necesario mejorar la comunicación dentro del Servicio, como así también del Servicio con el resto del Hospital, que lleven a una mejora en el clima laboral y por consiguiente a una mejora en la calidad de prestación.

- Necesidad de medición de algunos de los indicadores planteados para obtener datos que permitan evaluar los distintos procesos en forma confiable para la identificación y corrección de errores, demostrando la utilidad de medir, no sólo para la institución, sino también para las personas en particular.

- $\mathrm{Al}$ ser el Laboratorio un Servicio de Diagnóstico, es necesario que cada vez el tiempo de retorno de resultados sea menor, favoreciendo el diagnóstico temprano y oportuno de las patologías, que llevan a un mejor y más eficiente tratamiento, por lo que es necesario disminuir el tiempo de espera de turno como así también el de obtención de resultados.

- Marcadas deficiencias edilicias, de acuerdo a lo manifestado por los tres grupos consultados, que generan inconvenientes en el desarrollo normal de las actividades, superposición de tareas, uso no eficiente de recursos, siendo necesario que sean atendidas por las autoridades frente a futuras reformas edilicias del Hospital.

จ Dado que la planificación es una actividad dinámica que requiere de un continuo análisis, correcciones y nuevo análisis es necesario repetir periódicamente estas encuestas para que nos brinden información y permitan nuevas correcciones.

$\Rightarrow$ El Servicio de Laboratorio, como integrante del sistema de Salud, debe permanentemente adecuarse a los cambios que se observan, por lo que cada vez más la Planificación Estratégica en el mismo se hace necesaria y requiere de aquellos que los conducen el conocimiento de esta herramienta de gestión. 
XI. BIBLIOGRAFÍA

- Aguirre- Gas. H. Evaluación de la atención médica. Expectativas de pacientes y trabajadores. Salud Pública de México. 1990; 32(2). 170-180.

- Arévalo, César y Chávez ,Sileny. Planificación Estratégica de los Servicios de Salud Módulo 3, Introducción a la Planificación en los Servicios de Salud módulo 3, Curso Especial de Posgrado en Gestión Local en Salud. CCSS-UCR,_San José 1998 p 11.

- Asenjo, M.A. Las Claves de la Gestión Hospitalaria. Barcelona: Gestión 2000 - 1999.

- Barral, María. Gestión integrada en el laboratorio clínico. Acta bioquímica clínica latinoamericana. V. 41 n.3 La Plata jul. /sep. 2007.

- Botta, Mirta; Warley, Jorge; Roig, Nora Fasano de. Tesis, Tesinas, Monografías e informes. Editorial Biblos. Buenos Aires 2007.

- Caja Costarricence de Seguro Social. Dirección de Planificación Institucional. Marco Metodológico para la Elaboración del Plan Anual Operativo. Costa Rica; 1998.

- Caminal, J. La medida de la satisfacción: Un instrumento de participación de la población en la mejora de la calidad de los servicios sanitarios. Rev. Calidad Asistencial. 2001; 16:276-9

- Castillo, Luis; Dougnac, Alberto; Vicente, Irene; Muñoz, Víctor; Rojas, Víctor. Los predictores de satisfacción de pacientes en un centro hospitalario universitario. Rev Médica Chile. 2007; 135: 697-701. 
- Corrella, José María. La Gestión de los Servicios de Salud.’La Planificación Sanitaria”. Editorial Días de Santos. Madrid 1996.

- Donabedian, A. Garantía y Monitoría de la Calidad de la Atención Médica. Instituto Nacional de Salud Pública. México 1992.

- Donabedian, A. Continuidad y cambio en la búsqueda de calidadSalud Pública. México 1993; 35 (3) 238-347.

- Eco, H. Cómo se hace una tesis, Edit. Gedisa, Barcelona 1982.

- Etcheverry, Graciela Susana. Tesis de maestría: Abordaje de Unidades de Laboratorio bajo el Paradigma de Gestión Clínica en el Área de La Plata y Gran La Plata. Escuela de Economía de la Salud y Administración de Organizaciones de Salud. Facultad de Ciencias Económicas. Universidad Nacional de La Plata.

- Fernández Espina, C. Introducción a la calidad: conceptos generales. En: Confederación Latinoamericana de bioquímica Clínica, Fernández Espina C, Mazziotta D. gestión de la Calidad en el Laboratorio.

- Froman, B. Del manual de la calidad al manual de gestión. La herramienta estratégica. Madrid: ediciones AENOR; 2001. Clínico. Editorial Médica Panamericana. Buenos Aires 2005. p.1-26.

- Güllick, Luther. Ensayos sobre la ciencia de la AdministraciónEscuela Nacional de Administración Pública. Madrid, España; 1973.

- Hampton, David. Administración. Ed. Mac Graw-Hill. México. 1996,p 728-748.

- Hernandez Orozco, Carlos. Planificación y Programación. Ed.Uned. San José; 1993. 
- Hulka, Bárbara S; Zyzanski, Stephen J. Validación de una escala de satisfacción de los pacientes: Teoría, Métodos y PrácticaMedical Care 20 (6); 649-653,jun 1982. Publicado en White,Kerrl. Investigaciones sobre servicios de salud: una antología. Editores

- Kerrl, L; White...( et all)- Washington D.C OPS, 1992. (Publicación Científica, 534).

- Levy, Alberto. Planeamiento Estratégico. Ed. Macchi. Buenos Aires 1981.

- Malagón Londoño; Galán Morera; Pontón Laverde. Garantía de la Calidad en Salud. Ed. Panamericana. Bogotá 2001.

- Mancuso, Gilda; Lembo, Lilian; Pelaez, Agustina; Bettoli, Lucas- Formación de Recursos Humanos (Breviario entre salud, trabajo y equipo). Ed. Prometeo, libros. Buenos Aires 2004.

- Norma ISO 9000:2000. Sistemas de Gestión de la Calidad. Conceptos y Vocabulario.

- Norma ISO 9004:2000. Sistemas de Gestión de la Calidad. Directrices para la mejora del desempeño.

- OPS. Boletín epidemiológico Vol. 22, n 4, 2001.

- Ortiz Espinosa, Rosa María; Muñoz Juárez, Sergio; Torres Carreño, Erik. Satisfacción de los usuarios de 15 hospitales de Hidalgo, México. Rev. Esp. Salud Pública v.78 n.4.Madrid jul.ago.2004

- Pasos Nogueira, Roberto. Perspectiva de la Gestión de Calidad total en los Servicios de Salud- Serie Paltex Salud y Sociedad. $2000 \mathrm{~N}^{\circ}$ 4- OPS. Washington. 1997 p 90. 
- Pérez Lázaro, JJ; García Alegre, J; Tejedor Fernández, M. Gestión Clínica: conceptos y metodología de aplicación. Rev. Calidad Asistencial 2002; 17:305 - 11.

- Ramírez-Sánchez,Teresita; Nájera-Aguilar, Patricia; NigendaLópez ,Gustavo. Percepción de la calidad de la atención de los servicios de salud en México: perspectiva de los usuarios Salud pública Méx vol.40 n.1 Cuernavaca Jan. /Feb. 1998

- Ruiz Narváez, Oswaldo. Nociones Básicas sobre Planificación en la Administración de un Laboratorio Clínico del Primer Nivel de Atención. Rev. cienc. adm. Financ .segur. soc v. 12 n.1. San José. Sep.2004.

- Sabuqui, Roberto. Mediciones e Indicadores de Gestión, ¿una ayuda ó un castigo? Contacto $\mathrm{N}^{\circ} 11$. FPNC. Fundace. IPACE. Buenos Aires 2007.

- Scarano, Eduardo R. Manual de Redacción de Escritos de Investigación. Ediciones Macchi. Buenos Aires 2004.

- Spadafora, Santiago Gerardo. Planificación en Salud. Módulo III. Instituto Universitario de la Fundación ISALUD. Departamento de Educación a Distancia. Buenos Aires 2007.

- Subsecretaría de Planificación de la salud. Investigación sobre el grado de satisfacción del Usuario. Hospital General de Agudos "San Roque" de Gonnet. Dirección Provincial de Planificación de la Salud. Ministerio de Salud prov. De Buenos Aires. La Plata 1996.

- Temes, JL; Parra, B. Gestión Clínica. Mc Graw Hill Interamericana. Madrid 2000. 
Estudio de las Características de la Demanda y Satisfacción de Clientes

- Varo, J. Gestión estratégica de la calidad en los servicios sanitarios. Ed. Díaz de Santos. Madrid 1994.

- Zorraquín Aracama, Susana; Ardigó, Roberto Enzo. Auditoría Médica Clásica y Moderan. Ed. Dunken. Buenos Aires 2001. 


\section{Agradecimientos}

* A mi familia, que sin su apoyo constante hubiese sido imposible llegar hasta aquí. A mis hijas y mi marido a quienes he quitado muchas horas de atención, además de brindarme su conocimiento y aliento permanentemente a seguir.

* Al Lic. Daniel E. Solari por su gran dedicación y apoyo permanente.

* A todos los integrantes de la Escuela de Economía de la Salud, docentes y administrativos, por su trato, conocimiento y afecto con el que he sido tratada

* A mis compañeros de curso, con los que hemos pasado gratos momentos, y con los cuales han nacido nuevas y muy buenas amistades.

* A mis compañeros de trabajo, por su desinteresada participación y colaboración.

\# A la Lic. Estefanía Solari, por su gran ayuda y conocimiento.

* A la Dra. Cristina N. Figueras, por haberme incentivado a iniciarme en esta tarea.

* A las autoridades del Hospital Interzonal Especializado en Agudos y Crónicos San Juan de Dios, por haberme permitido desarrollar este trabajo en la Institución en que trabajo desde hace muchos años.

* A todos aquellos que sin nombrarlos me han ayudado y me han dado su aliento.

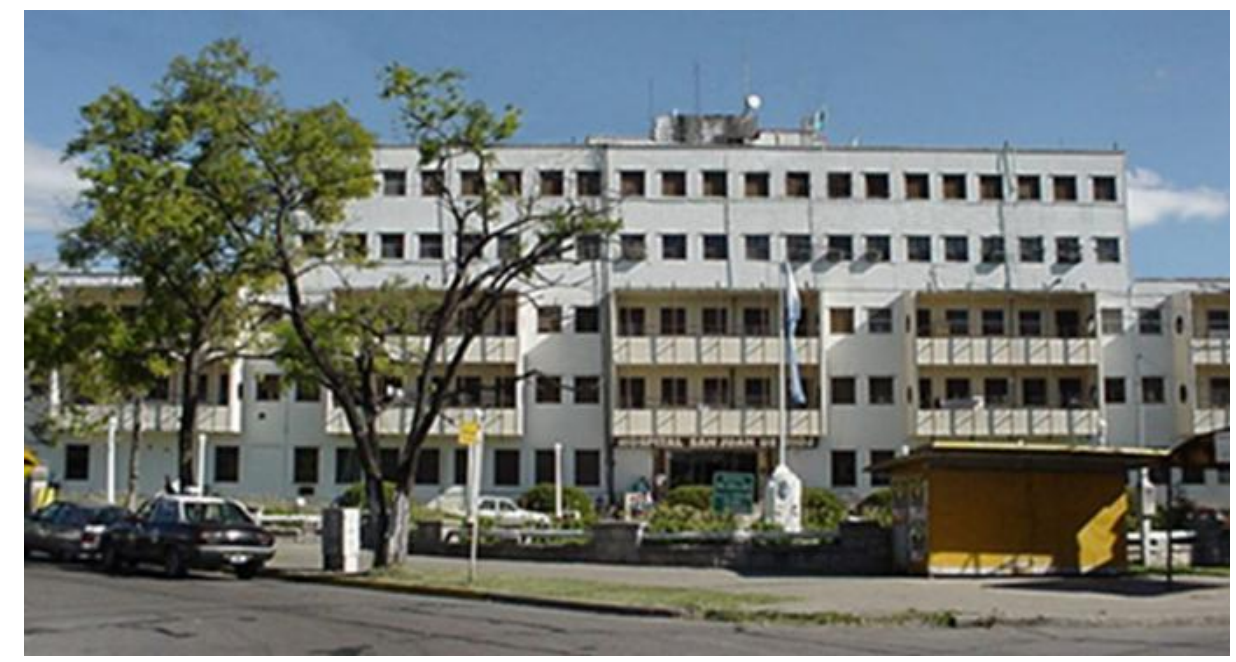

